\title{
Five Facts About Beliefs and Portfolios
}

\author{
Stefano Giglio, Matteo Maggiori, Johannes Stroebel and Stephen Utkus
}

September 2020

\author{
PRC WP2019-7 \\ Pension Research Council Working Paper \\ Pension Research Council \\ The Wharton School, University of Pennsylvania \\ 3620 Locust Walk, 3000 SH-DH \\ Philadelphia, PA 19104-6302 \\ Tel.: 215.573.3414 Fax: 215.573.3418 \\ Email:prc@wharton.upenn.edu \\ http://www.pensionresearchcouncil.org
}

Vanguard provided anonymized portfolio and survey data as well as survey research services for this project. We thank Klaus Adam, Isaiah Andrews, Nick Barberis, John Campbell, Darrell Duffie, Ben Enke, John Geanakoplos, Nicola Gennaioli, Gary Gorton, Camelia Kuhnen, Arvind Krishnamurthy, Hanno Lustig, Yueran Ma, Emi Nakamura, Stefan Nagel, Frank Schilbach, Alexi Savov, Amit Seru, and Andrei Shleifer, as well as numerous seminar and conference participants. The authors would also like to thank Catherine Clinton, Sophia Bunyaraksh, and Jean Young at Vanguard for their help with the project.All findings, interpretations, and conclusions of this paper represent the views of the author(s) and not those of the Wharton School or the Pension Research Council. (C) 2020 Pension Research Council of the Wharton School of the University of Pennsylvania. All rights reserved. 


\title{
Five Facts About Beliefs and Portfolios
}

\author{
Stefano Giglio, Matteo Maggiori, Johannes Stroebel and Stephen Utkus
}

\begin{abstract}
$\underline{\text { Abstract }}$
We study a newly-designed survey administered to a large panel of wealthy retail investors. The survey elicits beliefs that are important for macroeconomics and finance, and matches respondents with administrative data on their portfolio composition, their trading activity, and their log-in behavior. We establish five facts in this data: (1) Beliefs are reflected in portfolio allocations. The sensitivity of portfolios to beliefs is small on average, but varies significantly with investor wealth, attention, trading frequency, and confidence. (2) Belief changes do not predict when investors trade, but conditional on trading, they affect both the direction and the magnitude of trades. (3) Beliefs are mostly characterized by large and persistent individual heterogeneity. Demographic characteristics explain only a small part of why some individuals are optimistic and some are pessimistic. (4) Expected cash flow growth and expected returns are positively related, both within and across investors. (5) Expected returns and the subjective probability of rare disasters are negatively related, both within and across investors. These five facts provide useful guidance for the design of macro-finance models.
\end{abstract}

Keywords: Surveys, Expectations, Sentiment, Behavioral Finance, Discount Rates, Rare Disasters

JEL Codes: G11, G12, R30

Stefano Giglio

Yale School of Management, Yale University

NBER, CEPR

stefano.giglio@yale.edu

\section{Johannes Stroebel}

Stern School of Business, New York

University, NBER, CEPR

johannes.stroebel@stern.nyu.edu

\section{Matteo Maggiori}

Department of Economics, Harvard University

NBER, CEPR

maggiori@fas.harvard.edu

\author{
Stephen Utkus \\ Vanguard \\ steve utkus@vanguard.com
}




\title{
Five Facts About Beliefs AND Portfolios
}

\author{
Stefano Giglio*
}

\author{
Matteo Maggiori ${ }^{\dagger}$
}

\author{
Johannes Stroebel ${ }^{\ddagger}$
}

\author{
Stephen Utkus $\S$
}

September 2020

\begin{abstract}
We study a newly-designed survey administered to a large panel of wealthy retail investors. The survey elicits beliefs that are important for macroeconomics and finance, and matches respondents with administrative data on their portfolio composition, their trading activity, and their log-in behavior. We establish five facts in this data: (1) Beliefs are reflected in portfolio allocations. The sensitivity of portfolios to beliefs is small on average, but varies significantly with investor wealth, attention, trading frequency, and confidence. (2) Belief changes do not predict when investors trade, but conditional on trading, they affect both the direction and the magnitude of trades. (3) Beliefs are mostly characterized by large and persistent individual heterogeneity. Demographic characteristics explain only a small part of why some individuals are optimistic and some are pessimistic. (4) Expected cash flow growth and expected returns are positively related, both within and across investors. (5) Expected returns and the subjective probability of rare disasters are negatively related, both within and across investors. These five facts provide useful guidance for the design of macro-finance models.
\end{abstract}

JEL Codes: G11, G12, R30.

Keywords: Surveys, Expectations, Sentiment, Behavioral Finance, Discount Rates, Rare Disasters.

*Yale School of Management, NBER, CEPR: stefano.giglio@yale.edu.

$\dagger$ Graduate School of Business, Stanford University, NBER, CEPR: maggiori@stanford.edu.

${ }_{\ddagger}^{\ddagger}$ Stern School of Business, New York University, NBER, CEPR: johannes.stroebel@stern.nyu.edu.

§Vanguard: steve_utkus@vanguard.com.

Stephen Utkus is employed at Vanguard in a research capacity. Giglio, Maggiori, and Stroebel are unpaid consultants at Vanguard in order to access the anonymized data. Vanguard provided anonymized portfolio and survey data as well as survey research services for this project. We thank Klaus Adam, Isaiah Andrews, Nick Barberis, John Campbell, Darrell Duffie, Ben Enke, John Geanakoplos, Nicola Gennaioli, Gary Gorton, Camelia Kuhnen, Arvind Krishnamurthy, Hanno Lustig, Yueran Ma, Emi Nakamura, Stefan Nagel, Frank Schilbach, Alexi Savov, Amit Seru, and Andrei Shleifer, as well as numerous seminar and conference participants. The authors would also like to thank Catherine Clinton, Sophia Bunyaraksh, and Jean Young at Vanguard for their help with the project. 
Researchers are increasingly turning to survey data to calibrate and test macro-finance models. The unique benefit of survey data is that it can provide direct evidence on the beliefs of different agents about future economic outcomes such as stock returns and economic growth. These beliefs play a central role in both rational expectation models and behavioral models of macroeconomics and finance. Despite the potential for survey data to shed light on previously unobservable elements of macro-finance theories, its use has been criticized on many fronts. Critics have argued that survey data is often based on small and unrepresentative samples, that it is ridden with measurement error, that it asks qualitative questions that are not informative for models, and that it may not reveal those beliefs on which agents actually base their actions.

In this paper, we provide new evidence on the link between beliefs elicited through surveys and actions taken by survey respondents. To do this, we study a newly-designed online expectations survey of a large panel of individual retail investors with substantial wealth invested in financial markets. The survey elicits the investors' beliefs about future stock returns, GDP growth, and bond returns, and was designed to address prevailing criticisms of existing survey data. The survey design trades off asking quantitative questions about moments that are crucial for macrofinance theory with keeping the questions sufficiently simple that they can be answered by nonspecialists. The survey is also short, in order to not discourage respondents from participating repeatedly over time.

The survey was administered by Vanguard, one of the world's largest asset management firms, to an almost random sample of its U.S.-based clients. About $80 \%$ of the investors in the sample have retail trading accounts at Vanguard, while the remaining 20\% have employer-sponsored retirement accounts. The respondents are individuals relevant for macro-finance models: they participate in financial markets and they have substantial wealth, with the average respondent holding more than half a million dollars of assets at Vanguard. The survey has been conducted every two months since February 2017. In this paper, we study the first 21 survey waves - covering the period February 2017 to June 2020 — which generated a total of 46,419 responses. Many individuals responded to multiple survey waves, providing a substantial panel component to the data. We link survey responses to anonymized administrative data on the respondents' investment holdings and transactions at Vanguard. This allows us to explore the relationship between the elicited beliefs and real-world high-stakes investment behavior. Since Vanguard clients are potentially more likely to be buy-and-hold investors, whenever possible we confirm that the patterns in our survey data are consistent with the corresponding patterns in other surveys covering different investor populations.

Our most general finding is that survey data is highly informative about individuals' portfolio decisions. Specifically, we find a robust relationship between beliefs and portfolio allocations, both across individuals and within individuals over time. In this sense, we conclude that survey-based evidence is "here to stay," and that theoretical work has to continue to confront such evidence. We organize our findings around five facts that highlight empirical patterns about beliefs as well as their relationships with portfolios. We believe that these facts, which are robust to including or excluding the period around the March 2020 stock market decline induced by the COVID-19 crisis, can guide future empirical and theoretical work in macro-finance. 
Fact 1 summarizes our main findings on the relationship between beliefs and portfolios. We first document a statistically strong relationship between beliefs and portfolio composition. However, the average sensitivity of an investor's equity share to that investor's subjective expected stock return is substantially lower than predicted by benchmark frictionless macro-finance models. More specifically, we find that a one-percentage-point increase in expected stock returns over the next year is associated with a 0.7 percentage points higher equity share, which is one order of magnitude smaller than implied by standard calibrations of the frictionless Merton (1969) model. We rule out that this relatively low magnitude is primarily the result of attenuation bias from classical measurement error in beliefs. We also find that the perceived variance of stock returns has both an economically and statistically weak relationship with portfolios, and that a better measure of risk is the subjective probability of a large stock market drop (a rare disaster).

This relatively small response of equity shares to beliefs about stock returns is consistent with evidence documented across several other studies that link retail investors' equity market participation and equity shares to expected stock returns (e.g., Vissing-Jorgensen, 2003; Dominitz and Manski, 2007; Kézdi and Willis, 2011; Amromin and Sharpe, 2013; Ameriks et al., 2016). Our contribution to this literature is twofold. First, we use administrative data to confirm this fact for a large sample of wealthy investors, while accounting for key dimensions of measurement error. Second, we show that investors are heterogeneous in their sensitivity alongs several economically interesting dimensions. The sensitivity of portfolios to beliefs is increasing in wealth; it is also higher in tax-advantaged retail accounts, and increasing in investors' trading frequency, investors' attention to their portfolios, and investors' confidence in their own beliefs. We find that an idealized investor who holds a tax-advantaged retail account, pays attention to her portfolio, trades often, and is confident in her beliefs has a sensitivity that is about three times larger than the average sensitivity, and gets close to the sensitivities generated by frictionless benchmark models.

We next investigate the role of belief changes in explaining trading activity. Fact 2 establishes that an individual's belief changes have little or no explanatory power for predicting when trading occurs (the extensive margin), but help explain both the direction and magnitude of trading conditional on a trade occurring (the intensive margin). Our findings are thus consistent with models of infrequent trading that generate a flat hazard function of trading based on belief changes, with heterogeneous trading probabilities across people.

These first two facts are informative about a central element of both rational and behavioral macro-finance models: the transmission channel from beliefs to portfolio choices. Our results show that for the average investor, this passthrough is positive but weak, which might dampen the effects of belief changes on equilibrium prices and quantities in theoretical models. This cautions against commonly used calibrations of many representative agent behavioral models that use variation in survey-based beliefs to explain asset price movements. Specifically, the variation in asset demand implied by these models - many of which are based on Mertonian portfolio demand - is far too high relative to the passthrough from beliefs to portfolios observed in the data. At the same time, we show that this passthrough is heterogeneous across investors along economically interesting dimensions. Incorporating this heterogeneity into macro-finance models should help these models to jointly match data on beliefs, quantities, and asset prices. 
We next decompose the variation in beliefs across individuals and over time. Fact 3 establishes that individual beliefs are mostly characterized by heterogeneous and persistent individual fixed effects: some individuals are optimistic and some are pessimistic, and their beliefs are persistent and far apart. While there is some co-movement in beliefs across individuals over time, the time variation in average beliefs only accounts for about $5 \%$ of the total variation in beliefs in the panel. Instead, between $40 \%$ and $60 \%$ of all panel variation in beliefs is captured by individual fixed effects, while the rest is due to idiosyncratic individual variation and measurement error. We also find that the heterogeneity in beliefs is not well explained by observable respondent characteristics such as gender, age, wealth, attention, confidence, past returns, and geographic location. These characteristics sometimes have strong statistical relationships with beliefs, but their joint explanatory power is limited. We provide evidence that this is not the result of measurement error in eliciting beliefs. Instead, a likely explanation is that individual beliefs reflect a combination of many demographic characteristics and experiences, without a single dominant explanation.

Fact 3 provides a simple but powerful description of the panel variation of investor beliefs: investors disagree strongly and persistently about expected cash flows and returns. This contrasts with much of the existing literature that builds on survey evidence on beliefs, which has focused on representative agent models disciplined by matching the time-series behavior of average beliefs. This approach misses a more prominent feature of the data, the persistent individual heterogeneity. As a result, models that explicitly feature heterogenous agents with different beliefs are likely to offer a fruitful starting point for future work. Indeed, incorporating persistent belief heterogeneity into macro-finance models is not only a way to better match the survey evidence, but might also allow for interesting model dynamics, for example coming from the redistribution of wealth between optimists and pessimists as shocks are realized.

We next explore how beliefs about different objects correlate. Fact 4 establishes that higher expectations of GDP growth are associated with higher expectations of future stock returns, at both short and long horizons. In the cross-section, investors who expect higher cash flow growth also tend to expect higher returns. In the time series, when an investor becomes more optimistic about cash flow growth, she also becomes more optimistic about expected returns. The correlation between expected returns and cash flow growth is an informative moment for macro-finance analysis. Indeed, the Campbell and Shiller (1988) decomposition shows that expected cash-flow growth and expected returns have opposite effects on current valuations. Models that specify belief dynamics for one process (either cash flows or returns) imply equilibrium beliefs about the other process, and our work can be used to verify whether the resulting joint distribution of beliefs is qualitatively and quantitatively consistent with the data.

Fact 5 establishes that when individuals perceive large stock market declines to be more likely, they also expect stock returns to be lower. This relationship holds both across individuals and within individuals over time. This finding relates to an important strand of the macro-finance literature, which has emphasized that expectations of rare but potentially catastrophic events, socalled rare disasters, can help explain portfolio holdings and asset prices (see Rietz, 1988; Barro, 2006; Gabaix, 2012). Our results are consistent with versions of the rare disaster framework, like the model by Chen, Joslin and Tran (2012), that allow for heterogeneous beliefs about disaster 
probabilities and a willingness of investors to "agree to disagree."

We conclude this introduction by summarizing the desired characteristics of a model that would be consistent with our five facts. This represents just one way one could write such a model, based on our evidence, rather than the only possible model. The proposed model would have three key ingredients: (i) large and highly persistent heterogeneity in beliefs about both expected returns and cash flows, with the two beliefs positively related, (ii) a willingness to "agree to disagree" that allows for trading based on disagreement, and (iii) infrequent trading with an exogenous probability of trading that differs across agents. It is an interesting open question how well such a model would perform in quantitatively matching aggregate asset prices in addition to the main features of beliefs and portfolios documented in this paper.

Related Literature. Our paper contributes to a growing literature that focuses on exploring the role of beliefs in explaining a large number of economic outcomes (see DellaVigna, 2009; Benjamin, 2018, for a review). In this literature, Manski (2004) was among the first and most prominent to argue for using survey data about expected equity returns and risks to better understand individuals' investment behaviors. Over time, a series of papers has connected survey expectations to the behavior of respondents. For example, Ameriks et al. $(2015 a, b, 2016,2017,2018)$ have provided recent advances by linking survey evidence to retirement choices. As part of this agenda, Ameriks et al. (2016) find a low sensitivity of retail investors' equity investment to stock market expectations, a fact also documented by Vissing-Jorgensen (2003), Dominitz and Manski (2007), Kézdi and Willis (2009, 2011), Amromin and Sharpe (2013), Arrondel, Calvo Pardo and Tas (2014), Merkle and Weber (2014), Choi and Robertson (2018) and Drerup, Enke and Von Gaudecker (2017), with related work by Hurd, Van Rooij and Winter (2011), Hudomiet, Kézdi and Willis (2011) and De Marco, Macchiavelli and Valchev (2018). Our work builds on this literature by exploring a quantitative survey of a large panel of wealthy investors, which is matched to administrative data on these investors' portfolios and trading behaviors. Our survey, which was designed to inform theoretical models, allows us to discover new facts and deepen our understanding of existing patterns, both quantitatively and in terms of their variation across individuals and over time.

We also contribute to a macro-finance literature that has debated the tradeoffs between behavioral and rational modeling approaches, with survey evidence providing an important input (see Cochrane, 2011, 2017; Greenwood and Shleifer, 2014; Adam, Matveev and Nagel, 2018). Among the many proposed equilibrium models, the most relevant for our work are those that directly incorporate survey evidence (e.g., Barberis et al., 2015; Adam, Marcet and Beutel, 2017; Bhandari, Borovička and Ho, 2016) and those that feature heterogeneous belief (e.g., Scheinkman and Xiong, 2003; Geanakoplos, 2010; Caballero and Simsek, 2017; Martin and Papadimitriou, 2019).

Our work also relates to a literature that has explored the role of beliefs in other settings. For example, in the housing market (e.g., Piazzesi and Schneider, 2009; Case, Shiller and Thompson, 2012; Cheng, Raina and Xiong, 2014; Kuchler and Zafar, 2015; Burnside, Eichenbaum and Rebelo, 2016; Glaeser and Nathanson, 2017; Adelino, Schoar and Severino, 2018) as well as the role of firm expectations (e.g., Cummins, Hassett and Oliner, 2006; Bacchetta, Mertens and Van Wincoop, 2009; Coibion and Gorodnichenko, 2012; Gennaioli, Ma and Shleifer, 2016; Landier, Ma and Thesmar, 2017; Bachmann et al., 2018; Bordalo et al., 2018; García-Schmidt and Woodford, 2019; Fuhrer, 
2018). A further related literature has explored how individuals with different political convictions respond to political events (see Mian, Sufi and Khoshkhou, 2015; Kempf and Tsoutsoura, 2018; Meeuwis et al., 2018).

\section{SURVEY DESCRIPTION}

To explore the structure of investors' beliefs and their relationship with investors' portfolio allocations, we study a new online survey of U.S.-based individual investors who hold accounts at Vanguard, one of the world's largest asset management firms with more than $\$ 6$ trillion in assets under management. We refer to this survey as the GMSU-Vanguard survey in the rest of this paper. We first provide a high-level overview of the survey questions (we report the exact phrasing and the survey interface in the Appendix). We then explore the survey sample, the response rates, and the demographics of respondents and non-respondents, which allow us to analyze the dimensions of selection into responding.

\section{I.A Survey Design}

The survey includes questions on three broad topics: expected stock market returns, expected GDP growth rates, and expected bond returns. The survey implementation randomizes whether individuals were first asked about their expectations of stock returns or their expectations of GDP growth rates. The questions on bond returns are always asked last.

Expected Stock Market Returns. The survey asks respondents about their expectations for the return of the U.S. stock market. It elicits point estimates for the expected annualized returns over the coming year and the coming ten years. It also elicits subjective probabilities that the return over the next year would fall into one of five buckets: less than $-30 \%$, between $-30 \%$ and $-10 \%$, between $-10 \%$ and $30 \%$, between $30 \%$ and $40 \%$, and more than $40 \%{ }^{1}$ The ordering of the buckets (i.e., lowest to highest or highest to lowest) is randomized across survey respondents, and the survey enforces that the assigned probabilities add up to $100 \%$. As shown in the Appendix, the survey interface also presents real-time histograms of the survey responses as they are entered, which helps individuals visualize the probability distributions implied by their numerical answers.

Expected Real GDP Growth Rates. The survey also asks respondents about their expectations for the annualized growth rate of real GDP. It elicits point estimates for the expected growth rates over the coming three years and the coming ten years. It also elicites subjective probabilities that the annualized GDP growth rate over the coming three years would fall into one of five buckets: less than $-3 \%$, between $-3 \%$ and $0 \%$, between $0 \%$ and $3 \%$, between $3 \%$ and $9 \%$, and more than $9 \% .^{2}$ The ordering of buckets (i.e., lowest to highest or highest to lowest) is randomized across respondents.

\footnotetext{
${ }^{1}$ These buckets were chosen such that the tails correspond to extreme events that still have substantial probability mass based on historical frequency. Between 1927 and 2014, the share of 1-year stock returns in each bucket was: 3.7\% (lowest bucket), 11.6\% (second bucket), 65.9\% (third bucket), 13.8\% (fourth bucket), and 5\% (highest bucket).

${ }^{2}$ Between 1929 and 2015, the share of annualized U.S. real three-year GDP growth in each bucket was: $4.2 \%$ (lowest bucket), 5.4\% (second bucket), 33.3\% (third bucket), 50.8\% (fourth bucket), and 6.3\% (highest bucket).
} 
Expected Bond Returns. The final block of questions elicits respondents' expectations about the 1-year return of a 10-year U.S. government zero coupon bond. ${ }^{3}$

Difficulty and Confidence. At the end of every block of questions (i.e., about expected stock returns, expected GDP growth, and expected bond returns), the survey asks individuals how confident they are about their answers (on a five-point scale from "not at all confident" to "extremely confident"), and how difficult they found the questions (on a five-point scale from "not at all difficult" to "extremely difficult").

\section{I.B Survey Sample and Response Rate}

The online survey is conducted every two months by Vanguard among its U.S.-based individual customers. In this paper, we explore the first 21 waves of the survey, covering February 2017 to June 2020. In the first wave, 40, 000 clients were invited by email to participate in the survey. These clients were randomly selected such that $80 \%$ of the sample were retail investors and $20 \%$ were investors in defined contribution plans. ${ }^{4}$ Overall, the sample of individuals who are potentially contacted represents about $\$ 2$ trillion in assets. If individuals respond to the survey in any wave, they are recontacted in each subsequent wave. Individuals who do not respond to the first wave in which they are contacted are recontacted for two subsequent waves. If they respond in neither of these waves, they are dropped from the sample. Individuals can opt out of the study at any point and are, in this case, never contacted again. In the second wave, an additional 25,000 clients were invited to participate (in addition to those carried over from wave 1). Waves 3 to 5 invited 13, 000 new clients each; from wave 6 onward, the number of new clients contacted in each wave increased to 14,500 .

Response Rates. The left panel of Figure I shows the response rates for the first 21 waves, where we count only fully completed surveys as "responses." The orange-circle line shows that the response rates among individuals contacted for the first time were relatively stable at $2.5 \%-4 \%$ across waves. The response rates among individuals who were previously contacted but had not yet responded, given by the blue-diamond line, were between $1 \%$ and $2 \%$ across waves. The green-square line shows the response rates among individuals who had responded to at least one previous survey. The steady-state re-response rate of these individuals is between $10 \%$ and $15 \%$. It declines somewhat over time, though much of this decline is driven by compositional effects: in later survey waves, the average time since the last response of individuals who have previously responded is higher. These response rates translate into more than 2,000 survey responses on average per wave. Across the 21 waves, we received 46, 419 total responses.

The right panel of Figure I shows the number of responses in each wave, split out by how many overall survey waves the respondents participated in. Overall, about $25 \%$ of responses come from individuals who have responded to one survey only (though some of these may end up responding to future survey waves). Over $40 \%$ of responses come from individuals who have responded to at least four survey waves, and more than $25 \%$ come from individuals who have

\footnotetext{
${ }^{3}$ A last question also elicits expectations about future yield curves; we do not use this question in the current paper.

${ }^{4}$ Additional requirements to be potentially invited to take the survey are that clients: (i) had opted into receiving account statements via email, (ii) were older than 21 years, and (iii) had total Vanguard assets of at least $\$ 10,000$.
} 
responded to at least six waves. Appendix A.1 provides additional details on our response rates.

\section{Figure I: Survey Responses}
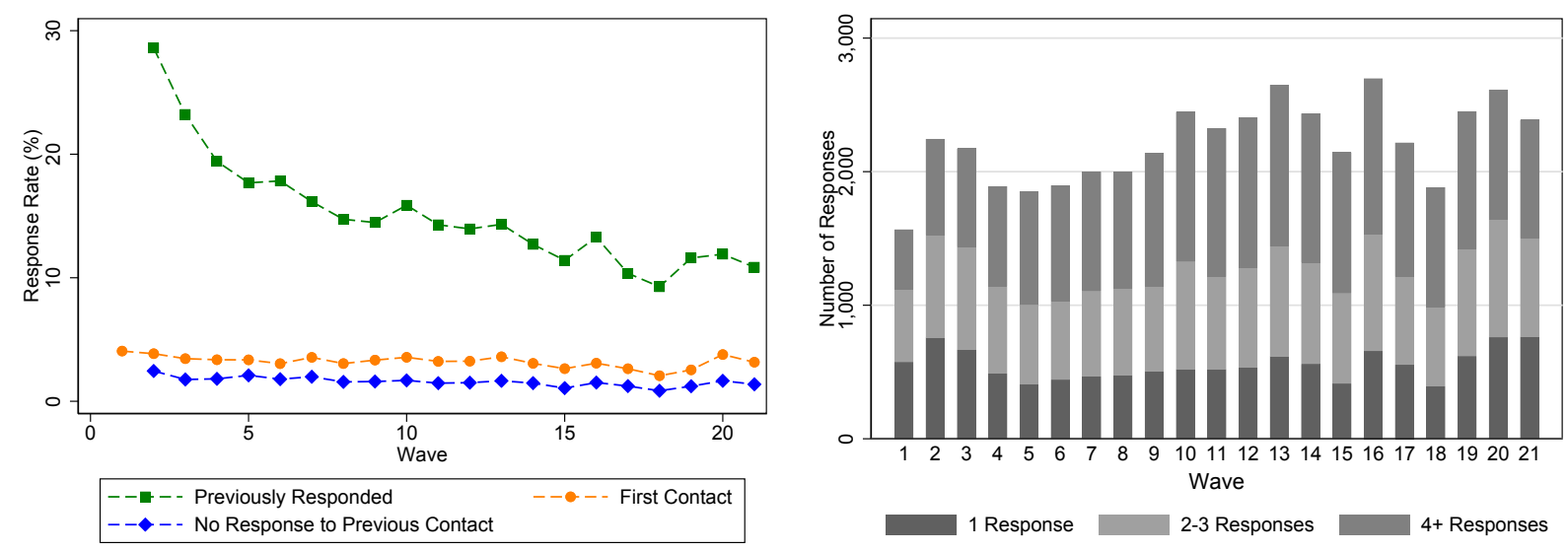

Note: Figure shows the responses to the GMSU-Vanguard Survey in each of the 21 waves between February 2017 and June 2020. The left panel shows response rates. The orange line (circles) shows the response rates for individuals contacted for the first time. The blue line (diamonds) shows the response rates for individuals that were contacted in previous waves, but who had not yet responded. The green line (squares) shows the response rates for individuals who had previously responded. The right panel shows the number of responses per wave. It splits out responses that come from individuals who only respond to one of the waves, from individuals who respond to two or three waves, and from individuals who respond to at least four waves.

Demographics of Respondents. Table I presents summary statistics on the demographics, portfolio composition, and trading behavior of the survey respondents as well as the non-respondents. The average survey respondent is about 60 years old, while $69 \%$ of respondents are male. Respondents hold assets with an average value of $\$ 520 \mathrm{k}$ at Vanguard, while the 10-90 percentile range of assets held at Vanguard is $\$ 23 \mathrm{k}$ to $\$ 1.3 \mathrm{~m}$. The average respondent logs into her Vanguard account about 3.7 times a month, has 1.5 active trades per month, and turns over $2.3 \%$ of her portfolio every month. Activity on the Vanguard site, both in terms of log-ins and in terms of trading activity, varies across survey respondents. At the 10th percentile of the distribution, respondents spend essentially no time on the Vanguard site, while at the 90th percentile of the distribution, respondents $\log$ in every third day. The average respondent has 7.2 unique assets in her portfolio, and holds $67.5 \%$ of her portfolio in equity, $20.9 \%$ in fixed income assets, and $10.1 \%$ in cash. ${ }^{5}$ There are substantial differences in portfolio allocations across our survey respondents. At the 10th percentile of the distribution, the equity share is $30.8 \%$, while at the 90 th percentile, it is $99.9 \%$.

Sample Selection. Like in all surveys, the sample of respondents is likely selected on a number of dimensions. We explore two types of selection: (i) selection into who is a Vanguard client, and (ii) selection into which Vanguard clients answer the survey.

We first compare the characteristics of respondents and non-respondents. Table I shows that survey respondents are older and more likely to be male than non-respondents. Respondents

\footnotetext{
${ }^{5}$ The CUSIP-level information on individual security holdings is matched with information from Morningstar for mutual funds to calculate the portfolio share held in equities, fixed income instruments, cash, and other investments. Investments in mutual funds are apportioned depending on the portfolio composition of each fund (e.g., $60 \%$ equity and $40 \%$ fixed income). Cash includes cash-equivalent investments such as money-market funds. The category "other investments" includes alternative investments such as commodities, real estate, and derivatives.
} 
Table I: Demographics - Survey Respondents and Non-Respondents

\begin{tabular}{|c|c|c|c|c|c|c|}
\hline & \multicolumn{4}{|c|}{ Survey Respondents } & \multirow{2}{*}{$\begin{array}{c}\text { Non- } \\
\text { respondents } \\
\text { Mean }\end{array}$} & \multirow[t]{2}{*}{ Difference } \\
\hline & Mean & P10 & P50 & $\mathrm{P90}$ & & \\
\hline Age (Years) & 60.1 & 39.0 & 63.0 & 76.0 & 52.3 & $7.86 * * *$ \\
\hline Male & 0.69 & 0 & 1 & 1 & 0.54 & $0.16^{* * *}$ \\
\hline \multicolumn{7}{|l|}{ Region } \\
\hline Northeast & 0.23 & 0 & 0 & 1 & 0.24 & $-0.01 * * *$ \\
\hline Midwest & 0.21 & 0 & 0 & 1 & 0.20 & $0.01 * * *$ \\
\hline South & 0.31 & 0 & 0 & 1 & 0.31 & 0.00 \\
\hline West & 0.25 & 0 & 0 & 1 & 0.25 & 0.00 \\
\hline Total Vanguard Wealth (k\$) & 520.0 & 23.2 & 227.8 & 1301.1 & 254.5 & $265.4^{* * *}$ \\
\hline Length of Vanguard Relationship (Years) & 17.11 & 5 & 17 & 29 & 14.32 & $2.78 * * *$ \\
\hline Active Trades / Month & 1.54 & 0.02 & 0.55 & 3.71 & 0.91 & $0.63^{* * *}$ \\
\hline Monthly Portfolio Turnover (\%) & 2.30 & 0.00 & 0.91 & 4.85 & 1.96 & $0.34 * * *$ \\
\hline Days with Log-Ins / Month & 3.71 & 0.09 & 1.53 & 10.96 & 1.81 & $1.90 * * *$ \\
\hline Total Time Spent / Month (Minutes) & 31.0 & 1.1 & 11.9 & 72.5 & 12.3 & $18.72 * * *$ \\
\hline \multicolumn{7}{|l|}{ Portfolio Shares (\%) } \\
\hline Equity & 67.5 & 30.8 & 70.7 & 99.9 & 71.5 & $-4.02 * * *$ \\
\hline Fixed Income & 20.9 & 0.0 & 15.8 & 48.4 & 17.3 & $3.54 * * *$ \\
\hline Cash & 10.1 & 0.0 & 1.7 & 31.4 & 10.1 & -0.01 \\
\hline Other/Unknown & 1.6 & 0.0 & 0.0 & 4.2 & 1.1 & 0.48 \\
\hline Number of Unique Assets & 7.22 & 1 & 4 & 16 & 4.65 & $2.57^{* * *}$ \\
\hline Number of Mutual Funds & 4.91 & 1 & 4 & 11 & 3.31 & $1.60 * * *$ \\
\hline Number of ETFs & 0.66 & 0 & 0 & 2 & 0.43 & $0.23 * * *$ \\
\hline Number of Stocks & 1.48 & 0 & 0 & 3 & 0.87 & $0.60 * * *$ \\
\hline Number of Bonds & 0.18 & 0 & 0 & 0 & 0.04 & $0.14 * * *$ \\
\hline
\end{tabular}

Note: Table shows summary statistics on both the survey respondents and non-respondents. Age, gender, location, total wealth at Vanguard, length of Vanguard relationship, and number of assets are measured as of June 2019. Other variables are presented as monthly averages between January 2017 and June 2019.

are also substantially wealthier, with average wealth held at Vanguard of \$520k for respondents relative to $\$ 254 \mathrm{k}$ for non-respondents. Respondents trade more frequently and their monthly portfolio turnover is larger; they also log into their Vanguard accounts more frequently than nonrespondents. ${ }^{6}$ Portfolio allocations of respondents and non-respondents are relatively similar, though the average respondent holds more unique assets. Overall, our sample over-represents individuals who are wealthier and who trade more often, and whose beliefs are thus more likely to affect asset prices.

We also analyze whether Vanguard clients are similar to the overall pool of retail investors. One concern is that Vanguard's investment philosophy of focusing on passive and low-fee investments attracts a selected sample of investors. Indeed, there are some differences between Vanguard clients and other retail investors. For example, Cogent Wealth Reports (2018) compared Vanguard retail clients to a representative sample of investors with at least $\$ 100 \mathrm{k}$ in investable assets. Vanguard clients were more likely to be older and richer than the comparison sample; they also held a larger portfolio share in risky assets and a larger share in passive-like instruments. These differences, however, do not mean that our sample is uninteresting or not quantitatively rel-

\footnotetext{
${ }^{6}$ Responding to the survey does not involve respondents logging into their Vanguard accounts; the process of answering the survey does therefore not lead to a mechanical increase in log-ins.
} 
evant. Vanguard manages more than \$6trn in investments (with the potential survey respondents holding around \$2trn), so the investors targeted in our study own a non-trivial fraction of global investable wealth. With the rising popularity of low-fee investment strategies, our sample is also likely to become even more relevant to understanding investments and asset prices. In addition, while there are some notable differences in characteristics between Vanguard investors and retail investors more generally, the two investor groups are similar on other important dimensions.

First, we compare the trading intensity of the survey respondents to the trading intensity observed in other investor samples studied in the literature. A recent paper by Meeuwis et al. (2018) analyzes typical retirement investors at a "large U.S. financial institution" that is not Vanguard; they report that $29.5 \%$ of those investors made an active trade in the past year. ${ }^{7}$ In our sample, which comprises both retail and retirement accounts, $67 \%$ of non-respondents and $78 \%$ of respondents made at least one active trade in the year 2017. We conclude that despite Vanguard's focus on passive buy-and-hold strategies, individuals in our sample do not appear to trade less frequently than representative retail investors at other firms. ${ }^{8}$

Second, we explore whether Vanguard investors are less likely than other investors to follow a "flow-performance" pattern, whereby they increase their positions in mutual funds that just experienced high returns (see Coval and Stafford, 2007). Appendix A.2 shows that the flowperformance sensitivity in the population of all investors in Vanguard funds as well as in the population of investors that respond to our survey is very similar to the flow-performance sensitivity documented in the literature.

Third, Appendix A.3 shows that the level and time-series variation in our survey responses are similar to those from other surveys that target different investor populations during the same period. Ultimately, it is a worthy pursuit for the future literature to extend our results to other contexts and investors populations to explore possible sources of interesting heterogeneity.

\section{I.C Survey Responses: Summary Statistics}

Table II shows summary statistics across the 46, 419 survey responses; Appendix A.4 presents the full distribution of the responses to the key questions. ${ }^{9}$ The average respondent takes about 8.5

\footnotetext{
${ }^{7}$ Meeuwis et al. (2018) report that their data "contains the characteristics and individual portfolio holdings of millions of anonymized households covering trillions of dollars in investable wealth." Their research focuses on a sub-sample that is "representative of 'typical' American investors with retirement saving", a group that holds $41 \%$ of household investable wealth in the United States.

${ }^{8}$ On the other hand, we would expect that some of our results might not generalize to a broader set of investors. For example, clients at brokerage firms that target day-traders or professional hedge funds are likely to have higher portfolio turnover. Indeed, Barber and Odean (2000) document the trading behavior of about 80,000 investors at a "large discount brokerage firm" in the United States, and find that the median person in their sample has a portfolio turnover of about $2.7 \%$ per month, relative to $0.91 \%$ in our sample.

${ }^{9}$ Even among the respondents who completed the entire survey flow, some respondents skipped a few questions. We verified that restricting our analysis to the sample of respondents who provided answers to every question does not affect our conclusions. We also explored the presence of extreme outlier responses, such as individuals reporting that the expected return on the U.S. stock market over the coming year was $400 \%$ or $-100 \%$. Since such outliers have extreme effects on the analysis, in our baseline analysis we set extreme outlier answers (below the bottom percentile, and above the top percentile) for each unbounded expectation question equal to missing. It is often the case that the same individuals report multiple answers outside the accepted ranges. Naturally, there are some critical judgment calls with selecting these cutoffs, which involve trading off retaining true extreme beliefs with excluding answers from individuals who probably misunderstood the question or the units. We have done extensive sensitivity analysis to confirm that our results are robust to a wide range of choices for the cutoff values. We also confirmed that the results
} 
minutes to answer all survey questions. The 10-90 percentile range for the total time to respond is 3.9 minutes to 13.5 minutes. Therefore, all respondents spend a sizable amount of time answering the questions, rather than carelessly clicking through the survey; this is consistent with the noncompensated nature of the survey requiring a certain intrinsic interest from participants.

Table II: Summary Statistics - Survey Responses

\begin{tabular}{|c|c|c|c|c|c|c|c|}
\hline & Mean & SD & P10 & $\mathrm{P} 25$ & P50 & P75 & $\mathrm{P} 90$ \\
\hline \multicolumn{8}{|l|}{ Expected Stock Returns } \\
\hline Expected 1Y Stock Return (\%) & 4.64 & 6.08 & -1 & 3 & 5 & 8 & 10 \\
\hline Expected 10Y Stock Return (\% p.a.) & 6.64 & 3.85 & 3 & 5 & 6 & 8 & 10 \\
\hline \multicolumn{8}{|l|}{ Probability 1Y Stock Return in Bucket (\%) } \\
\hline Less than $-30 \%$ & 5.3 & 8.5 & 0 & 0 & 3 & 8 & 10 \\
\hline$-30 \%$ to $-10 \%$ & 14.5 & 14.1 & 0 & 5 & 10 & 20 & 30 \\
\hline$-10 \%$ to $30 \%$ & 70.1 & 23.0 & 40 & 60 & 75 & 90 & 100 \\
\hline $30 \%$ to $40 \%$ & 7.3 & 10.6 & 0 & 0 & 5 & 10 & 20 \\
\hline More than $40 \%$ & 2.7 & 6.3 & 0 & 0 & 0 & 5 & 10 \\
\hline \multicolumn{8}{|l|}{ Expected GDP Growth } \\
\hline Expected 3Y GDP Growth (\% p.a.) & 2.77 & 2.16 & 1 & 2 & 3 & 3 & 4 \\
\hline Expected 10Y GDP Growth (\% p.a.) & 3.15 & 2.74 & 2 & 2 & 3 & 3 & 5 \\
\hline \multicolumn{8}{|l|}{ Probability p.a. 3Y GDP Growth in Bucket (\%) } \\
\hline Less than $-3 \%$ & 4.9 & 8.5 & 0 & 0 & 2 & 5 & 10 \\
\hline$-3 \%$ to $0 \%$ & 13.3 & 13.0 & 0 & 5 & 10 & 20 & 30 \\
\hline $0 \%$ to $3 \%$ & 58.7 & 25.8 & 20 & 40 & 60 & 80 & 90 \\
\hline $3 \%$ to $9 \%$ & 20.0 & 21.9 & 0 & 5 & 10 & 25 & 50 \\
\hline More than $9 \%$ & 3.1 & 8.5 & 0 & 0 & 0 & 5 & 10 \\
\hline \multicolumn{8}{|l|}{ Expected Bond Returns } \\
\hline Expected $1 Y$ Return of $10 Y$ zero coupon bond (\%) & 1.74 & 2.84 & -1 & 1 & 2 & 3 & 4 \\
\hline \multicolumn{8}{|l|}{ Difficulty ("Not at all difficult", ..., "Very difficult") } \\
\hline Expected Stock Returns & 2.35 & 0.98 & 1 & 2 & 2 & 3 & 4 \\
\hline Expected GDP Growth & 2.46 & 0.98 & 1 & 2 & 2 & 3 & 4 \\
\hline Expected Bond Returns & 2.84 & 1.00 & 1 & 2 & 3 & 3 & 4 \\
\hline \multicolumn{8}{|l|}{ Confidence ("Not at all confident", ..., "Very confident") } \\
\hline Expected Stock Returns & 3.04 & 0.85 & 2 & 3 & 3 & 4 & 4 \\
\hline Expected GDP Growth & 2.98 & 0.85 & 2 & 3 & 3 & 3 & 4 \\
\hline Expected Bond Returns & 2.62 & 0.86 & 2 & 2 & 3 & 3 & 4 \\
\hline Time of responding to survey (seconds) & 507 & 429 & 235 & 302 & 407 & 567 & 810 \\
\hline
\end{tabular}

Note: Table shows summary statistics of the answers across responses to the first 21 waves of the GMSU-Vanguard survey. The possible answers for "difficulty" are 1 = "Not at all difficult", 2 = "Not very difficult", $3=$ "Somewhat difficult", 4 = "Very difficult", 5 = "Extremely difficult." The possible answers for confidence are 1 = "Not at all confident", 2 = "Not very confident", 3 = "Somewhat confident", 4 = "Very confident", and 5 = "Extremely confident."

The average expected 1-year stock market return is $4.64 \%$, while the average annualized expected 10 -year stock market return is $6.64 \%$. There is substantial heterogeneity in the expected 1-year stock market return across responses. At the 10th percentile of the distribution, individuals reported a 1-year expected stock return of $-1 \%$, while at the 90 th percentile, they expected a return of $10 \%$. The across-responses standard deviation of expected 1-year returns is $6.08 \%$, much larger

are robust to winsorizing extreme answers rather than setting them equal to missing, and to dropping all answers of individuals who report extreme answers to at least one question. 
than the standard deviation of expectations of annualized 10-year returns, which is 3.85\%. This suggests that individuals anticipate some medium-run mean reversion in stock returns. When we ask individuals about their expectations of annualized GDP growth, the means for the next three years and the next ten years are quite similar at $2.77 \%$ and $3.15 \%$, respectively. The average respondent expected 1-year returns of 10-year U.S. Treasury zero coupon bonds to be $1.74 \%$, with a 10-90 percentile range across respondents of $-1 \%$ to $4 \%$.

Table II also shows that respondents put substantial probabilities on relatively large short-run stock market declines and GDP declines. The average individual assigns a $5.3 \%$ chance to the 1-year return of the stock market being less than -30\%, while the median respondent assigns a 3\% chance to such an event. As with the other answers, there is substantial across-answer heterogeneity. Answers at the 25th percentile of the distribution correspond to a $0 \%$ chance of returns lower than $-30 \%$, while those at the 90 th percentile of the distribution correspond to a $10 \%$ probability of such events. Similarly, in the case of GDP growth, individuals assign an average probability of an annualized decline in GDP of more than 3\% over the coming three years of $4.9 \%$.

Most individuals report finding the survey questions relatively easy to understand, though the questions on bond returns were perceived to be more difficult than the questions on expected stock market returns and expected GDP growth. There also appears to be a relatively wide range of confidence that individuals have in their answers. For each of the three survey blocks, individuals at the 10th percentile of the distribution report being "not very confident" in their answers, while individuals at the 90th percentile reported being "very confident."

\section{BELIEFS AND PORTFOLIOS}

In this section, we analyze the relationship between respondents' beliefs and their portfolio allocations. In the main body of the paper, we explore the role of expectations about 1-year stock returns in determining equity shares. In Appendix A.6, we analyze the role of other moments of the belief distribution (e.g., beliefs about the probability of large stock market declines), the role of stock market expectations over longer horizons, and the role of beliefs about bond returns and GDP growth. To estimate the sensitivity of equity shares to beliefs, we run the following regression:

$$
\text { EquityShare }_{i, t}=\alpha+\beta E_{i, t}\left[R_{1 y}\right]+\gamma X_{i, t}+\psi_{t}+\epsilon_{i, t} .
$$

The unit of observation is a survey response by individual $i$ in wave $t$. The dependent variable is the equity share in the individual's Vanguard portfolio at time $t$. Since most Vanguard investors find it hard to short-sell or obtain leverage, the equity share is essentially censored at both $0 \%$ and $100 \%$. We thus estimate regression 1 using tobit models. The coefficient $\beta$ captures the increase in an individual's equity share for each percentage point increase in the expected 1-year stock return.

Column 1 of Table III shows estimates from this regression without controlling for any additional covariates. An extra percentage point of expected 1-year stock returns is associated with a 0.67 percentage point increase in respondents' equity shares. ${ }^{10}$ In column 2 of Table III, we control

\footnotetext{
${ }^{10}$ Appendix A.6 shows that about half of the increase in equity shares of individuals who expect higher stock market returns comes from substituting away from cash rather than substituting away from fixed income securities.
} 
Table III: Expected Returns and Portfolio Equity Shares

\begin{tabular}{|c|c|c|c|c|c|c|c|c|}
\hline & \multicolumn{8}{|c|}{ Equity Share (\%) } \\
\hline & (1) & (2) & (3) & (4) & (5) & (6) & (7) & (8) \\
\hline Expected 1Y Stock Return (\%) & $\begin{array}{c}0.672^{* * *} \\
(0.034)\end{array}$ & $\begin{array}{c}0.690^{* * *} \\
(0.034)\end{array}$ & $\begin{array}{c}1.164^{* * *} \\
(0.061)\end{array}$ & $\begin{array}{c}0.634^{* * *} \\
(0.053)\end{array}$ & $\begin{array}{c}0.818^{* * *} \\
(0.042)\end{array}$ & $\begin{array}{c}1.177^{* * *} \\
(0.062)\end{array}$ & $\begin{array}{c}1.188^{* * *} \\
(0.069)\end{array}$ & $\begin{array}{c}1.146 * * * \\
(0.071)\end{array}$ \\
\hline $\begin{array}{l}\text { Expected } 1 Y \text { Stock Return (\%) } \\
\quad x \text { Assets }>\$ 225 \mathrm{k}\end{array}$ & & & & $\begin{array}{l}0.114^{*} \\
(0.067)\end{array}$ & & & & \\
\hline $\begin{array}{l}\text { Expected } 1 Y \text { Stock Return (\%) } \\
\text { x Above Median Time }\end{array}$ & & & & & & & $\begin{array}{l}-0.021 \\
(0.056)\end{array}$ & \\
\hline $\begin{array}{l}\text { Expected } 1 Y \text { Stock Return (\%) } \\
\quad x \text { Closest prior trade } 2 \text { weeks before }\end{array}$ & & & & & & & & $\begin{array}{l}0.479 \\
(0.356)\end{array}$ \\
\hline $\begin{array}{l}\text { Expected } 1 Y \text { Stock Return (\%) } \\
\quad x \text { Closest prior trade } 1 \text { week before }\end{array}$ & & & & & & & & $\begin{array}{r}0.460 * * \\
(0.220)\end{array}$ \\
\hline $\begin{array}{l}\text { Expected } 1 Y \text { Stock Return (\%) } \\
\quad x \text { Closest next trade } 1 \text { week after }\end{array}$ & & & & & & & & $\begin{array}{l}0.384 \\
(0.245)\end{array}$ \\
\hline $\begin{array}{l}\text { Expected } 1 Y \text { Stock Return (\%) } \\
\quad \times \text { Closest next trade } 2 \text { weeks after }\end{array}$ & & & & & & & & $\begin{array}{l}0.188 \\
(0.266)\end{array}$ \\
\hline Controls & $\mathrm{N}$ & Y & $Y$ & Y & $\mathrm{Y}$ & $\mathrm{Y}$ & $\mathrm{Y}$ & $\mathrm{Y}$ \\
\hline ORIV & $\mathrm{N}$ & $\mathrm{N}$ & $\mathrm{N}$ & $\mathrm{N}$ & $\mathrm{N}$ & Y & Y & Y \\
\hline Sample & & & $\begin{array}{c}E \text { (Return) } \\
0 \%-15 \%\end{array}$ & & $\begin{array}{l}\text { Feb } 2017 \text { - } \\
\text { Feb } 2020\end{array}$ & & & $\begin{array}{c}\text { Retail } \\
\text { accounts }\end{array}$ \\
\hline $\mathrm{N}$ & 44,595 & 44,565 & 39,296 & 44,565 & 39,859 & 44,235 & 44,235 & 41,142 \\
\hline
\end{tabular}

Note: Table shows results from regression 1. The unit of observation is a survey response. The dependent variable is the equity share. Columns 2-8 control for the respondents' age, gender, region of residence, wealth, and the survey wave. For the interaction specifications in columns 4, 7, and 8, we also include dummy variables for the respondent characteristics that we estimate the sensitivity for. Standard errors are clustered at the respondent level. Significance levels: ${ }^{*}(\mathrm{p}<0.10),{ }^{* *}(\mathrm{p}<0.05),{ }^{* * *}(\mathrm{p}<0.01)$.

for demographic characteristics such as age, gender, wealth, and region of residence, as well as survey-wave fixed effects. Figure II shows a conditional binscatter plot of the resulting relationship between expected returns and equity shares. The estimated sensitivity of portfolio shares to beliefs is similar to that in column $1 .{ }^{11}$ Given the wide heterogeneity in beliefs across individuals, our estimates imply substantial belief-driven variation in equity shares: quantitatively, a one-standard-deviation increase in expected 1-year stock returns is associated with a 0.16 standard deviation increase in equity shares. ${ }^{12}$

Figure II suggests that the estimated relationship between beliefs and portfolios might be sensitive to beliefs at the two extremes. Therefore, we next run regression 1 on a sample of respondents that report expected returns between $0 \%$ and $15 \%$. This drops about $10 \%$ of our responses. Column 3 of Table III shows that the sensitivity estimate in this restricted specification is almost $70 \%$ higher, suggesting that outliers have some effect on the relationship.

\footnotetext{
${ }^{11}$ While the estimates of $\beta$ are the primary object of interest, the coefficients on the control variables are also interesting. Males and females do not have significantly different equity shares. Equity shares are strongly declining in age, with individuals above 70 years of age having about 20 percentage points lower equity share than individuals below the age of 40. Equity shares also do not differ significantly across regions, and are only weakly declining with wealth.

${ }^{12}$ In Appendix A.6 we explore the effect of other moments of the belief distribution on equity shares. We find that the subjective risk of large stock market declines has a more significant effect on portfolio allocations than the subjective variance. We also show that long-run stock market beliefs matter in addition to short-run beliefs, and highlight that beliefs about other investments, including fixed income investments, also influence the optimal equity share. Expected
} 


\section{Figure II: Expected 1-Year Stock Returns and Equity Share}

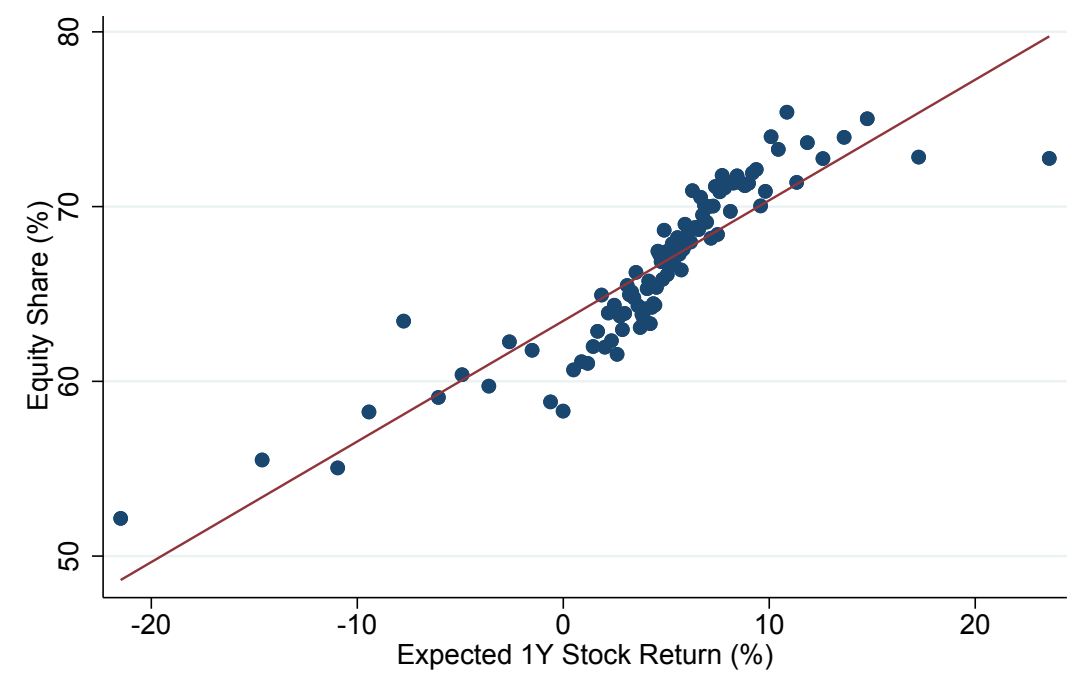

Note: Figure shows a conditional binscatter plot of survey respondents' expected 1-year stock returns and the equity share in their portfolios, conditional on the respondents' age, gender, region, wealth, and the survey wave.

To highlight the economic magnitude of the estimated $\beta$-coefficient, we perform a back-of-theenvelope calculation using the Merton (1969) model, which shows that for power-utility investors:

$$
\text { EquityShare }_{i, t}=\frac{1}{\gamma} \frac{E_{i}[R]-R_{f}}{\operatorname{Var}_{i}[R]}
$$

Here, $\gamma$ is the individual's coefficient of relative risk aversion, $E_{i}[R]$ is the individual's expected stock return, $R_{f}$ is the risk-free rate, and $\operatorname{Var}_{i}[R]$ is the individual's subjective variance of equity returns. We measure EquityShare ${ }_{i, t}$ in the Vanguard data, and $E_{i}[R]$ with the survey answer to 1year expected stock returns. For the back-of-the-envelope calculation, we assume that individuals have a common measure of the variance $\operatorname{Var}_{i}[R]=\operatorname{Var}[R] .^{13}$ Similarly, we assume a common and constant coefficient of relative risk aversion. In this simplified setting, the $\beta$ estimated in Table III corresponds to $\beta=\frac{1}{\gamma \operatorname{Var}[R]}$. The historical standard deviation of stock market returns is around $20 \%$ a year. The simple model thus implies that a $\beta$ of 0.69 requires a coefficient of relative risk aversion of $\gamma=36$. This is considerably higher than most estimates in the experimental literature, which usually finds values of $\gamma$ between 3 and 10. To obtain a realistic coefficient of relative risk aversion, let us say around 4, we would need an estimate of $\beta$ of around 6.25; for $\gamma=6$, we would require $\beta=4.2$. In other words, the sensitivity estimated in column 2 is an order of magnitude too small to align with the simplest frictionless model. ${ }^{14}$ This relatively small response of equity

GDP growth does not appear to significantly affect the equity share once we control for expected stock returns.

${ }^{13}$ In Appendix A.6, we relax this assumption and measure the variance of 1-year expected stock returns that is implied by the distribution question; this does not affect the estimated effect of changes in expected equity returns on equity shares. We find the simple calculation with a common variance across individuals parameterized to the historical variance to be appealing for several reasons: (i) in many models, it is easy to learn the variance of returns but hard to learn the mean; (ii) equation 2 is particularly sensitive to measurement errors in the denominator; and (iii) model misspecification is likely and other moments (e.g., tail event probabilities) may also be important.

${ }^{14}$ Note that in this model, $\gamma$ drives both the sensitivity of the equity portfolio share to changes in expected returns 
shares to beliefs about stock returns is consistent with evidence documented across a number of other studies that link measures of equity market participation and equity shares to expected stock market returns (e.g., Vissing-Jorgensen, 2003; Dominitz and Manski, 2007; Kézdi and Willis, 2011; Amromin and Sharpe, 2013; Ameriks et al., 2016; Drerup, Enke and Von Gaudecker, 2017).

In many models, asset prices are driven by wealth-weighted beliefs, rather than beliefs that are equally weighted across all investors. We thus explore whether the sensitivity of portfolios to beliefs is different for wealthier individuals. Column 4 of Table III shows that respondents with more than $\$ 225 \mathrm{k}$ in assets - which corresponds to our sample median - have a sensitivity that is marginally larger than that of individuals with lower wealth; in unreported results, we find that the sensitivity does not increase substantially for even higher levels of wealth. These results show that even the wealth-weighted sensitivity would not be large enough to generate the quantity movements implied by Mertonian portfolio demand.

One natural question concerns the extent to which our findings are driven by the large drop and subsequent recovery of the stock market resulting from the COVID-19 pandemic in the first half of 2020. ${ }^{15}$ As we show below, following the stock market crash of March 2020, average beliefs in the April 2020 wave fell dramatically, and had only partially recovered by the June 2020 wave. In column 5 of Table III, we restrict our analysis to the first 19 waves of the GMSU-Vanguard survey, ending near the all-time high of the S\&P 500 in February 2020. The estimated sensitivity of portfolios to beliefs over this period, which generally saw rising stock prices, is somewhat higher, with a $\beta \approx 0.82$. This finding suggests that the substantial decline in expected returns following the crash was associated with only a modest active reduction in equity shares (see also Giglio et al., 2020). However, even the somewhat higher elasticity during the relatively calm period in the stock market between February 2017 and February 2020 remains substantially below that implied by the frictionless model. This results highlights that the weak estimated relationship between beliefs and portfolios is not primarily the result of the large stock market crash during our sample. Indeed, Appendix A.12 highlights that all results in this paper are robust to both including and excluding the COVID-19 stock market crash in the sample.

There are a number of possible explanations for this relatively low estimated average sensitivity of equity shares to expected stock returns. The first set of explanations involves measurement error in the key measure of beliefs, $E_{i, t}\left[R_{1 y}\right]$, and the associated attenuation bias that such measurement error would entail. The second set of explanations centers around possible frictions in the transmission of beliefs to portfolios. Indeed, the Merton (1969) model is based on a number of strong assumptions, including that investors continuously pay attention to their portfolios, that they continuously rebalance them, that they are confident in their beliefs, and that there are no other frictions to trading, such as the tax implications from realizing capital gains. ${ }^{16}$ Any devia-

as well as the unconditional level of the equity share. In particular, for $\gamma=4$, an average risk premium of $6 \%$, and a standard deviation of $20 \%$, we obtain an average equity share of $38 \%$. When $\gamma=30$, the equity share drops to $5 \%$. This means that high risk aversion can explain the low sensitivity of portfolios to beliefs, but at the cost of grossly missing the average level of the equity portfolio share.

${ }^{15}$ After one of the longest and most pronounced stock market booms on record during 2009-2019, the U.S. stock market experienced a sudden crash starting on Monday, February 24th, following increasingly negative news about the COVID-19 pandemic. On March 23, the S\&P 500 reached its lowest point at 34\% below the February peak, before recovering to about $8 \%$ below the peak by the time of the June 2020 wave of the GMSU-Vanguard survey.

${ }^{16}$ Another possible set of alternative explanations falls under the category of "optimists take risks outside of Van- 
tion of investor behavior from these assumptions suggests that the high sensitivity in the Merton (1969) model is likely to be an upper bound for real world applications.

\section{II.A Possible Explanation I: Measurement Error}

We start by exploring whether measurement error can account for the relatively low estimated average sensitivity of portfolio allocations to beliefs. A first possible explanation is that classical measurement error in beliefs may induce attenuation bias in our estimates of $\beta .{ }^{17}$ To deal with such measurement error, we exploit the fact that, from each survey response, we obtain two separate estimates of the same explanatory variable, $E_{i, t}\left[R_{1 y}\right]$. The first measure is the expected return as reported directly by the survey respondents. The second measure is the implied mean of the distribution over possible returns reported by each respondent. ${ }^{18}$ The correlation across the two measures is 0.49 , and the different elicitation methods likely have measurement errors that are not perfectly correlated. This setting thus allows us to exploit recent advances from the econometrics literature on instrumental variables (IV) approaches to reduce the bias from measurement error.

In principle, the attenuation bias from classical measurement error could be addressed by instrumenting for one of the estimates of expected return with the other, though there is no theoretical guidance as to which estimate should be the instrumented variable and which should be the instrument. Our approach follows the Obviously Related Instrumental Variables (ORIV) strategy proposed by Gillen, Snowberg and Yariv (2019), which consolidates the information from these different formulations to provide an estimator that is more efficient than either of the two IV strategies alone. Column 6 of Table III shows that this ORIV approach increases the estimated sensitivity by more than $70 \%$ relative to column 2 , to $\beta=1.18$. Classical measurement error, therefore, accounts for a non-trivial component of the low sensitivity. This finding highlights the value for future surveys to include various ways of eliciting the same beliefs, thereby allowing researchers to use ORIV techniques to reduce the attenuation bias associated with measurement error that is imperfectly correlated across elicitation methods.

Nevertheless, even the sensitivity obtained by using ORIV techniques remains far below that implied by the frictionless Merton (1969) model. In this light, it is important to emphasize that if measurement error is positively correlated across the two elicitations, something that is not unlikely in our setting, then instrumented coefficients will still be biased downward, although less so than without instrumenting. We next take a number of steps to determine whether such correlated

guard portfolios." For example, more optimistic respondents might have other accounts, at a different firm, and predominantly take risks in those accounts. Such an explanation is inconsistent with the evidence in Ameriks et al. (2016), who field a survey to show that equity shares observed in the Vanguard data are quite representative of equity shares across Vanguard users' wider range of accounts. The same study also helps mitigate the concern that more optimistic respondents might be more risk averse: that survey observes one cross-section of both expected returns and risk-aversion (elicited via lottery-type questions) and concludes that risk-aversion heterogeneity is not sufficient to explain the low estimated average sensitivity of portfolios to beliefs.

${ }^{17}$ We refer to classical measurement error as the concern that the reported belief is a noisy measure of individuals' true beliefs, $E_{i, t}\left[R_{1 y}\right]=E_{i, t}\left[R_{1 y}\right]^{\text {True }}+\epsilon_{i, t}$, where $\epsilon_{i, t}$ represents i.i.d. and mean zero measurement error.

${ }^{18}$ To construct the implied mean from the distribution, we first compute, for each bucket, the average historical return conditional on the return being in that bucket, and then we weight these estimates by the subjective probabilities of each bucket reported by the respondent. Our results are unchanged if we take the mid-points of the buckets, and assign a value of $-40 \%$ for the lowest open-ended bucket (expected 1-year stock returns $\leq-30 \%$ ) and a value of $50 \%$ for the highest open-ended bucket (expected 1-year stock returns $\geq 40 \%$ ). 
measurement error explains a substantial part of the remaining gap between our estimates and the predictions from frictionless models. In the end, we find it unlikely that correlated measurement error is an important contributor to the low estimated sensitivity. Instead, we find that frictions in the transmission of beliefs to portfolios explain much of the remaining gap between our estimates and the quantitative predictions of the frictionless benchmark model.

To further explore the role of measurement error, we next analyze the hypothesis that the time spent by individuals to answer the questions may allow us to identify individuals who are more or less subject to various types of measurement error. Column 7 of Table III shows that we obtain similar estimates of the sensitivity among people in the top and bottom halves of the time-spent distribution. Similarly, in unreported results we find that cutting out the top and bottom $10 \%$ of the time-spent distribution has little effect on the estimated sensitivity.

We also investigate whether beliefs that are elicited close to when people trade are less noisy and, therefore, more closely related to respondents' portfolios. This test is motivated by the model of Azeredo da Silveira and Woodford (2019), which predicts that beliefs should be most closely aligned with portfolios just before an agent trades. Column 8 of Table III shows that respondents who traded in the four weeks around the survey date have a higher sensitivity of beliefs to portfolios, a feature we will explore more extensively in the following section. However, the coefficients are estimated with substantial measurement error and do not allow us to determine with any precision whether individuals who traded the week before versus the week after the survey have a differential sensitivity of portfolios to beliefs. ${ }^{19}$

\section{II.B Possible Explanation II: Heterogeneous Frictions}

We next show that deviations from the frictionless benchmark model of Merton (1969) can help us account for much of the remaining difference between our estimates and the predictions from that model.

Capital Gains Taxes. A first friction that can reduce the passthrough from changes in beliefs to portfolios is the presence of capital gains taxes that can arise in the rebalancing process. To test for the importance of this friction, we exploit that some survey respondents have both standard and tax-advantaged individually-managed accounts. Columns 1 and 2 of Table IV focus on these individuals, thus controlling for potential differences in individuals' preferences such as their aversion to realize gains and losses. In column 1, we study the equity share in their standard retail accounts, while in column 2, we focus on the equity share in their tax-advantaged retail accounts (usually IRAs). We find that, for the same individuals, the equity share in the tax-advantaged accounts is more aligned with the individuals' beliefs than the equity share in the standard brokerage accounts. This evidence suggests that capital gains taxes can be an important friction that inhibits the transmission of beliefs to portfolios relative to the predictions from frictionless models.

Default Options in Defined Contribution Plans. As described in Section I, our survey sample includes investors holding two types of tax-advantaged accounts: individually-managed taxadvantaged retirement accounts and employer-sponsored retirement accounts such as defined contribution plans (though very few investors hold both types of accounts). Investments in the

\footnotetext{
${ }^{19} \mathrm{We}$ also do not find evidence of an increase in the probability of trading following the survey.
} 
Table IV: Expected Returns and Portfolios - Heterogeneity

\begin{tabular}{|c|c|c|c|c|c|c|c|}
\hline & \multicolumn{7}{|c|}{ Equity Share (\%) } \\
\hline & (1) & (2) & (3) & (4) & (5) & (6) & (7) \\
\hline Expected 1Y Stock Return (\%) & $\begin{array}{c}1.198 * * * \\
(0.140)\end{array}$ & $\begin{array}{c}1.419 * * * \\
(0.100)\end{array}$ & $\begin{array}{c}1.270 * * * \\
(0.178)\end{array}$ & & & & \\
\hline $\begin{array}{l}\text { Expected } 1 Y \text { Stock Return (\%) } \\
\text { x Monthly Turnover }<0.5 \%\end{array}$ & & & & $\begin{array}{c}0.737 * * * \\
(0.133)\end{array}$ & & & \\
\hline $\begin{array}{l}\text { Expected } 1 Y \text { Stock Return }(\%) \\
\quad x \text { Monthly Turnover } \in[0.5 \%, 4 \%]\end{array}$ & & & & $\begin{array}{c}1.330^{* * *} \\
(0.084)\end{array}$ & & & \\
\hline $\begin{array}{l}\text { Expected } 1 Y \text { Stock Return (\%) } \\
\quad \times \text { Monthly Turnover }>4 \%\end{array}$ & & & & $\begin{array}{c}1.758^{* * *} \\
(0.231)\end{array}$ & & & \\
\hline $\begin{array}{l}\text { Expected } 1 Y \text { Stock Return (\%) } \\
\times \text { Monthly Vanguard Visits } \in(0,1)\end{array}$ & & & & & $\begin{array}{c}1.048^{* * *} \\
(0.116)\end{array}$ & & \\
\hline $\begin{array}{l}\text { Expected } 1 Y \text { Stock Return (\%) } \\
\quad x \text { Monthly Vanguard Visits } \in[1,7)\end{array}$ & & & & & $\begin{array}{c}1.106 * * * \\
(0.072)\end{array}$ & & \\
\hline $\begin{array}{l}\text { Expected } 1 Y \text { Stock Return (\%) } \\
\quad \times \text { Monthly Vanguard Visits } \in[7,31)\end{array}$ & & & & & $\begin{array}{c}1.640 * * * \\
(0.135)\end{array}$ & & \\
\hline $\begin{array}{l}\text { Expected } 1 Y \text { Stock Return (\%) } \\
\quad x \text { Low Confidence }\end{array}$ & & & & & & $\begin{array}{c}0.810^{* * *} \\
(0.127)\end{array}$ & \\
\hline $\begin{array}{l}\text { Expected } 1 Y \text { Stock Return (\%) } \\
\times \text { Medium Confidence }\end{array}$ & & & & & & $\begin{array}{c}1.229 * * * \\
(0.072)\end{array}$ & \\
\hline $\begin{array}{l}\text { Expected 1Y Stock Return (\%) } \\
\quad \text { x High Confidence }\end{array}$ & & & & & & $\begin{array}{c}1.448 * * * \\
(0.268)\end{array}$ & \\
\hline $\begin{array}{l}\text { Expected 1Y Stock Return (\%) } \\
\quad \text { x Not Idealized }\end{array}$ & & & & & & & $\begin{array}{c}1.338 * * * \\
(0.075)\end{array}$ \\
\hline $\begin{array}{l}\text { Expected 1Y Stock Return (\%) } \\
\quad x \text { Idealized }\end{array}$ & & & & & & & $\begin{array}{c}3.553^{* * *} \\
(1.329)\end{array}$ \\
\hline Controls + Fixed Effects & Y & Y & Y & Y & Y & Y & Y \\
\hline Sample & $\begin{array}{l}\text { Retail } \\
\text { Account }\end{array}$ & $\begin{array}{l}\text { Retail } \\
\text { Account } \\
\text { Tax Adv. }\end{array}$ & $\begin{array}{c}\text { Defined } \\
\text { Contribution } \\
\text { Plans }\end{array}$ & & & & $\begin{array}{c}\text { Retail } \\
\text { Account } \\
\text { Tax Adv. }\end{array}$ \\
\hline $\mathrm{N}$ & 19,921 & 19,921 & 4,112 & 41,252 & 44,235 & 44,235 & 34,486 \\
\hline
\end{tabular}

Note: Table shows results from regression 1, estimated using ORIV. The dependent variable is the equity share. In column 1 it is the equity share in individually-managed retail accounts, in column 2 it is the equity share in individuallymanaged tax-advantaged retail accounts, and in column 3 it is the equity share in institutionally-managed retirement plans (defined contribution plans). In columns 5-6, it is pooled across the three types of accounts, while column 4 uses data from both types of retail accounts only. The sample in columns 1 and 2 is restricted to respondents holding both types of retail accounts. In column 6, "low confidence" corresponds to individuals who reported being "not at all confident" or "not very confident" in their answers about expected stock returns; "medium confidence" corresponds to individuals who report being "somewhat confident" or "very confident" about their answers; and "high confidence" corresponds to individuals who report being "extremely confident." "Idealized" respondents in column 7 are those whose behavior most closely corresponds to that of the assumptions in the frictionless model: they have average monthly portfolio turnover of at least $4 \%$, they have at least seven log-ins a month, and they report to be extremely confident in their beliefs. For the interaction specifications in columns 4, 5, and 6, we also include dummy variables for the respondent characteristics that we estimate the sensitivity for. Standard errors are clustered at the respondent level. Significance levels: * $(\mathrm{p}<0.10),{ }^{* *}(\mathrm{p}<0.05),{ }^{* * *}(\mathrm{p}<0.01)$. 
first account usually represent an active decision of the investor. Within defined contribution plans, it is increasingly common to automatically enroll employees at prespecified contribution rates and into prespecified assets. ${ }^{20}$ A robust empirical finding is that these default investments are very sticky (e.g., Madrian and Shea, 2001; Beshears et al., 2009). Among Vanguard investors, Clark, Utkus and Young (2015) found that 89\% of participants under automatic enrollment remained 100\% invested in the default option after 12 months. Many investors in defined contribution plans thus appear to make relatively few active portfolio allocation decisions that could reflect their beliefs. Consistent with this, comparing columns 2 and 3 of Table IV shows that the average sensitivity of portfolios to beliefs in institutionally-managed defined contribution plans is somewhat smaller than it is in individually-managed tax-advantaged accounts, though the differences are not statistically significant. This suggests a role for another deviation from the assumption of the frictionless benchmark model, namely that a substantial amount of wealth is invested through sticky default options rather than through active allocations.

Infrequent Trading. Another plausible contributor to the low estimated sensitivity of portfolios to beliefs is that even those investors that actively choose their portfolios only adjust them infrequently (e.g., Duffie, Sun et al., 1990; Gabaix and Laibson, 2001; Agnew, Balduzzi and Sunden, 2003; Peng and Xiong, 2006; Abel, Eberly and Panageas, 2007; Alvarez, Guiso and Lippi, 2012; Adam et al., 2015). To the extent that investors change their beliefs over time and report their current beliefs in the survey, the contemporaneous portfolios may thus not be fully reflective of current beliefs. Prior research has focused on several complementary explanations for infrequent portfolio adjustments. The first explanation is the cost of monitoring portfolio allocations, which can cause investors to only infrequently pay attention to their portfolios. The second explanation is that even after paying attention to their portfolios, a number of additional costs may prevent investors from trading; these can include physical transaction costs from brokerage commissions and capital gains taxes (see above), and mental costs from the need to determine optimal behavior based on beliefs and current portfolios.

We next explore whether infrequent trading can help explain the low sensitivity of portfolio allocations to beliefs. We first split respondents with retail accounts into three groups depending on their trading behavior during the sample period. Specifically, we classify individuals by the average monthly turnover in their portfolios, but our results are robust to other definitions of "infrequent trading," such as the average monthly number of trades. Column 4 of Table IV shows that individuals with a monthly portfolio turnover of at least $4 \%$ have a sensitivity of equity shares to beliefs that is more than twice as large as that of individuals with a monthly portfolio turnover of less than $0.5 \%$. These findings suggest that trading intensity is an important determinant of how strongly (and quickly) beliefs are reflected in portfolio holdings.

We also analyze the role of a specific motivation behind infrequent trading, namely investor attention, in explaining this relationship (see DellaVigna and Pollet, 2009; Barber and Odean, 2013; Ouimet and Tate, 2017; Arnold, Pelster and Subrahmanyam, 2018, for discussions of investor attention). We measure investor attention as the average frequency with which investors log into

\footnotetext{
${ }^{20}$ Indeed, by the end of 2017, 46\% of Vanguard plans had adopted automatic enrollment (about half of those enrolled all eligible employees, and the other half enrolled newly eligible employees only).
} 
their Vanguard accounts during our sample period. Appendix Figure A.3 shows that this measure is correlated with, but different from actual trading activity. Column 5 of Table IV shows that individuals who log into their Vanguard accounts more frequently have a higher sensitivity of equity shares to beliefs: individuals who log in more than seven times per month have a $56 \%$ higher sensitivity than individuals who log in less than once per month. ${ }^{21}$ This result suggests that investor attention is an important driver of the attenuated relationship between beliefs and portfolios.

Confidence. A further mechanism that is potentially important in understanding how differences in beliefs translate into portfolio holdings is the confidence that individuals have in their own beliefs. Indeed, a large literature suggests that individuals who are more confident in their own beliefs are more likely to trade on them (e.g., De Long et al., 1990; Kyle and Wang, 1997; Daniel, Hirshleifer and Subrahmanyam, 1998; Odean, 1999; Gervais and Odean, 2001; Barber and Odean, 2001; Grinblatt and Keloharju, 2009; Hoffmann and Post, 2016; Drerup, Enke and Von Gaudecker, 2017). To explore the effect of investor confidence on the extent to which beliefs are reflected in portfolios, we exploit the fact that the survey directly elicits how confident individuals are about their answers. ${ }^{22}$ While individuals who are more confident log in or trade slightly more often, most of the variation in trading and attention is within individuals with the same reported confidence (see Appendix Figure A.3). This means that any variation in sensitivity by confidence is picking up a conceptually different object than variation in sensitivity by trading frequency or attention. Column 6 of Table IV shows that individuals who report being "extremely confident" in their stock market beliefs have an almost two times higher sensitivity of portfolio shares to beliefs than individuals who report being "not at all confident" or "not very confident."

The Idealized Frictionless Investor. There is substantial heterogeneity across individuals in the sensitivity of portfolios to beliefs, and those individuals who are most similar to the frictionless benchmark on a number of dimensions have the highest sensitivities. In column 7 of Table IV, we explore the sensitivity of those respondents whose behavior comes closest to the frictionless model on all four dimensions jointly: individuals who are actively investing in tax-advantaged retail accounts, who are very confident in their beliefs, who pay substantial attention, and whose trading volume is significant. For respondents in that group, we estimate a $\beta$ of 3.6, though the standard error around this estimate is quite large. This estimate gets quite close to the benchmark of $\beta=$ 6.25 implied by the frictionless Merton (1969) model with $\gamma=4$, and matches the predictions from that model with a $\gamma \approx 7$, a value squarely within the range considered in the asset pricing literature. This powerful result shows the importance of frictions for quantitatively explaining the deviations of observed average sensitivities from the benchmark Merton (1969) model.

\footnotetext{
${ }^{21}$ Note that while the frequency of trading and log-ins strongly affects the relationship between beliefs and portfolios, they are not strongly correlated with either the level of beliefs or the equity share themselves.

${ }^{22}$ Mapping confidence as reported in the survey to economic theory is not straightforward. One possibility is that confidence captures the degree of certainty that individuals have about the entire distribution of outcomes. Individuals who are less confident think that there is a higher probability that the outcomes will be drawn from a distribution different from the one that they report in the survey. One possibility that we ruled out is that confidence simply reflects individuals' uncertainty about the expected outcome. While confidence is inversely related to the standard deviation of outcomes implied by the distribution questions, the relation is far from perfect, and the effect of confidence on actions such as portfolio risk-taking goes well beyond the effect induced by the standard deviation.
} 


\section{II.C Summary of Explanations for Low Sensitivity, and their Implications.}

This section documents that investors' portfolios systematically vary with their beliefs. However, the average sensitivity is smaller than that predicted by frictionless models. Some of the low estimated sensitivity can be attributed to various forms of measurement error, but this accounts for only a small part of the observed gap. Instead, we identified a number of frictions that can help explain the low average sensitivity. Overall, our findings suggest that heterogeneous investor attention, adjustment costs, capital gains taxes, and confidence are important mediators of the transmission from beliefs to portfolio allocations, and should therefore play a more prominent role in the design of macro-finance models going forward. We sum up these findings in the following fact:

Fact 1. Portfolio shares vary systematically with individuals' beliefs. However, the average sensitivity of an investor's portfolio share in equity to that investor's expected stock market returns is lower than predicted by simple and frictionless asset pricing models. This sensitivity is higher in tax-advantaged retail accounts and is increasing in wealth, investor trading frequency, investor attention, and investor confidence.

Our results on the relatively low average sensitivity of portfolios to beliefs speak to a large class of both rational and behavioral macro-finance models that explicitly account for survey evidence on beliefs. These models' predictions for asset prices usually rest on two modeling blocks: (i) beliefs that change over time in a way that is consistent with survey data, and (ii) individual portfolios that react strongly to changes in these beliefs, often by building on modifications of Mertonian portfolio demand in CARA-normal setups. In contrast to this assumption, we find that for the majority of investors in our sample, infrequent trading, inattention, and lack of confidence in beliefs reduce the passthrough from beliefs to portfolios relative to the frictionless benchmark.

It is an open question whether a model in which agents have a lower sensitivity of portfolio demand to beliefs can match asset prices without further adjustments; our research suggests that successful models should match expectations and portfolio dynamics together with asset prices. Motivated by our finding of strong heterogeneity in investor behavior, one possibility for adjustments to current models is to explicitly account for the heterogeneity in terms of wealth and sensitivity of portfolios to beliefs. For example, behavioral models such as those reviewed by Barberis (2018) often feature two types of investors - such as behavioral investors and rational arbitrageurs - each modeled with its own demand for stocks similar to equation 2. Asset prices are then determined by the dynamics of expectations of the behavioral agents, modulated by the relative wealth shares of the two agents and their relative demand sensitivities. In the context of these models, equilibrium prices might still be significantly driven by the behavioral investors' beliefs if these investors tend to have higher sensitivity of their portfolios to their beliefs compared to the other investors. This suggests how the models could be modified to match these new moments. Indeed, several factors can amplify the equilibrium price effects of these changes in expectations: a larger wealth share owned by the behavioral investors; a lower elasticity of the

remaining investors to demand shocks, as studied for institutional investors by Gabaix and Koijen (2020); or other frictions, as in Adam et al. (2015). 


\section{Trading AND the PAssthrough of Beliefs To PortFolios}

Fact 1 highlights that low portfolio turnover reduces the measured sensitivity of portfolios to beliefs in the cross-section of survey respondents. In this section, we explore the relationship between trading activity and time-series variation in beliefs. We establish that active trades are not only infrequent, as is apparent from the summary statistics presented in Table I, but also do not appear to be prompted by changes in beliefs. The way that belief changes translate into changes in portfolios is through the direction and magnitude of trading conditional on a trade occurring.

Before presenting the analysis, we briefly discuss how we measure trading; Appendix A.7 provides additional details. We observe information on all transactions for clients with a retail account. These transactions include money being moved in and out of the Vanguard accounts, purchases and sales of securities, and purchases, sales, and exchanges of shares in mutual funds. We aggregate all trades by asset class: equity, fixed income, cash and cash-equivalents, and other investments. Since we observe beliefs only when an investor answers the survey, we also aggregate all trades that occur between two consecutive survey responses; these time windows differ across investors who respond to different survey waves. ${ }^{23}$ This approach allows us to focus on changes in portfolio shares over a given time window that are induced by active trading, filtering out any changes resulting from market movements. We then regress the change in the equity share due to trading for individual $i$ over time window $w$, given as $\Delta$ EquityShare $_{i, w}$, on the expected 1year stock return at the beginning of the window, $E_{i, w-}\left[R_{1 y}\right]$, the change in this expectation during the window, $\Delta E_{i, w}\left[R_{1 y}\right]$, and the equity share at the beginning of the window, EquityShare $e_{i, w-}$ :

$$
\Delta \text { EquityShare }_{i, w}=\alpha+\beta E_{i, w-}\left[R_{1 y}\right]+\gamma \Delta E_{i, w}\left[R_{1 y}\right]+\delta \text { EquityShare }_{i, w-}+\phi X_{i, w}+\epsilon_{i, w} .
$$

The vector $X_{i, w}$ includes a set of time-window-length fixed effects, as well as controls for age, gender, region of residence, wealth, wave fixed effects, and dummies for initial equity shares of $0 \%$ and $100 \%$. Column 1 of Table V reports the main coefficients; in Appendix A.7, we also report the coefficients on the control variables as well as estimates with the sample restricted to the pre-COVID-19 period. A one-percentage-point increase in expected returns at the beginning of the window predicts a 0.13 percentage point increase in the equity share due to trading over the following window; a one-percentage-point change in beliefs over the window predicts a 0.23 percentage point change in the equity share. While these sensitivities are statistically significant, they are smaller than what we obtained from the cross-sectional analysis in Section II. ${ }^{24}$ Column 1 also shows that investors with high equity shares at the beginning of the window tend to actively reduce their equity exposures, potentially a sign of rebalancing of their positions.

The low sensitivity in column 1 could reflect two different mechanisms. First, it could simply result from the fact that individuals trade infrequently, so that the average sensitivity to beliefs

\footnotetext{
${ }^{23}$ For example, if an investor has answered waves 1, 2 and 5 of the survey, we would identify two time windows: the 2-month period between wave 1 and wave 2, and the 6-month period between wave 2 and wave 5. Each time window would appear as a separate observation in regression 3.

${ }^{24}$ Since these regressions are analyzing changes over time in portfolio choice, rather than levels as in Section II, they make use of a different source of variation; while one would expect these two approaches to produce similar results in a frictionless world, this is not necessarily the case if trading frictions are present.
} 
Table V: Trading Analysis

\begin{tabular}{|c|c|c|c|c|c|}
\hline & $\Delta$ Equity Share (\%) & Probability Trade & Probability Trade & Probability Buy & $\Delta$ Equity Share (\%) \\
\hline & (1) & (2) & (3) & (4) & (5) \\
\hline$\Delta$ Expected 1Y Stock Return (\%) & $\begin{array}{c}0.229 * * * \\
(0.033)\end{array}$ & & & $\begin{array}{c}0.977^{* * *} \\
(0.201)\end{array}$ & $\begin{array}{c}0.587^{* * *} \\
(0.085)\end{array}$ \\
\hline Expected 1Y Stock Return (\%) & $\begin{array}{c}0.130 * * * \\
(0.019)\end{array}$ & $\begin{array}{c}0.006 \\
(0.130)\end{array}$ & & $\begin{array}{c}1.489 * * * \\
(0.199)\end{array}$ & $\begin{array}{c}0.395^{* * *} \\
(0.062)\end{array}$ \\
\hline Lagged Equity Share (\%) & $\begin{array}{c}-0.048^{* * *} \\
(0.004)\end{array}$ & $\begin{array}{c}-0.121^{* * *} \\
(0.021)\end{array}$ & & $\begin{array}{c}-0.337^{* * *} \\
(0.031)\end{array}$ & $\begin{array}{c}-0.161^{* * *} \\
(0.011)\end{array}$ \\
\hline $\mid \Delta$ Expected 1Y Stock Return (\%) | & & $\begin{array}{c}0.258 \\
(0.223)\end{array}$ & & & \\
\hline Extreme Equity Share Dummies & $\mathrm{Y}$ & $\mathrm{Y}$ & $\mathrm{Y}$ & $\mathrm{Y}$ & Y \\
\hline Time Betweeen Wave Dummies & Y & Y & Y & Y & Y \\
\hline Other Fixed Effects and Controls & Y & Y & $\mathrm{N}$ & Y & Y \\
\hline Specification & & & & $\begin{array}{l}\text { Conditional on } \\
\text { Trading }\end{array}$ & $\begin{array}{l}\text { Conditional on } \\
\text { Trading }\end{array}$ \\
\hline R-Squared & 0.031 & 0.380 & 0.364 & 0.483 & 0.154 \\
\hline $\mathrm{N}$ & 22,439 & 22,439 & 23,441 & 6,606 & 6,606 \\
\hline
\end{tabular}

Note: Table shows results from regression 3. The unit of observation is a window between two consecutive survey responses by the same individual. The dependent variable in columns 1 and 5 is the change in the equity share due to active trading between the two survey waves. The dependent variable in columns 2 and 3 is an indicator for whether there was any active trading between the two survey waves, defined as an active change in the equity share of at least one percentage point. The dependent variable in column 4 is an indicator of whether the individual actively increased her portfolio share in equity by at least one percentage point during the window as a result of trading between the two survey waves. All columns control for the length of time between two consecutive answers, and for dummies capturing extreme start-of-period equity shares of $0 \%$ or $100 \%$. All columns, except column 3 , also control for the respondents' age, gender, region of residence, wealth, and the survey wave. Columns 4 and 5 condition the sample on windows with active trades. All results are obtained using ORIV. The $R$-Squared is computed from OLS specifications. Standard errors are clustered at the respondent level. Significance levels: ${ }^{*}(p<0.10), *^{* *}(p<0.05),{ }^{* * *}(p<0.01)$.

appears low (extensive margin). Alternatively, it could reflect a low sensitivity of trading to beliefs even when investors trade actively (intensive margin). We next explore these explanations.

The Extensive Margin of Trading. A large literature aims to explain trading volume in financial markets via a mix of changes in beliefs and overconfidence (e.g., Harrison and Kreps, 1978; Hong and Stein, 1999; Scheinkman and Xiong, 2003; Hong and Stein, 2007). A related literature has studied the optimal frequency and size of trading in the presence of limited information and transaction costs (e.g., Duffie, Sun et al., 1990; Gabaix and Laibson, 2001; Abel, Eberly and Panageas, 2007; Alvarez, Guiso and Lippi, 2012). A natural question in our setup, therefore, is whether changes in beliefs are associated with trading activity.

Column 2 of Table V shows results from a regression similar to equation 3, except that the dependent variable is an indicator of whether the investor has actively traded during the time window (defined as an active change in the equity share of at least one percentage point), and the change in expected returns over the window is replaced with its absolute value. The ability of belief changes to predict trading is statistically and economically small, with both beginningof-window expected returns and changes over the window having no effect on the probability of trade. While the $R^{2}$ of the regression appears high at $38 \%$, column 3 of Table V, which does not include controls for beliefs, portfolio shares, and demographics, displays a similarly high $R^{2}$ of 
$36 \%$. The high $R^{2}$ in columns 2 and 3 are thus due to the window-length fixed effects: trading is mechanically more likely to occur over longer time windows. The incremental explanatory power of beliefs, portfolios, and demographics in predicting the extensive margin of trading is small.

The Intensive Margin of Trading. In our next analysis, we condition on time windows during which individuals trade actively, and ask whether the direction and the magnitude of the trade can be explained by beliefs. We start by predicting the direction of trading. Column 4 of Table $\mathrm{V}$ reports the results of a regression similar to equation 3, except that the dependent variable is now an indicator of whether the investor has actively increased her equity share by at least one percentage point during the window. Beliefs predict the direction of trading conditional on a trade actually occurring: an investor who expects future returns at the beginning of the wave to be one percentage point higher is around 1.5 percentage points more likely to buy equities in a given window. The fact that beginning-of-wave beliefs affect subsequent trading activity is consistent with our earlier findings of infrequent trading: if trading occurs infrequently, one's current portfolio does not always capture one's current beliefs. A one percentage point increase in expected returns over the wave is also associated with a 1 percentage point higher probability of actively increasing the equity share (conditional on trading).

Column 5 of Table $\mathrm{V}$ explores the magnitude of trading conditional on a trade occurring. The dependent variable is the change in the equity share due to active trading: that is, the regression is the same as for column 1, but the results are conditional on trading taking place (again, measured by the equity share changing by at least $1 \%$ in any direction due to active trading). Conditional on trading, the sensitivity of trading to beliefs increases by a factor of three compared to the unconditional results: a one-percentage-point increase in investors' expected 1-year stock returns corresponds to a 0.4 percentage point increase in the equity share due to trading. When we condition on larger trades (at least a $5 \%$ change in the equity share) the magnitudes increase considerably with estimates around $0.92 \%$ for the change in beliefs and $0.77 \%$ for the level of beliefs. ${ }^{25}$

Appendix Table A.13 presents the same analysis as Table V but restricts the sample to end in February 2019, just before the COVID-19 crisis. It shows broadly similar patterns with a stronger quantitative relationship on the intensive margin between beliefs and trading. During the COVID19 crisis, particularly during the stock market crash in March 2020, beliefs became substantially more pessimistic while portfolios change only by a small amount. Those who became more pessimistic do tend to trade out of equity conditional on trading, confirming the association of beliefs and trading even during a major turmoil.

Our analysis in this section confirms that trading patterns play a central role in reducing the passthrough of beliefs into asset demand. We summarize the key results in the following fact:

\footnotetext{
${ }^{25}$ We also investigate how the allocation of "new funds" across different asset classes depends on individuals' beliefs. We consider all cases in which, during a window, we see a net inflow of outside cash into the Vanguard account that is at least $20 \%$ of the existing Vanguard assets. Of course, we do not observe whether these are new funds, such as labor income, or proceeds from other asset sales outside of Vanguard. Since investors devote some time to deciding an allocation for funds when they first transfer them to their trading account, this represents a particularly informative window to observe how beliefs affect portfolio composition. We repeat the regression of Column 5 of Table V, but also condition on a large inflow occurring during the window. We find that when investors actually trade during that window (that is, they actively allocate the new money), the sensitivity of equity shares to beliefs increases significantly, to 0.92 for belief changes and to 0.68 for belief levels.
} 
Fact 2. While belief dynamics have little to no explanatory power for predicting when trading occurs (extensive margin of trading), they explain both the direction and magnitude of trading conditional on a trade occurring (intensive margin of trading).

As we discussed above, one promising path for future theoretical work hoping to generate the relatively low average sensitivity of portfolios to beliefs is to explicitly account for infrequent trading. The results in this section suggest that one parsimonious way to model such behavior is to introduce infrequent random trading, whereby an agent is selected at random based on a memory-less distribution to have the possibility of trading in a given period. This approach would be reminiscent of the Calvo (1983) adjustment model for firm pricing decisions, and would be consistent with both the fact that the only observable variable that predicts whether an individual trades is the window length, as well as with the low average passthrough of beliefs to portfolios established in Fact 1. Researchers who want to match the cross-sectional heterogeneity in trading frequency in addition to the low average trading frequency could explicitly model different arrival rates of trading opportunities for different individuals. ${ }^{26}$

\section{VARIANCE DECOMPOSITION OF BELIEFS}

Section I documented substantial heterogeneity in investors' beliefs. In this section, we further explore this heterogeneity by decomposing the panel variation of beliefs into three components: fixed individual characteristics, common variation in individual beliefs over time, and a residual component that captures both idiosyncratic individual time variation and measurement error.

To motivate this variance decomposition, Panel A of Figure III shows the time-series of average 1-year expected returns in the GMSU-Vanguard survey. The average expected return displays meaningful time-series variation, with a range of over 4 percentage points over our sample period. The largest month-to-month change was in March 2020, when average expected returns fell by over four percentage points after the stock market crash induced by the COVID-19 crisis. Panel B of Figure III shows the same time series of average expected returns as in Panel A, but also includes the 10th and 90th percentiles of the cross-sectional distribution of answers in each wave. The cross-sectional variation in expected returns dwarfs the time-series variation, not only in "normal times," but also during the COVID-19 crisis.

This pattern is not unique to our survey or our sample period. For example, the bottom row of Figure III shows similar plots for the RAND survey, which covers the period from November 2008 to January 2016 and thus includes part of the financial crisis and the following stock market recovery (see Appendix A.3 for more details on the RAND survey). Unfortunately, the RAND survey does not directly elicit beliefs about expected returns, so we focus on beliefs about the probability of a stock market increase over the coming year. We find that the RAND survey also features cross-sectional dispersion in beliefs that is much larger than the time-series variation.

There are two potential interpretations consistent with the substantial cross-sectional dispersion in beliefs. At one extreme, individual responses might display substantial idiosyncratic varia-

\footnotetext{
${ }^{26}$ The correlation between age, wealth, and trading frequency established in Appendix A.4, as well as the analysis presented in Appendix Table A.6, can provide further guidance to researchers hoping to incorporate heterogeneous infrequent trading into richer life-cycle models.
} 
Figure III: Time-Series and Cross-Sectional Variation: GMSU-Vanguard and RAND

(A) Time Series (GMSU-Vanguard)

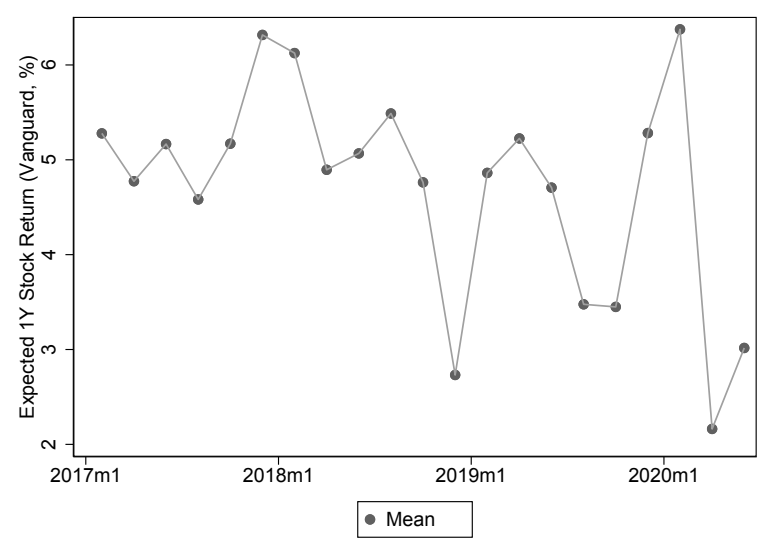

(C) Time Series (RAND)

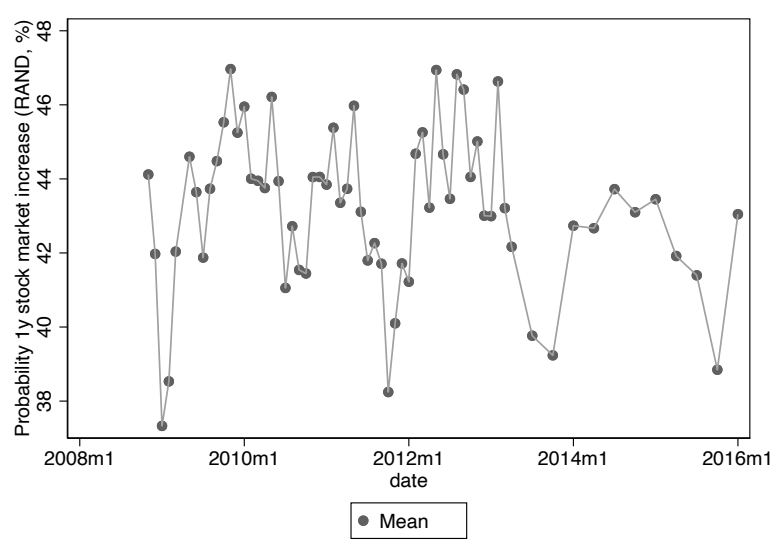

(B) Time Series and Cross Section (GMSU-Vanguard)

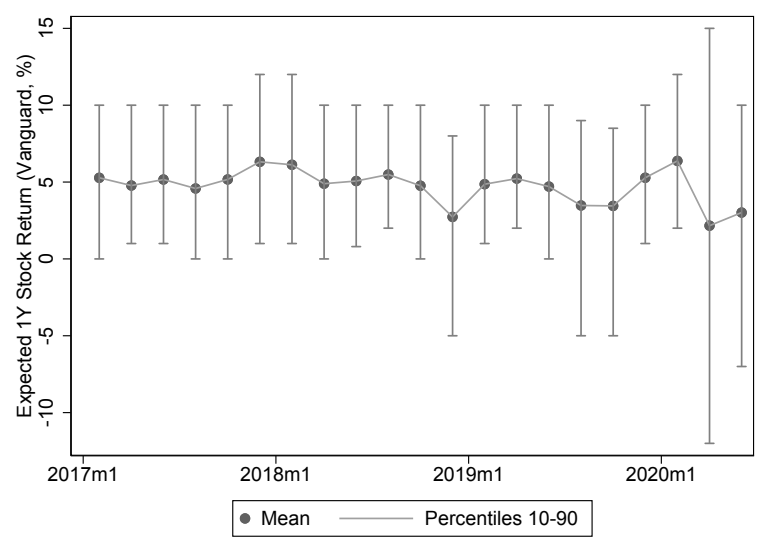

(D) Time Series and Cross Section (RAND)

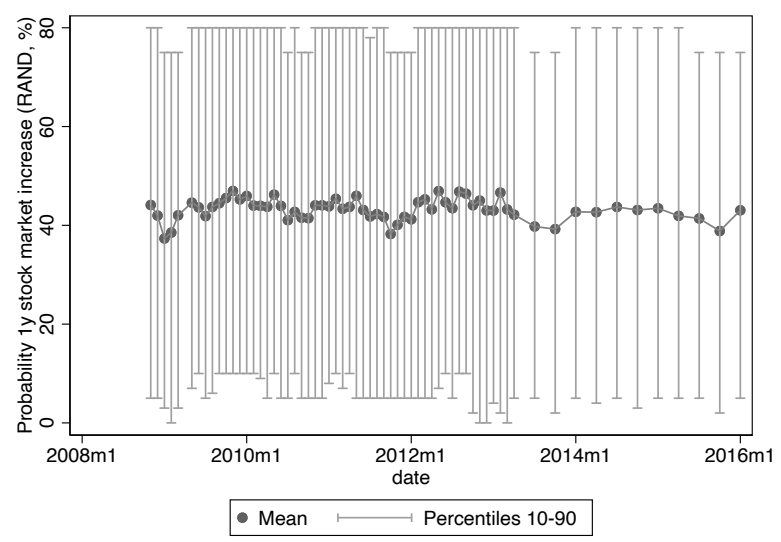

Note: Figure reports the time series of the average beliefs from the GMSU-Vanguard survey (top row, 1-year expected return question) and from the RAND survey (bottom row, probability of a 1-year stock market increase). The right panels in each row also plots the 10th and 90th percentiles of the survey answers in each wave.

tion over time, with the same individual reporting very different beliefs at different points in time. At the other extreme, the observed cross-sectional variation could be due to persistent heterogeneity in beliefs; that is, the same investors are always optimistic or always pessimistic. Since these interpretations have substantially different implications for theoretical models of asset pricing, we next exploit the panel dimension of our survey to determine their quantitative relevance.

The Dominance of Individual Fixed Effects. We denote the belief expressed by individual $i$ at time $t$ as $B_{i, t}$. For the (unbalanced) panel of these beliefs, we then run the following regressions:

$$
\begin{aligned}
B_{i, t} & =\chi_{t}+\epsilon_{1, i, t}, \\
B_{i, t} & =\phi_{i}+\epsilon_{2, i, t} \\
B_{i, t} & =\phi_{3, i}+\chi_{3, t}+\epsilon_{3, i, t} .
\end{aligned}
$$


Equation 4 estimates a set of time (i.e., survey wave) fixed effects, $\chi_{t}$, that absorb the common time-series variation of respondents' beliefs. Equation 5 estimates a set of individual fixed effects, $\phi_{i}$, that absorb the average belief over time of each respondent. Equation 6 jointly estimates both individual and time fixed effects. In our baseline analysis, we estimate these regressions including all responses from individuals who have responded to at least five waves.

Table VI: Decomposing the Variation in Beliefs: Individual and Time Fixed Effects

\begin{tabular}{lcccc}
\hline & \multicolumn{3}{c}{$\mathrm{R}^{2}$ (\%) of Panel Regression } & \\
\cline { 2 - 4 } & & Time FE & Individual FE & Time+ Individual FE \\
\cline { 2 - 4 } Expected 1Y Stock Return (\%) & 5.0 & 47.5 & 51.5 & 1,960 \\
Expected 10Y Stock Return (\% p.a.) & 0.5 & 45.0 & 45.5 & 1,964 \\
Probability 1Y Stock Return <-10\% & 2.7 & 51.5 & 53.6 & 2,011 \\
St.d. Expected 1Y Stock Return (\%) & 0.5 & 56.7 & 57.2 & 2,011 \\
Confidence (Stock Qs) & 1.4 & 60.6 & 62.0 & 1,988 \\
Expected 3Y GDP Growth (\% p.a.) & 3.8 & 43.9 & 46.8 & 1,968 \\
Expected 10Y GDP Growth (\% p.a.) & 0.6 & 39.7 & 40.2 & 1,952 \\
Probability p.a. 3Y GDP Growth < 0\% & 5.1 & 45.4 & 49.3 & 2,010 \\
St.d. Expected p.a. 3Y GDP Growth (\%) & 1.0 & 56.5 & 57.3 & 2,010 \\
Confidence (GDP Qs) & 0.8 & 38.8 & 63.8 & 1,978 \\
Expected 1Y Return of 10Y bond (\%) & 2.4 & 62.9 & 40.7 & 1,953 \\
Confidence (Bond Qs) & 0.4 & 63.3 & 1,969 \\
\hline
\end{tabular}

Note: Table reports the $R^{2}$ s corresponding to the three regressions 4,5 , and 6 , and the number of individual respondents $\mathrm{N}$. We only include respondents that have responded to at least five waves. Each row corresponds to a different survey question that is used as the dependent variable.

Table VI reports the $R^{2}$ of the three regressions for a subset of survey questions. Most of the panel variation in beliefs is absorbed by individual fixed effects. Consider, for example, the first row, which decomposes the panel variation in 1-year expected stock returns. Time fixed effects capture $5 \%$ of the total panel variation, whereas individual fixed effects capture $47.5 \%$ of the total variation. The remaining variation is a combination of idiosyncratic belief changes within individuals over time, as well as measurement error in beliefs. ${ }^{27}$ This large difference in explanatory power of time fixed effects and individual fixed effects is common across all beliefs. The same patterns hold when we decompose the heterogeneity in individuals' confidence in their beliefs: most of the variation is across individuals rather than over time. ${ }^{28}$

There are two possible concerns with this analysis. First, the relatively short time period over which we observe survey responses might make the fixed effects appear more important than they truly are. Second, the large COVID-19 shock might overstate the importance of time-series variation, since shocks of that magnitude are historically rare.

On the concern that our analysis may be overfitting the fixed effects in sample, especially for investors that reply only a few times, we find that when we increase the minimum number of

\footnotetext{
${ }^{27}$ These findings echo results in Dominitz and Manski (2011), who show that individuals' responses for the probability of a positive equity return over the coming twelve months were correlated across two waves of the Michigan Survey of Consumers. The authors also found substantial heterogeneity in this probability across individuals.

${ }^{28}$ In Appendix A.10, we apply the same variance decomposition to portfolios and find that individual fixed effects explain $87 \%$ of the panel variation in equity shares during our sample period. When we relate the individual fixed effects extracted from beliefs to those extracted from portfolios, we recover a sensitivity very similar to our benchmark estimates in Section II.
} 
waves that an individual has to answer to be included in the analysis, results are very similar. In particular, Table VII shows how the $R^{2}$ of the individual fixed effects changes as we increase the minimum number of responses per individual. ${ }^{29}$ We find at most a modest deterioration in the importance of individual fixed effects as we increase the minimum number of answers. This finding suggests that our results are not driven by overfitting the fixed effects for people who have responded only a few times. ${ }^{30}$

Table VII: Decomposing the Variation in Beliefs: Robustness

\begin{tabular}{|c|c|c|c|c|c|c|c|c|}
\hline & \multicolumn{4}{|c|}{$R^{2}$ (total, \%) } & \multicolumn{4}{|c|}{ Number of Individuals } \\
\hline & \#Resp $\geq 5$ & \#Resp $\geq 6$ & \#Resp $\geq 7$ & \#Resp $\geq 8$ & \#Resp $\geq 5$ & \#Resp $\geq 6$ & \#Resp $\geq 7$ & \#Resp $\geq 8$ \\
\hline Expected 1Y Stock Return (\%) & 47.5 & 46.5 & 46.6 & 45.9 & 1,960 & 1,361 & 974 & 712 \\
\hline Expected 10Y Stock Return (\% p.a.) & 45.0 & 43.7 & 45.8 & 44.9 & 1,964 & 1,360 & 959 & 704 \\
\hline Probability 1Y Stock Return < -10\% & 51.5 & 51.3 & 52.1 & 52.3 & 2,011 & 1,389 & 1,003 & 729 \\
\hline St.d. Expected $1 Y$ Stock Return (\%) & 56.7 & 57.6 & 57.7 & 57.8 & 2,011 & 1,389 & 1,003 & 729 \\
\hline Confidence (Stock Qs) & 60.6 & 60.4 & 60.9 & 60.5 & 1,988 & 1,374 & 975 & 718 \\
\hline Expected 3Y GDP Growth (\% p.a.) & 43.9 & 43.2 & 42.8 & 39.6 & 1,968 & 1,371 & 978 & 715 \\
\hline Expected 10Y GDP Growth (\% p.a.) & 39.7 & 39.6 & 38.5 & 36.7 & 1,952 & 1,342 & 963 & 708 \\
\hline Probability p.a. 3 Y GDP Growth $<0 \%$ & 45.4 & 44.1 & 43.9 & 44.4 & 2,010 & 1,392 & 1,000 & 730 \\
\hline St.d. Expected p.a. 3Y GDP Growth (\%) & 56.5 & 57.5 & 57.5 & 58.3 & 2,010 & 1,392 & 1,000 & 730 \\
\hline Confidence (GDP Qs) & 62.8 & 62.7 & 62.2 & 62.1 & 1,978 & 1,364 & 978 & 721 \\
\hline Expected 1 Y Return of $10 \mathrm{Y}$ bond (\%) & 38.8 & 37.3 & 35.6 & 34.7 & 1,953 & 1,342 & 968 & 705 \\
\hline Confidence (Bond Qs) & 62.9 & 62.9 & 62.6 & 63.1 & 1,969 & 1,363 & 981 & 703 \\
\hline
\end{tabular}

Note: The left panel reports the $R^{2}$ s corresponding to regression 5 . The right panel reports the number of individuals that responded the required number of times. Across columns, we increase the minimum number of responses for an individual to be included in the sample from five to eight. Each row corresponds to a different survey question that is used as the dependent variable.

We also perform the variance decomposition presented above on the RAND survey, which also has a panel structure. As discussed above, the RAND survey ran for more than seven years and covered much of the Great Recession and subsequent recovery; overall, there are 61 survey waves. A total of 4,734 individuals participated in the survey, 3,166 of whom responded at least 10 times, 1,780 at least 30 times, and 1,032 at least 50 times. When we perform the same variance decomposition for the RAND survey, we find quantitatively similar results (see Appendix A.9 for details). Indeed, across all questions in the RAND survey that relate to expected stock returns, time fixed effects explain around $1 \%$ of the panel variation, while individual fixed effects explain $50-60 \%$ of the variation. Importantly, the results are robust to increasing the minimum number of waves that an individual has to respond to in order to be included from three all the way to fifty.

\footnotetext{
${ }^{29}$ The table also reports the number of individuals who respond a certain number of times. The number of observations is of course greater since each individual has answered multiple times.

${ }^{30}$ Another possibility is that the fixed effects capture what in reality is a stationary but extremely persistent process of beliefs, even though there is no difference in the permanent component of beliefs. Since the economic interpretation of permanent versus extremely persistent differences in beliefs is not one that is crucial to most theories, we do not aim to definitively distinguish between these interpretations. Instead, we view our results as emphasizing that there is large and persistent cross-sectional dispersion of beliefs and the fixed-effects analysis is simply a transparent way to document this pattern. Nevertheless, one can try to statistically disentangle the two interpretations by estimating a panel model for beliefs that features both fixed effects and an AR(1) component and use a statistical test to distinguish between the two explanations. When we estimate this model using the Arellano and Bond (1991) estimator for dynamic panel data, we find that the autoregressive component is small in absolute value and statistically insignificant (for example, it is -0.03 for 1 -year expected returns), providing suggestive evidence against the AR(1) interpretation of our results.
} 
These results highlight that our findings are robust to different economic environments as well as to observing substantially more responses per individual. ${ }^{31}$

To explore the concern that our results might overstate the importance of time-series variation once the COVID-19 shock is included, Appendix Table A.14 reports an analysis similar to Table VI, but restricting the sample to end in February 2020, before the COVID-19 crisis. Naturally, the importance of the time-series variation decreases, and the results are, if anything, strengthened: individual fixed effects are even more important to explain the panel variation in beliefs. While a reader might want to informally think of the period before and the period including the COVID19 shock as upper and lower bounds for the relative importance of individual fixed effects and time series variation, the economic conclusions are very similar.

The importance of persistent cross-sectional dispersion in beliefs provides useful insights for the design of macro-finance models. In particular, much of the existing literature that builds on survey evidence of beliefs has focused on representative agent models disciplined by matching the time-series behavior of average beliefs (e.g., Barberis et al., 2015). This literature misses a crucial feature of the data: individual heterogeneity. Our results offer a new set of moments that can be used to enrich the models in this under-explored dimension. In this direction, models that explicitly feature heterogeneous agents with different beliefs, such as the model of Geanakoplos (2010), are likely to offer a fruitful starting point for further exploration.

Beliefs and Demographics. Having established the importance of individual fixed effects in explaining the panel variation in beliefs, it is natural to ask whether observable characteristics can explain why some individuals are permanently optimistic and others are permanently pessimistic. We find that observable individual characteristics have little explanatory power for beliefs, even though some of these characteristics are related to beliefs in statistically significant ways. To establish this finding, we run the following regression:

$$
\phi_{3, i}=\alpha+\Gamma X_{i}+\epsilon_{i}
$$

where $\phi_{3, i}$ are the individual fixed effects estimated in regression 6 , and $X_{i}$ are the following individual characteristics: dummy variables for age groups, wealth quintiles, region of residence, gender, confidence, and quintiles for the number of days with Vanguard log-ins in an average month. ${ }^{32}$ In addition, motivated by recent evidence that investors' past experiences influence their beliefs (e.g., Malmendier and Nagel, 2011), we also include the average return on the equity and fixed income components of the investors' portfolios since 2011 as controls in $X_{i}$. Table VIII shows the $R^{2}$ s from these regressions, which capture the share of variation in the fixed effects that is explained by the demographics.

\footnotetext{
${ }^{31}$ While the pattern of persistent and large belief differences across retail investors appears consistent across surveys covering different time horizons and investor populations, it would be interesting to study the same relationship among institutional investors or professional forecasters. However, such analyses need to carefully account for the various incentives of the respondents, which is less of a concern in non-public surveys of retail investor beliefs. For example, Ottaviani and Sørensen (2006) discuss various aspects of professional forecasters' strategic behavior, highlighting the presence of incentives to herd (see also Graham, 1999; Rangvid, Schmeling and Schrimpf, 2013).

${ }^{32}$ For dynamic variables such as age and wealth, we take the average over the sample. For geographic location and gender, we take the value of the most recent observation.
} 
Table VIII: Beliefs Heterogeneity and Demographics

\begin{tabular}{lccccc}
\hline $\mathbf{R}^{\mathbf{2}}$ & \#Resp $\geq 1$ & \#Resp $\geq 2$ & \#Resp $\geq 3$ & \#Resp $\geq 4$ & \#Resp $\geq 5$ \\
\hline Expected 1Y Stock Return (\%) & 2.5 & 4.3 & 5.3 & 6.1 & 6.8 \\
Expected 10Y Stock Return (\% p.a.) & 1.9 & 3.5 & 4.4 & 4.8 & 5.6 \\
Probability 1Y Stock Return <-10\% & 3.0 & 4.4 & 6.3 & 6.5 & 6.9 \\
St.d. Expected 1Y Stock Return (\%) & 7.1 & 8.3 & 10.8 & 10.2 & 9.4 \\
Expected 3Y GDP Growth (\% p.a.) & 2.3 & 3.0 & 3.5 & 4.5 & 5.3 \\
Expected 10Y GDP Growth (\% p.a.) & 3.0 & 3.7 & 3.8 & 4.0 & 4.4 \\
Probability p.a. 3Y GDP Growth < 0\% & 5.0 & 6.4 & 8.5 & 8.5 & 7.9 \\
St.d. Expected p.a. 3Y GDP Growth (\%) & 4.8 & 4.8 & 5.3 & 5.1 & 4.3 \\
Expected 1Y Return of 10Y bond (\%) & 2.2 & 3.0 & 3.0 & 3.7 & 4.1 \\
\hline
\end{tabular}

Note: The table reports the $R^{2}$ statistics corresponding to regression 7 . In each column, going from left to right, we increase from 1 to 5 the minimum number of responses for an individual to be included in the sample. Each row corresponds to a different question in the survey.

The observed characteristics have only small explanatory power, with values for the $R^{2}$ between $2 \%$ and $7 \%$ depending on the question (using our complete sample in the analysis). When we restrict the analysis to explaining fixed effects that are estimated on more observations, and which should therefore be more precise, there is only a modest increase in the $R^{2}$. We thus conclude that classical measurement error in beliefs cannot explain the low predictive power of demographics for beliefs.

Appendix A.8 reports the coefficients on the various demographic characteristics from regression 7. Despite the low overall explanatory power of demographics for beliefs, some of these characteristics have statistically significant relationships with beliefs. For example, we find that older individuals are more optimistic, while wealthier respondents are more pessimistic. In addition, we find that individuals who experienced higher past equity returns are more optimistic about future stock returns, while individuals who experienced higher past fixed income returns are more optimistic about future bond returns.

These results relate to the literature that explores the relationship between expectations and demographic characteristics and personal experiences. It is common in this literature to find strong statistical relationships but low explanatory power for expectations using variables such as wealth, gender, IQ, place of birth, current location, own past experience, or friends' past experiences (see, for example, Malmendier and Nagel, 2011; Kuchler and Zafar, 2015; Armona, Fuster and Zafar, 2016; Das, Kuhnen and Nagel, 2017; Bailey et al., 2017, 2018; Ben-David et al., 2018; Coibion, Gorodnichenko and Kamdar, 2018; D'Acunto et al., 2019). The low predictive power suggests that these individual fixed effects reflect complex combinations of individual characteristics and experiences, some of which economic research has yet to discover. We collect the findings from this section in the following fact.

Fact 3. Variation in individual beliefs is mostly characterized by heterogeneous individual fixed effects: between $40 \%$ and $60 \%$ of the panel variation in responses is due to individual fixed effects, and $5 \%$ is due to common time series variation. The remaining variation is accounted for by idiosyncratic individual variation over time and measurement error. Only a small part of the persistent heterogeneity in individual beliefs is explained by observable demographic characteristics. 


\section{COVARIATION IN EXPECTED RETURNS AND EXPECTED CASH FlOWS}

Asset prices are determined by expectations of future returns and cash flows. It is therefore natural to investigate how expectations of returns and economic growth are related both across individuals and within each individual over time.

Figure IV presents conditional binscatter plots of the relationship between short-run and longrun expectations of stock returns and GDP growth. Panel A shows that expectations about shortrun and long-run stock returns are positively correlated, with an unconditional correlation coefficient of 0.30. Interestingly, even those respondents who expect negative returns over the next year expect long-run returns to be positive. Similarly, short-run and long-run GDP growth are positively correlated, with an unconditional correlation coefficient of 0.65 (see Panel B of Figure IV). The bottom row of Figure IV shows that expectations of stock returns and economic growth are positively correlated, both at the short horizon (Panel C, unconditional correlation coefficient of 0.26 ) and at the long horizon (Panel D, unconditional correlation coefficient of 0.27 ).

Figure IV: Relationships Among Different Beliefs Within the Same Survey

(A) Stock Returns: 1Y vs. 10Y

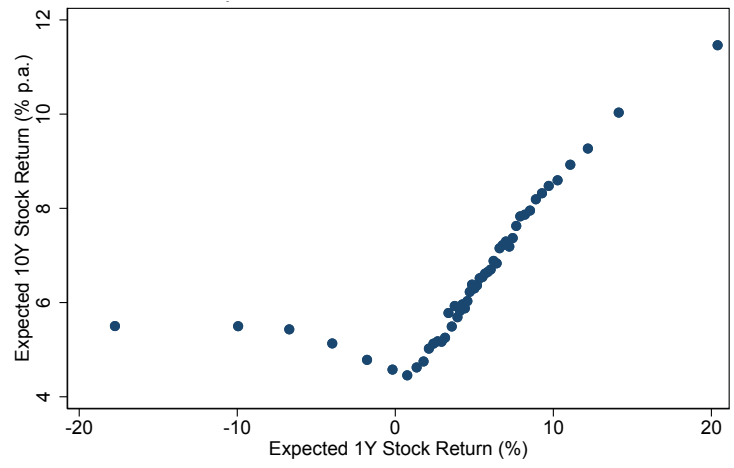

(C) Stock Return vs. GDP Growth (Short Run)

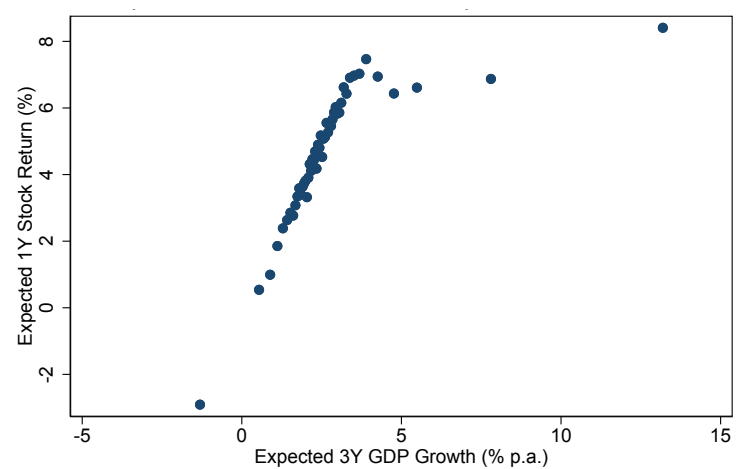

(B) GDP Growth: 3Y vs. 10Y

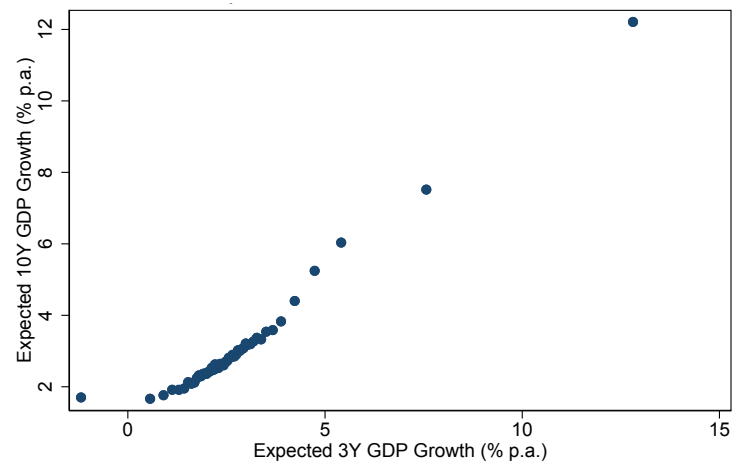

(D) Stock Return vs. GDP Growth (Long Run)

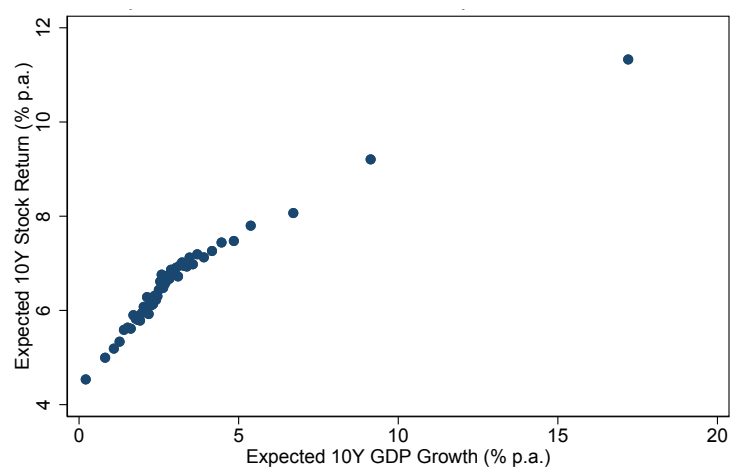

Note: Figure shows conditional binscatter plots across different answers from within the same survey response, conditional on the respondents' age, gender, region, wealth, and the survey wave.

Table IX presents these results in regression form, both with and without including individual fixed effects. While these regressions are restricted to linear specifications, and therefore miss some of the interesting nonlinearities in Figure IV, the findings confirm the strong link between expectations about different objects, both across horizons as well as across domains. Importantly, 
we see these patterns in both the cross-section and the time series (when we control for individual fixed effects). In the cross-section, individuals who are more optimistic about stock returns tend to also be more optimistic about GDP growth. In the time series, we find that when an investor becomes more optimistic about stock returns, she also becomes more optimistic about GDP growth. ${ }^{33}$ Appendix A.12 shows that these patterns also hold when excluding the period of the stock market crash in March 2020. We summarize these results in the following fact:

\section{Table IX: Correlation Across Survey Responses}

\begin{tabular}{|c|c|c|c|c|}
\hline \multirow[t]{2}{*}{ PANEL A } & \multicolumn{2}{|c|}{ Expected 10Y Stock Returns (\%, p.a.) } & \multicolumn{2}{|c|}{ Expected 10Y GDP Growth (\%, p.a.) } \\
\hline & (1) & $(2)$ & (3) & (4) \\
\hline Expected 1Y Stock Return (\%) & $\begin{array}{c}0.198 * * * \\
(0.006)\end{array}$ & $\begin{array}{c}0.100 * * * \\
(0.009)\end{array}$ & & \\
\hline Expected 3Y GDP Growth (\%, p.a.) & & & $\begin{array}{c}0.824 * * * \\
(0.016)\end{array}$ & $\begin{array}{c}0.640 * * * \\
(0.039)\end{array}$ \\
\hline Controls & Y & $\mathrm{Y}$ & $\mathrm{Y}$ & Y \\
\hline Individual Fixed Effects & $\mathrm{N}$ & Y & $\mathrm{N}$ & Y \\
\hline R-Squared & 0.111 & 0.711 & 0.442 & 0.810 \\
\hline$\underline{\mathrm{N}}$ & 42,978 & 42,978 & 42,751 & 42,751 \\
\hline \multirow[t]{2}{*}{ PANEL B } & \multicolumn{2}{|c|}{ Expected 10Y Stock Returns (\%, p.a.) } & \multicolumn{2}{|c|}{ Expected 10Y GDP Growth (\%, p.a.) } \\
\hline & (1) & $(2)$ & (3) & (4) \\
\hline Expected 3Y GDP Growth (\%, p.a.) & $\begin{array}{c}0.710^{* * *} \\
(0.023)\end{array}$ & $\begin{array}{c}0.381 * * * \\
(0.044)\end{array}$ & & \\
\hline Expected 10Y GDP Growth (\%, p.a.) & & & $\begin{array}{c}0.388 * * * \\
(0.015)\end{array}$ & $\begin{array}{c}0.260 * * * \\
(0.035)\end{array}$ \\
\hline Controls & Y & Y & $\mathrm{Y}$ & Y \\
\hline Individual Fixed Effects & $\mathrm{N}$ & $\mathrm{Y}$ & $\mathrm{N}$ & Y \\
\hline R-Squared & 0.105 & 0.712 & 0.089 & 0.717 \\
\hline $\mathrm{N}$ & 42,926 & 42,926 & 42,543 & 42,543 \\
\hline
\end{tabular}

Note: Table shows results from regressing answers to different expectation questions onto each other; Panel A relates short-run and long-run beliefs within the same domain, while Panel B relates beliefs across domains over similar time horizons. The unit of observation is a survey response. All specifications control for the respondents' age, gender, region of residence, wealth, and the survey wave. Columns 2 and 4 also control for respondent fixed effects. Standard errors are clustered at the respondent level. Significance levels: ${ }^{*}(\mathrm{p}<0.10),{ }^{* *}(\mathrm{p}<0.05),{ }^{* * *}(\mathrm{p}<0.01)$.

Fact 4. Higher expectations of stock returns are associated with higher expectations of GDP growth, and higher short-run expectations are associated with higher long-run expectations (for both stock returns and GDP growth), both across and within individuals.

The correlation between expected returns and cash flow growth is an informative moment for macro-finance models. To see why, it is useful to refer to the Campbell and Shiller (1988) decomposition, which shows how prices, expected cash flows, and expected returns are linked:

\footnotetext{
${ }^{33}$ While Table IX shows the results in a linear setting, a similar conclusion can be reached in a nonlinear setting as well, by building binscatter plots that relate the fixed effects of beliefs across domains (thus isolating the crosssectional component) and by plotting the residual components after taking out fixed effects (thus focusing on the within-individual time variation). We report these plots in Appendix A.11. The conclusions are identical to those in this section: the panel-correlation of beliefs across different domains and across different horizons reflects similar correlations in the persistent and transient components of beliefs.
} 


$$
p d_{t} \approx E_{i, t} \sum_{j=0}^{\infty} \rho^{j} \Delta d_{t+1+j}-E_{i, t} \sum_{j=0}^{\infty} \rho^{j} r_{t+1+j} .
$$

In this equation, $p d_{t}$ is the logarithm of the price-dividend ratio of an asset, $\Delta d_{t+1}$ is the growth of cash flows between $t$ and $t+1$, and $r_{t+1}$ is the return of the asset between between $t$ and $t+1$. For expositional convenience, we assume that this equation holds approximately under each investor $i$ 's expectations $E_{i, t}$. If we take our GDP growth responses to proxy for cash flow growth, then we can use this equation to interpret our empirical results.

One immediate implication of Fact 4 is in the time-series dimension (see De la $\mathrm{O}$ and Myers, 2017). As the Campbell-Shiller decomposition shows, cash flow expectations and expected returns have opposite effects on current valuations. All else equal, when investors become more optimistic about cash flows, asset prices rise; but if expected returns simultaneously increase, as they do in the data, prices will be lower through a discount-rate effect. Therefore, accounting for the joint variation of expected returns and expected cash flow growth is important to understand the movement of asset prices. For example, models that match survey variation in expected cash-flow growth, but ignore the correlated variation in expected returns, are likely to overstate the power of the variation in cash flow expectations for explaining time-series variation in asset prices (e.g., Bordalo et al., 2020).

The implications of our results for the cross-section (disagreement among investors at each point in time) are more subtle. While investors might disagree about future cash flows or about future expected returns, they all face the same current price $p d_{t}$. Assuming that the CampbellShiller identity holds for each individual, whether they are an optimist or a pessimist, this implies that expectations of cash flows and expectations of returns need to be positively correlated in the cross-section. ${ }^{34}$ For example, consider two investors, one optimistic and one pessimistic about future cash flow growth. Given that they both face the same price, the optimistic investor has to expect higher returns than the pessimistic one. ${ }^{35}$ However, the Campbell-Shiller decomposition is silent about the exact horizon at which this correlation will occur. For example, it does not tell us whether disagreement about short-term cash flows is matched by disagreement about shortterm expected returns or by disagreement about long-term expected returns. This is where our empirical results add value to this decomposition: the results provide evidence on the correlations of cash flow and returns at specific horizons, thereby guiding the calibration of the term structure of disagreement in asset pricing models.

\section{RARE DISASTERS AND EXPECTED RETURNS}

In the previous sections, we explored a number of moments of the belief distribution that have been of central interest to the asset pricing literature, such as average expected returns and average expected GDP growth rates. In addition, an important strand of the macro-finance literature

\footnotetext{
${ }^{34}$ The equation is an identity and thus only imposes mild restrictions on expectations. Nonetheless, agents' expectations might violate the identity, e.g., because they have imperfect knowledge of the current price-dividend ratio.

${ }^{35}$ The Campbell-Shiller decomposition as written assumes that investors believe that all mispricing will be corrected eventually; if that was not the case, the equation would feature an extra term, containing the limit of $p d_{t+n}$ for $n \rightarrow \infty$.
} 
has emphasized that expectations of rare but potentially catastrophic events, sometimes called rare disasters, can help explain expected returns, portfolio holdings, and asset prices (Rietz, 1988; Barro, 2006; Gabaix, 2012). ${ }^{36}$ To further understand these relationships, we exploit that our survey directly elicits expectations of disaster probabilities for both stock returns (i.e., 1-year stock returns of less then $-30 \%$ ) and GDP growth (i.e., annualized 3-year GDP growth of less than $-3 \%$ ). ${ }^{37}$

We first explore the relationship between individuals' expectations of the probabilities of stock market disasters and GDP disasters. The left panel of Figure V shows that expectations of the two types of disasters are positively related at the individual level (the slope of the regression line is 0.39); in unreported results, we find that this is also true within individuals over time. These findings suggest that expectations of rare stock market disasters come with expectations of lower cash flows and are not just purely the result of expecting higher future returns (i.e., beliefs about stock market disasters are not purely due to beliefs about discount rate variation).

\section{Figure V: Stock Disasters, GDP Disasters, and Expected Returns}
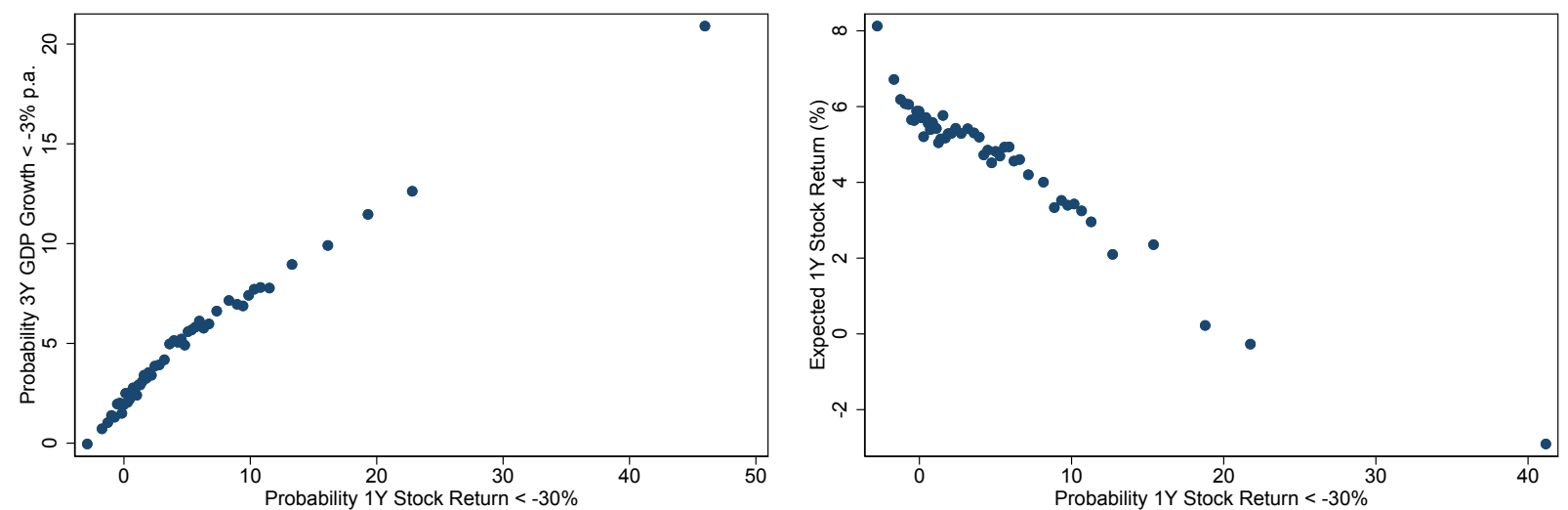

Note: The left panel shows a conditional binned scatter plot of survey respondents' subjective probabilities that the 1-year stock returns are below $-30 \%$ and their expectations that annualized average GDP growth over the next three years is below $-3 \%$. The right panel shows a conditional binned scatter plot of survey respondents' subjective probabilities that the 1-year stock returns are below $-30 \%$ and their expected 1-year stock returns. Both panels condition on the respondents' age, gender, region, wealth, and the survey wave.

We also analyze the relationship between expected returns and expected disaster probabilities. The right panel of Figure V shows that individuals who report a higher subjective probability of a stock-market disaster also report lower expected stock returns. To explore this relationship more formally, we run the following regression:

$$
E_{i, t}\left[R_{1 y}\right]=\alpha+\beta \operatorname{Prob}_{i, t}\left[R_{1 y}<-30 \%\right]+\gamma X_{i, t}+\psi_{t}+\epsilon_{i, t}
$$

where the coefficient of interest is $\beta$. We additionally control for demographic characteristics such as age, gender, wealth, and region of residence, as well as survey-wave fixed effects.

The specification in column 1 of Table $X$ corresponds to the right panel of Figure V. The estimate of $\beta$ implies that a 5 percentage point increase in an individual's subjective probability of a

\footnotetext{
${ }^{36}$ Recently, Goetzmann, Kim and Shiller (2018) have studied the determinants of beliefs about rare disasters.

${ }^{37}$ Appendix A.6 highlights the importance of subjective disaster probabilities for portfolio formation: holding fixed the mean, respondents with a higher perceived probability of stock market disasters also had lower equity shares.
} 
Table X: Expected Stock Returns and Rare Disasters Beliefs

\begin{tabular}{|c|c|c|c|c|c|c|}
\hline & \multicolumn{6}{|c|}{ Expected 1Y Stock Return (\%) } \\
\hline & (1) & $(2)$ & (3) & (4) & (5) & (6) \\
\hline Probability 1Y Stock Return < -30\% & $\begin{array}{c}-0.212^{* * *} \\
(0.008)\end{array}$ & & $\begin{array}{l}-0.270 * * * \\
(0.013)\end{array}$ & & $\begin{array}{c}-0.146^{* * *} \\
(0.013)\end{array}$ & $\begin{array}{c}-0.153^{* * *} \\
(0.017)\end{array}$ \\
\hline Probability $1 Y$ Stock Return $<-10 \%$ & & $\begin{array}{c}-0.152^{* * *} \\
(0.003)\end{array}$ & & & & \\
\hline $\begin{array}{l}\text { Probability } 1 Y \text { Stock Return }<-30 \% \\
\text { x Low Bucket First }\end{array}$ & & & & $\begin{array}{c}-0.208^{* * *} \\
(0.010)\end{array}$ & & \\
\hline $\begin{array}{l}\text { Probability } 1 Y \text { Stock Return }<-30 \% \\
\text { x High Bucket First }\end{array}$ & & & & $\begin{array}{c}-0.217^{* * *} \\
(0.012)\end{array}$ & & \\
\hline Controls & Y & Y & Y & $\mathrm{Y}$ & Y & Y \\
\hline Individual Fixed Effects & & & & & Y & $\mathrm{Y}$ \\
\hline Specification & & & $\begin{array}{c}\text { Prob } \in \\
{[0.1 \%, 10 \%]}\end{array}$ & & & $\begin{array}{c}\text { Prob } \in \\
{[0.1 \%, 10 \%]}\end{array}$ \\
\hline R-Squared & 0.117 & 0.244 & 0.055 & 0.438 & 0.722 & 0.764 \\
\hline $\mathrm{N}$ & 43,492 & 43,492 & 23,466 & 43,492 & 43,492 & 22,670 \\
\hline
\end{tabular}

Note: Table shows results from regression 8 . The unit of observation is a survey response; the dependent variable is the expected one year stock return. Columns 1 to 4 control for the respondents' age, gender, region of residence, wealth, and the survey wave. Columns 5 and 6 include individual fixed effects, survey wave fixed effects, and a dummy for the randomization order of the buckets in the distribution question. Columns 3 and 6 restrict the sample to individuals who report expected probabilities of a stock market disaster between $0.1 \%$ and $10 \%$. Standard errors are clustered at the respondent level. Significance levels: * $(\mathrm{p}<0.10),{ }^{* *}(\mathrm{p}<0.05),{ }^{* * *}(\mathrm{p}<0.01)$.

stock market disaster is associated with a one-percentage-point decline in her subjective expected returns. Column 2 shows that a similar negative relationship occurs when we consider the probability of less extreme outcomes, i.e., returns below $-10 \%$. Column 3 restricts the data to those answers that report the probability of a stock market return of less than $-30 \%$ to be between $0.1 \%$ and $10 \%$. We find that excluding extreme responses increases the magnitude of the sensitivity from -0.21 to -0.27 . Column 4 shows that the results are not meaningfully affected by the order in which the buckets are presented to the respondent in the distribution question (high-to-low vs. low-to-high). Column 5 includes individual fixed effects, and column 6 does the same but restricts the probabilities to be in the same range as in column 3. These latter columns show that the negative relationship between expected returns and subjective disaster probabilities also holds in the time series for each individual. Appendix A.12 shows that these patterns also hold when excluding the period of the stock market crash in March 2020. We collect the findings in this section in the following fact.

Fact 5. Higher subjective probabilities of stock market disasters are associated with lower expected stock market returns, both across and within individuals.

Our cross-sectional results in Columns 1-4 of Table X map most closely to models in which agents disagree about the probability of disasters and are overconfident in their beliefs (i.e., they "agree to disagree"). For example, in the model of Chen, Joslin and Tran (2012), agents differ in their subjective beliefs about the probability of cash flow disasters. Since all agents observe the current 
stock price, those agents who think that disasters are more likely also tend to expect lower returns. Our findings support the Chen, Joslin and Tran (2012) model prediction that the optimists expect both high returns and a lower probability of disaster relative to the pessimists.

Our results on the within-individual time-series relationship between disaster beliefs and expected returns in columns 5 and 6 of Table $X$ relate to the literature on time-varying rare-disasters with representative agents (e.g., Gabaix, 2012; Wachter, 2013). In these models, a representative agent with rational expectations prices assets in an economy affected by time-varying rare disasters. In equilibrium, expected returns and the disaster probability are positively related in the time series. The intuition is that a higher disaster probability induces individuals to demand higher compensation for holding the stock market, which increases equilibrium expected returns. The relationship in the data at the individual level appears with an opposite sign relative to the theory. Mapping our individual-level partial-equilibrium results into a general equilibrium representative-agent model is beyond the scope of this paper, but offers an interesting avenue to further develop the rare disaster paradigm (see Jin, 2015, for a behavioral model in this direction).

\section{CONCLUSION}

In this paper we analyzed a new survey of investor beliefs. We combined the survey responses with administrative data on respondents' portfolio holdings and trading activity to establish five facts about the relationship between investor beliefs and portfolios. These facts provide guidance on the construction of macro-finance models. In particular, we highlight three ingredients for new models that the future literature could develop: (i) large and highly persistent heterogeneity in beliefs about both expected returns and cash flows, with the two beliefs positively related, (ii) a willingness to "agree to disagree" that allows for trading based on disagreement, and (iii) infrequent trading with an exogenous probability of trading that differs across agents. An interesting open question is how well such a model would perform in quantitatively matching asset prices in addition to the main features of beliefs and portfolios documented in this paper.

\section{REFERENCES}

Abel, Andrew B, Janice C Eberly, and Stavros Panageas. 2007. "Optimal inattention to the stock market." American Economic Review, 97(2): 244-249.

Adam, Klaus, Albert Marcet, and Johannes Beutel. 2017. "Stock price booms and expected capital gains." American Economic Review, 107(8): 2352-2408.

Adam, Klaus, Dmitry Matveev, and Stefan Nagel. 2018. “Do survey expectations of stock returns reflect risk-adjustments?" National Bureau of Economic Research.

Adam, Klaus, Johannes Beutel, Albert Marcet, and Sebastian Merkel. 2015. "Can a financial transaction tax prevent stock price booms?" Journal of monetary economics, 76: S90-S109.

Adelino, Manuel, Antoinette Schoar, and Felipe Severino. 2018. "Perception of house price risk and homeownership." National Bureau of Economic Research.

Agnew, Julie, Pierluigi Balduzzi, and Annika Sunden. 2003. "Portfolio choice and trading in a large 401 (k) plan." American Economic Review, 93(1): 193-215.

Alvarez, Fernando, Luigi Guiso, and Francesco Lippi. 2012. "Durable consumption and asset management with transaction and observation costs." American Economic Review, 102(5): 22722300. 
Ameriks, John, Andrew Caplin, Minjoon Lee, Matthew D Shapiro, and Christopher Tonetti. 2015a. "The Wealth of Wealthholders." National Bureau of Economic Research Working Paper 20972.

Ameriks, John, Gábor Kézdi, Minjoon Lee, and Matthew D Shapiro. 2016. "Heterogeneity in Expectations, Risk Tolerance, and Household Stock Shares." Ann Arbor, 1001: 48109-1248.

Ameriks, John, Joseph Briggs, Andrew Caplin, Matthew D Shapiro, and Christopher Tonetti. 2018. "The long-term-care insurance puzzle: Modeling and measurement." NBER Working Paper, , (22726).

Ameriks, John, Joseph S Briggs, Andrew Caplin, Matthew D Shapiro, and Christopher Tonetti. 2015b. "Long-Term-Care Utility and Late-in-Life Saving." National Bureau of Economic Research.

Ameriks, John, Joseph S Briggs, Andrew Caplin, Minjoon Lee, Matthew D Shapiro, and Christopher Tonetti. 2017. "Older Americans Would Work Longer If Jobs Were Flexible." National Bureau of Economic Research.

Amromin, Gene, and Steven A Sharpe. 2013. "From the horse's mouth: Economic conditions and investor expectations of risk and return." Management Science, 60(4): 845-866.

Arellano, Manuel, and Stephen Bond. 1991. "Some tests of specification for panel data: Monte Carlo evidence and an application to employment equations." The review of economic studies, 58(2): 277-297.

Armona, Luis, Andreas Fuster, and Basit Zafar. 2016. "Home price expectations and behavior: evidence from a randomized information experiment."

Arnold, Marc, Matthias Pelster, and Marti G Subrahmanyam. 2018. "Paying Attention."

Arrondel, Luc, Hector Calvo Pardo, and Derya Tas. 2014. "Subjective return expectations, information and stock market participation: evidence from France."

Azeredo da Silveira, Rava, and Michael Woodford. 2019. "Noisy Memory and Over-Reaction to News." Vol. 109, 557-61.

Bacchetta, Philippe, Elmar Mertens, and Eric Van Wincoop. 2009. "Predictability in financial markets: What do survey expectations tell us?" Journal of International Money and Finance, 28(3): 406426.

Bachmann, Rüdiger, Kai Carstensen, Stefan Lautenbacher, and Martin Schneider. 2018. “Uncertainty and Change: Survey Evidence of Firms' Subjective Beliefs."

Bailey, Michael, Eduardo Dávila, Theresa Kuchler, and Johannes Stroebel. 2017. "House price beliefs and mortgage leverage choice." National Bureau of Economic Research.

Bailey, Michael, Ruiqing Cao, Theresa Kuchler, and Johannes Stroebel. 2018. "The economic effects of social networks: Evidence from the housing market." Journal of Political Economy, 126(6): 000-000.

Barber, Brad M, and Terrance Odean. 2000. "Trading is hazardous to your wealth: The common stock investment performance of individual investors." The journal of Finance, 55(2): 773-806.

Barber, Brad M, and Terrance Odean. 2001. "Boys will be boys: Gender, overconfidence, and common stock investment." The quarterly journal of economics, 116(1): 261-292.

Barber, Brad M, and Terrance Odean. 2013. "The behavior of individual investors." In Handbook of the Economics of Finance. Vol. 2, 1533-1570. Elsevier.

Barberis, Nicholas. 2018. "Psychology-Based Models of Asset Prices and Trading Volume." Handbook of Behavioral Economics-Foundations and Applications 1, 79.

Barberis, Nicholas, Robin Greenwood, Lawrence Jin, and Andrei Shleifer. 2015. "X-CAPM: An extrapolative capital asset pricing model." Journal of financial economics, 115(1): 1-24.

Barro, Robert J. 2006. "Rare disasters and asset markets in the twentieth century." Quarterly Journal of Economics, 121(3): 823-866.

Ben-David, Itzhak, Elyas Fermand, Camelia M Kuhnen, and Geng Li. 2018. "Expectations Uncertainty and Household Economic Behavior." National Bureau of Economic Research.

Benjamin, Daniel J. 2018. "Errors in Probabilistic Reasoning and Judgment Biases." Handbook of Behavioral Economics, 2.

Beshears, John, James J Choi, David Laibson, and Brigitte C Madrian. 2009. "The importance of default options for retirement saving outcomes: Evidence from the United States." In Social security policy in a changing environment. 167-195. University of Chicago Press.

Bhandari, Anmol, Jaroslav Borovička, and Paul Ho. 2016. "Identifying ambiguity shocks in business cycle models using survey data." National Bureau of Economic Research.

Bordalo, Pedro, Nicola Gennaioli, Rafael La Porta, and Andrei Shleifer. 2020. "Expectations of 
Fundamentals and Stock Market Puzzles." National Bureau of Economic Research.

Bordalo, Pedro, Nicola Gennaioli, Yueran Ma, and Andrei Shleifer. 2018. "Overreaction in macroeconomic expectations." Working Paper.

Burnside, Craig, Martin Eichenbaum, and Sergio Rebelo. 2016. "Understanding booms and busts in housing markets." Journal of Political Economy, 124(4): 1088-1147.

Caballero, Ricardo J, and Alp Simsek. 2017. "A risk-centric model of demand recessions and speculation." National Bureau of Economic Research.

Calvo, Guillermo A. 1983. "Staggered prices in a utility-maximizing framework." Journal of monetary Economics, 12(3): 383-398.

Campbell, John Y, and Robert J Shiller. 1988. "The dividend-price ratio and expectations of future dividends and discount factors." The Review of Financial Studies, 1(3): 195-228.

Case, Karl E, Robert J Shiller, and Anne Thompson. 2012. "What have they been thinking? Home buyer behavior in hot and cold markets." National Bureau of Economic Research.

Cheng, Ing-Haw, Sahil Raina, and Wei Xiong. 2014. "Wall Street and the housing bubble." American Economic Review, 104(9): 2797-2829.

Chen, Hui, Scott Joslin, and Ngoc-Khanh Tran. 2012. "Rare disasters and risk sharing with heterogeneous beliefs." The Review of Financial Studies, 25(7): 2189-2224.

Choi, James J, and Adriana Z Robertson. 2018. "What matters to individual investors? Evidence from the horse?s mouth." National Bureau of Economic Research.

Clark, Jeffrey W, Stephen P Utkus, and Jean A Young. 2015. "Automatic enrollment: The power of the default." Valley Forge, PA: Vanguard.

Cochrane, John H. 2011. "Presidential address: Discount rates." The Journal of finance, 66(4): 10471108.

Cochrane, John H. 2017. "Macro-finance." Review of Finance, 21(3): 945-985.

Cogent Wealth Reports. 2018. "Investor Brand Builder 2018."

Coibion, Olivier, and Yuriy Gorodnichenko. 2012. "What can survey forecasts tell us about information rigidities?" Journal of Political Economy, 120(1): 116-159.

Coibion, Olivier, Yuriy Gorodnichenko, and Rupal Kamdar. 2018. "The formation of expectations, inflation, and the phillips curve." Journal of Economic Literature, 56(4): 1447-91.

Coval, Joshua, and Erik Stafford. 2007. "Asset fire sales (and purchases) in equity markets." Journal of Financial Economics, 86(2): 479-512.

Cummins, Jason G, Kevin A Hassett, and Stephen D Oliner. 2006. "Investment behavior, observable expectations, and internal funds." American Economic Review, 96(3): 796-810.

D'Acunto, Francesco, Daniel Hoang, Maritta Paloviita, and Michael Weber. 2019. "IQ, expectations, and choice." Bank of Finland Research Discussion Paper, , (2).

Daniel, Kent, David Hirshleifer, and Avanidhar Subrahmanyam. 1998. "Investor psychology and security market under-and overreactions." the Journal of Finance, 53(6): 1839-1885.

Das, Sreyoshi, Camelia M Kuhnen, and Stefan Nagel. 2017. "Socioeconomic status and macroeconomic expectations." National Bureau of Economic Research.

De la O, Ricardo, and Sean Myers. 2017. "Subjective Cash Flow and Discount Rate Expectations."

DellaVigna, Stefano. 2009. "Psychology and economics: Evidence from the field." Journal of Economic literature, 47(2): 315-72.

DellaVigna, Stefano, and Joshua M Pollet. 2009. "Investor inattention and Friday earnings announcements." The Journal of Finance, 64(2): 709-749.

De Long, J Bradford, Andrei Shleifer, Lawrence H Summers, and Robert J Waldmann. 1990. "Noise trader risk in financial markets." Journal of political Economy, 98(4): 703-738.

De Marco, Filippo, Marco Macchiavelli, and Rosen Valchev. 2018. "International Diversification and Information Heterogeneity." Available at SSRN 3048344.

Dominitz, Jeff, and Charles F Manski. 2007. "Expected equity returns and portfolio choice: Evidence from the Health and Retirement Study." Journal of the European Economic Association, 5(23): 369-379.

Dominitz, Jeff, and Charles F Manski. 2011. "Measuring and interpreting expectations of equity returns." Journal of Applied Econometrics, 26(3): 352-370.

Drerup, Tilman, Benjamin Enke, and Hans-Martin Von Gaudecker. 2017. “The precision of subjective data and the explanatory power of economic models." Journal of Econometrics, 200(2): 378389.

Duffie, Darrell, Tong-sheng Sun, et al. 1990. "Transactions costs and portfolio choice in a discretecontinuous-time setting." Journal of Economic dynamics and control, 14(1): 35-51. 
Fuhrer, Jeffrey C. 2018. "Intrinsic Expectations Persistence: Evidence from professional and household survey expectations."

Gabaix, Xavier. 2012. "Variable rare disasters: An exactly solved framework for ten puzzles in macro-finance." Quarterly Journal of Economics, 127(2): 645-700.

Gabaix, Xavier, and David Laibson. 2001. "The 6D bias and the equity-premium puzzle." NBER macroeconomics annual, 16: 257-312.

Gabaix, Xavier, and Ralph Koijen. 2020. "In Search of the Origins of Financial Fluctuations: The Inelastic Markets Hypothesis." Working Paper.

García-Schmidt, Mariana, and Michael Woodford. 2019. "Are low interest rates deflationary? A paradox of perfect-foresight analysis." American Economic Review, 109(1): 86-120.

Geanakoplos, John. 2010. "The leverage cycle." NBER macroeconomics annual, 24(1): 1-66.

Gennaioli, Nicola, Yueran Ma, and Andrei Shleifer. 2016. "Expectations and investment." NBER Macroeconomics Annual, 30(1): 379-431.

Gervais, Simon, and Terrance Odean. 2001. "Learning to Be Overconfident." The Review of Financial Studies, 14(1): 1-27.

Giglio, Stefano, Matteo Maggiori, Johannes Stroebel, and Stephen Utkus. 2020. "Inside the mind of a stock market crash." National Bureau of Economic Research.

Gillen, Ben, Erik Snowberg, and Leeat Yariv. 2019. "Experimenting with Measurement Error: Techniques with Applications to the Caltech Cohort Study." Journal of Political Economy, 127(4): 1826-1863.

Glaeser, Edward L, and Charles G Nathanson. 2017. "An extrapolative model of house price dynamics." Journal of Financial Economics, 126(1): 147-170.

Goetzmann, William, Dasol Kim, and Robert Shiller. 2018. "Availability, Media, Earthquakes, and Lottery Winners: Determinants of Crash Beliefs From Investor Surveys." Working Paper.

Graham, John R. 1999. "Herding among investment newsletters: Theory and evidence." The Journal of Finance, 54(1): 237-268.

Greenwood, Robin, and Andrei Shleifer. 2014. "Expectations of returns and expected returns." The Review of Financial Studies, 27(3): 714-746.

Grinblatt, Mark, and Matti Keloharju. 2009. "Sensation seeking, overconfidence, and trading activity." The Journal of Finance, 64(2): 549-578.

Harrison, J Michael, and David M Kreps. 1978. "Speculative investor behavior in a stock market with heterogeneous expectations." The Quarterly Journal of Economics, 92(2): 323-336.

Hoffmann, Arvid OI, and Thomas Post. 2016. "How does investor confidence lead to trading? Linking investor return experiences, confidence, and investment beliefs." Journal of Behavioral and Experimental Finance, 12: 65-78.

Hong, Harrison, and Jeremy C Stein. 1999. "A unified theory of underreaction, momentum trading, and overreaction in asset markets." The Journal of finance, 54(6): 2143-2184.

Hong, Harrison, and Jeremy C Stein. 2007. "Disagreement and the stock market." Journal of Economic perspectives, 21(2): 109-128.

Hudomiet, Peter, Gábor Kézdi, and Robert J Willis. 2011. "Stock market crash and expectations of American households." Journal of Applied Econometrics, 26(3): 393-415.

Hurd, Michael, Maarten Van Rooij, and Joachim Winter. 2011. "Stock market expectations of Dutch households." Journal of Applied Econometrics, 26(3): 416-436.

Jin, Lawrence. 2015. "A speculative asset pricing model of financial instability."

Kempf, Elisabeth, and Margarita Tsoutsoura. 2018. "Partisan professionals: Evidence from credit rating analysts." National Bureau of Economic Research.

Kézdi, Gábor, and Robert J Willis. 2009. "Stock market expectations and portfolio choice of American households." Unpublished manuscript, University of Michigan.

Kézdi, Gábor, and Robert J Willis. 2011. "Household stock market beliefs and learning." National Bureau of Economic Research.

Kuchler, Theresa, and Basit Zafar. 2015. "Personal experiences and expectations about aggregate outcomes."

Kyle, Albert S, and F Albert Wang. 1997. "Speculation duopoly with agreement to disagree: Can overconfidence survive the market test?" The Journal of Finance, 52(5): 2073-2090.

Landier, Augustin, Yueran Ma, and David Thesmar. 2017. "New experimental evidence on expectations formation."

Madrian, Brigitte C, and Dennis F Shea. 2001. "The power of suggestion: Inertia in 401 (k) par- 
ticipation and savings behavior." The Quarterly journal of economics, 116(4): 1149-1187.

Malmendier, Ulrike, and Stefan Nagel. 2011. "Depression babies: do macroeconomic experiences affect risk taking?" The Quarterly Journal of Economics, 126(1): 373-416.

Manski, Charles F. 2004. "Measuring expectations." Econometrica, 72(5): 1329-1376.

Martin, Ian, and Dimitris Papadimitriou. 2019. "Sentiment and speculation in a market with heterogeneous beliefs."

Meeuwis, Maarten, Jonathan A Parker, Antoinette Schoar, and Duncan I Simester. 2018. "Belief disagreement and portfolio choice." National Bureau of Economic Research.

Merkle, Christoph, and Martin Weber. 2014. "Do investors put their money where their mouth is? Stock market expectations and investing behavior." Journal of Banking E Finance, 46: 372-386.

Merton, Robert C. 1969. "Lifetime portfolio selection under uncertainty: The continuous-time case." The review of Economics and Statistics, 247-257.

Mian, Atif, Amir Sufi, and Nasim Khoshkhou. 2015. "Government economic policy, sentiments, and consumption." National Bureau of Economic Research.

Odean, Terrance. 1999. "Do investors trade too much?" American economic review, 89(5): 1279-1298.

Ottaviani, Marco, and Peter Norman Sørensen. 2006. "The strategy of professional forecasting." Journal of Financial Economics, 81(2): 441-466.

Ouimet, Paige, and Geoffrey A Tate. 2017. "Attention for the Inattentive: Positive Effects of Negative Financial Shocks." Available at SSRN 2760422.

Peng, Lin, and Wei Xiong. 2006. "Investor attention, overconfidence and category learning." Journal of Financial Economics, 80(3): 563-602.

Piazzesi, Monika, and Martin Schneider. 2009. "Momentum traders in the housing market: survey evidence and a search model." American Economic Review, 99(2): 406-11.

Rangvid, Jesper, Maik Schmeling, and Andreas Schrimpf. 2013. "What do professional forecasters' stock market expectations tell us about herding, information extraction and beauty contests?" Journal of Empirical Finance, 20: 109-129.

Rietz, Thomas A. 1988. "The equity risk premium a solution." Journal of monetary Economics, 22(1): 117-131.

Scheinkman, Jose A, and Wei Xiong. 2003. "Overconfidence and speculative bubbles." Journal of political Economy, 111(6): 1183-1220.

Vissing-Jorgensen, Annette. 2003. "Perspectives on behavioral finance: Does" irrationality" disappear with wealth? Evidence from expectations and actions." NBER macroeconomics annual, 18: 139-194.

Wachter, Jessica A. 2013. "Can time-varying risk of rare disasters explain aggregate stock market volatility?" The Journal of Finance, 68(3): 987-1035. 


\section{"Five Facts About Beliefs And Portfolios" ONLINE APPENDIX}

Stefano Giglio Matteo Maggiori Johannes Stroebel Steve Utkus

A.1 Response Rates to the GMSU-Vanguard Survey

A.2 Flow-Performance Relationship in the Vanguard Data

A.3 Time-Series Dynamics: A Comparison With Other Surveys

A.4 Additional Summary Statistics

A.5 Baseline Regressions: Re-weighted Sample

A.6 Other Beliefs and Portfolios

A.7 Trading: Data and Further Results

A.8 Beliefs and Demographics

A.9 Variance Decomposition of Beliefs - RAND Survey

A.10 Persistent Heterogeneity in Beliefs \& Portfolio Shares

A.11 Relationship Among Beliefs: Persistent vs. Transitory

A.12 Key Results: Sample up to February 2020

B.1 Invitation Email and Survey Flow

B.1 


\section{A.1 Response Rates to the GMSU-VAnguard SuRVEy}

In this Appendix, we further explore the response rates to the GMSU-Vanguard Survey. The top panel of Figure A.1 reports the number of responses in each wave, with different colors tracking the first wave to which an individual responded. Starting in wave 5, we received more responses from individuals who are re-respondents than from individuals who are responding for the first time. The bottom panel shows that only about $25 \%$ of responses come from individuals who have responded to one survey only (and some of these may end up responding to future survey waves). About $42 \%$ of responses come from individuals who have responded to at least four survey waves, and more than $25 \%$ come from individuals who have responded to at least six survey waves.

Figure A.1: Number of Responses by Wave

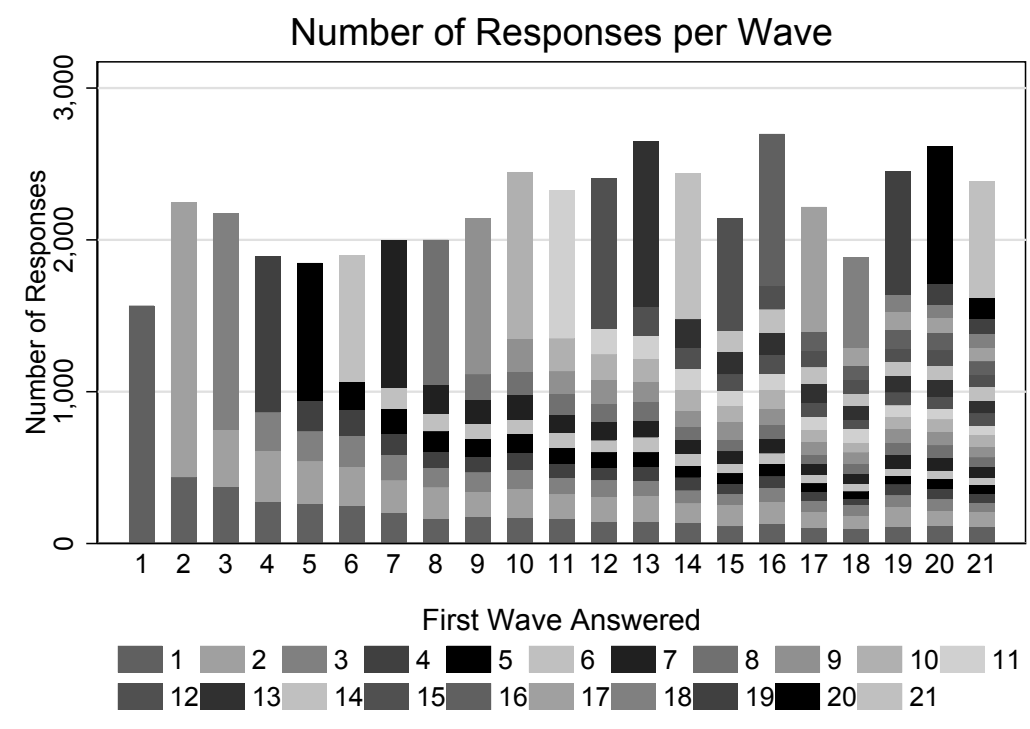

Number of Responses

By Total Responses from Respondent

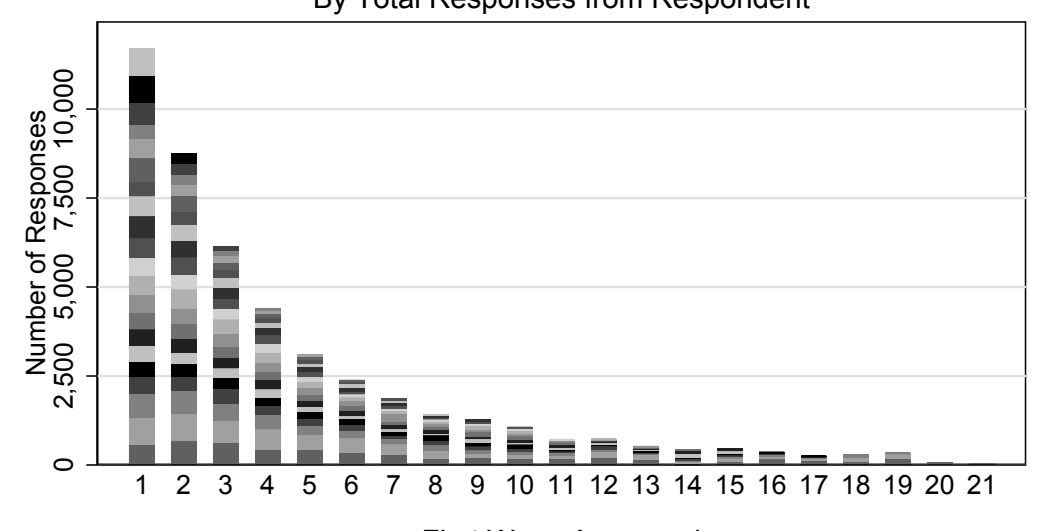

First Wave Answered

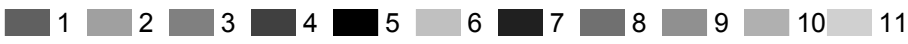

\begin{tabular}{l|l|l|l|l|l|l|l|l|l|}
12 & 13 & 14 & 15 & 16 & 17 & 18 & 19 & 20 & 21
\end{tabular}

Note: Figure shows the number of responses to the GMSU-Vanguard Survey. The top panel shows the number of responses per wave. The bottom panel shows the total number of responses separately by the number of survey waves a person has responded to. In both panels, the colors correspond to the waves in which these individuals first answered. 


\section{A.2 Flow-Performance Relationship in the VANGUARD DATA}

The mutual fund literature has established that funds generally experience inflows after a positive return and that these inflows persist for several months after the high returns. In this Appendix, we document that similar patterns exist for the sample of Vanguard funds and among the sample of Vanguard investors.

We take the work of Coval and Stafford (2007) as the benchmark for our analysis. In particular, Coval and Stafford (2007) regress each fund's current inflows (measured as a percentage of beginning-of-period total net assets) on twelve monthly lags of the funds' past returns and twelve monthly lags of flows into the funds. For convenience, we report the estimates from column 4 of Table 1 of Coval and Stafford (2007) in column 5 of Table A.1 below. In the interest of readability, we do not report the coefficients on the 12 monthly lags of inflows and focus on the coefficients on past returns, which are at the heart of the flow-performance relationship. As is clear from the table, Coval and Stafford (2007) found that lagged returns indeed positively affect current inflows, with the strongest effects for the returns in the most recent months. This is the standard flow-performance result referenced in the literature, which also includes contributions by Sirri and Tufano (1998) and Del Guercio and Tkac (2002).

Columns 1 and 2 of Table A.1 report estimates using the same regression specification as in Coval and Stafford (2007), but focusing only on Vanguard data. We follow Coval and Stafford (2007) in imposing thresholds on funds' assets under management (AUM) and the size of AUM changes for inclusion in the regression. These restrictions avoid giving weight in the results to large flows into funds very early in their operation. Specifically, we only use funds after they reach the minimum threshold of $\$ 10 \mathrm{~m}$ assets under management. ${ }^{1}$ Columns 3 and 4 of Table A.1 repeat the same analysis but restrict the sample to be pre-COVID-19, thus ending in February 2020. The pre-COVID-19 period is perhaps more comparable with the earlier estimates of Coval and Stafford (2007).

In columns 1 and 3 of Table A.1, we explore aggregate flows into the universe of Vanguard mutual funds. The coefficients are very similar to those from Coval and Stafford (2007) reported in column 5, in particular for the first few lags of returns that are of central interest in the flowperformance literature. In columns 2 and 4, we perform the analysis using only the flows into Vanguard funds coming from our survey respondents. Here we only include funds that are well represented in our sample. In particular, we focus on funds where our respondents collectively hold at least $0.04 \%$ of the total assets under management. This restriction ensures that our estimate of the flow-performance relationship is not dominated by noise for those funds that are held by only a small fraction of our respondents. Overall, these restrictions imply that the sample used to produce the results in columns 2 and 4 include $75 \%$ of the funds that were used to produce the results in columns 1 and 2 (and an even larger share of the AUM). Again, the coefficients in those specifications are very close to those in the existing literature.

\footnotetext{
${ }^{1}$ We also impose additional filters. In particular, we drop observations in which the total fund flows are more than $200 \%$ or less than $-50 \%$ in a month, or in which the reported fund return differs by more than 20 percentage points from the return implied by combining fund flows and AUMs. These filters mostly exclude a few months at the very beginning of the life of a fund.
} 
These results highlight that investors in Vanguard funds exhibit the same qualitative and quantitative flow-performance patterns documented in the previous literature for mutual funds more generally. We also find that the specific sample of investors that respond to our survey behaves similarly in this respect to the broader population of investors.

\section{Table A.1: Fund Flows and Past Performance}

\begin{tabular}{lccccc}
\hline & \multicolumn{3}{c}{ Current Fund Flows (\% TNA) } \\
\cline { 2 - 5 } & $(1)$ & $(2)$ & $(3)$ & $(4)$ & $(5)$ \\
& Aggregate & Individual & Aggregate, Pre-Covid & Individual, Pre-Covid & Coval/Stafford \\
\cline { 2 - 6 } & & & & & \\
& $0.063^{* * *}$ & $0.065^{* * *}$ & $0.090^{* * *}$ & $0.066^{* * *}$ & 0.074 \\
L1.Returns (\%) & $(0.007)$ & $(0.012)$ & $(0.008)$ & $(0.015)$ & $\{23.88\}$ \\
& $0.017^{* *}$ & $0.078^{* * *}$ & $0.027^{* * *}$ & $0.101^{* * *}$ & 0.037 \\
L2.Returns (\%) & $(0.007)$ & $(0.012)$ & $(0.008)$ & $(0.015)$ & $\{12.13\}$ \\
L3.Returns (\%) & $0.028^{* * *}$ & $0.061^{* * *}$ & $0.019^{*}$ & $0.079^{* * *}$ & 0.033 \\
& $(0.007)$ & $(0.013)$ & $(0.008)$ & $(0.015)$ & $\{11.04\}$ \\
L4.Returns (\%) & 0.003 & 0.008 & -0.003 & 0.011 & 0.024 \\
& $(0.007)$ & $(0.014)$ & $(0.008)$ & $(0.014)$ & $\{7.99\}$ \\
L5.Returns (\%) & $0.024^{* *}$ & $0.067^{* * *}$ & $0.023^{* *}$ & $0.064^{* * *}$ & 0.015 \\
& $(0.007)$ & $(0.014)$ & $(0.007)$ & $(0.014)$ & $\{4.98\}$ \\
L6.Returns (\%) & 0.006 & 0.017 & 0.002 & 0.016 & 0.013 \\
L7.Returns (\%) & $(0.007)$ & $(0.014)$ & $(0.007)$ & $(0.014)$ & $\{4.38\}$ \\
& $-0.017^{*}$ & $-0.071^{* * *}$ & -0.007 & $-0.074^{* * *}$ & 0.006 \\
L8.Returns (\%) & $(0.007)$ & $(0.014)$ & $(0.007)$ & $(0.014)$ & $\{2.01\}$ \\
L9.Returns (\%) & $-0.015^{*}$ & 0.004 & -0.008 & 0.006 & 0.004 \\
& $(0.007)$ & $(0.014)$ & $(0.007)$ & $(0.014)$ & $\{1.24\}$ \\
L10.Returns (\%) & $-0.016^{*}$ & $0.050^{* * *}$ & $-0.022^{* *}$ & $0.061^{* * *}$ & 0.003 \\
& $(0.007)$ & $(0.014)$ & $(0.007)$ & $(0.014)$ & $\{0.99\}$ \\
L11.Returns (\%) & -0.011 & $0.053^{* * *}$ & -0.012 & $0.043^{* *}$ & 0.007 \\
& $(0.007)$ & $(0.013)$ & $(0.007)$ & $(0.014)$ & $\{2.48\}$ \\
L12.Returns (\%) & $-0.019 *$ & $0.031^{*}$ & $-0.016^{*}$ & $0.030^{*}$ & 0.000 \\
Control for 12 Lags of Fund Flows & $(0.007)$ & $(0.014)$ & $(0.007)$ & $(0.014)$ & $\{0.13\}$ \\
\hline R-Squared & -0.004 & 0.013 & -0.004 & 0.015 & -0.009 \\
N & $(0.007)$ & $(0.014)$ & $(0.007)$ & $(0.014)$ & $-\{3.02\}$ \\
\hline & $Y$ & $Y$ & $Y$ & $Y$ & $Y$ \\
\hline
\end{tabular}

Note: Table reports results from regressions of mutual fund flows on lagged fund flows and lagged fund returns. Columns 1 and 2 report full sample estimates, columns 3 and 4 report pre-COVID-19 estimates, and column 5 reports the estimates from Coval and Stafford (2007). Mutual fund flows are measured as a percentage of beginning-of-period total net assets (TNA). In columns 1 and 3, mutual fund flows are reported directly by each Vanguard fund and exclude valuation movements of existing assets. In columns 2, 4, and 5, mutual fund flows are estimated as the percentage change in TNA over the month, controlling for capital gains and losses of the initial holdings: $\left[T N A_{t}-T N A_{t-1} \times\left(1+R_{t-1}\right)\right] / T N A_{t-1}$. The pooled regression results are based on OLS coefficients, where the mean of each variable has been subtracted. In columns 1 to 4 , we report standard errors and significance levels: ${ }^{*}(\mathrm{p}<0.10),{ }^{* *}(\mathrm{p}<0.05),{ }^{* * *}(\mathrm{p}<0.01)$. In column 5, we follow Coval and Stafford (2007) original paper and report $t$-statistics. 


\section{A.3 Time-Series Dynamics: A COMPARISON With OTHER SURVEYS}

In this Appendix, we compare the time-series variation of average beliefs in the GMSU-Vanguard survey with similar measures in other surveys. By comparing patterns of beliefs across different surveys over the same time period, we can explore the extent to which the various surveys capture similar belief movements, despite differences in their samples and survey designs.

Specifically, for each wave, we average our survey responses across individuals, focusing on the question about expected 1-year stock returns. We then compare the time-series dynamics of this average expected return to similar ones from four existing surveys: Robert Shiller's investor survey, the Duke (Graham-Harvey) CFO survey, the American Association of Individual Investors survey (AAII), and the RAND American Life Panel Survey (Financial Crisis). The Duke CFO survey asks explicitly about expected 1-year stock returns and is therefore directly comparable with our survey, but the last available response is December 2019. All other surveys ask questions that are related to expected returns, but cannot be directly mapped to them. In those cases, we use the survey questions that are most closely related to 1-year expected stock returns. For the Shiller survey, we use the share of respondents that report expecting an increase in stock market valuations over the next year; for the RAND survey, we calculate the average (across respondents) probability of a stock market increase over the next year; and for the AAII survey, we compute the difference between the percentage of bullish and bearish investors. Figure A.2 plots the time series of the GMSU-Vanguard survey together with the other surveys. For readability, we separate the plots into different panels that focus on comparisons between the GMSU-Vanguard survey and at most two other surveys (Panel A: AAII; Panel B Duke CFO and RAND; Panel C: Shiller).

Since the beginning of the GMSU-Vanguard survey in February 2017, there has been significant variation in average 1-year expected stock returns. Expected returns in the first survey wave were just above $5 \%$. They reached above $6 \%$ by February 2020, before abruptly decreasing to just above $2 \%$ after the COVID-19 crash in March 2020. We also observe a drop and recovery in the last quarter of 2018, a pattern that mirrors the dynamics of the S\&P 500 index over that same period.

During the pre-COVID-19 period, the patterns are broadly shared across surveys. First, quantitatively, Panel B of Figure A.2 shows that both the level and the variation of average beliefs during our sample period is quite similar to those in the Duke CFO survey (the RAND survey ended before the start of our sample). Second, qualitatively, the peak in optimism in our survey at the end of 2017 is shared by most other surveys, despite differences in elicitation methods and target populations. Similarly, all surveys experience a drop in positive sentiment around the last quarter of 2018. During the COVID-19 period — that is, our April and June 2020 surveys — our survey reports a drop in expectations. This drop is closely matched by the AAII survey; the Shiller survey shows instead an increase in optimism. ${ }^{2}$ We conclude that over the COVID-19 crisis, existing surveys have diverged somewhat, with some reporting a turn to pessimistic beliefs and others an increase in optimism. What drives the differential behavior remains an open question.

\footnotetext{
${ }^{2}$ Over this period we also investigated the University of Michigan Surveys of Consumers ("probability of stock market increases in next year") and the New York Fed Survey of Consumer Expectations ("probability that U.S. stock prices will be higher one year from now"). The Michigan survey reports a drop in expectations while the New York Fed survey reports an increase in expectations over this period.
} 


\section{Figure A.2: Comparison With Other Surveys}

(A) GMSU-Vanguard vs. AAII

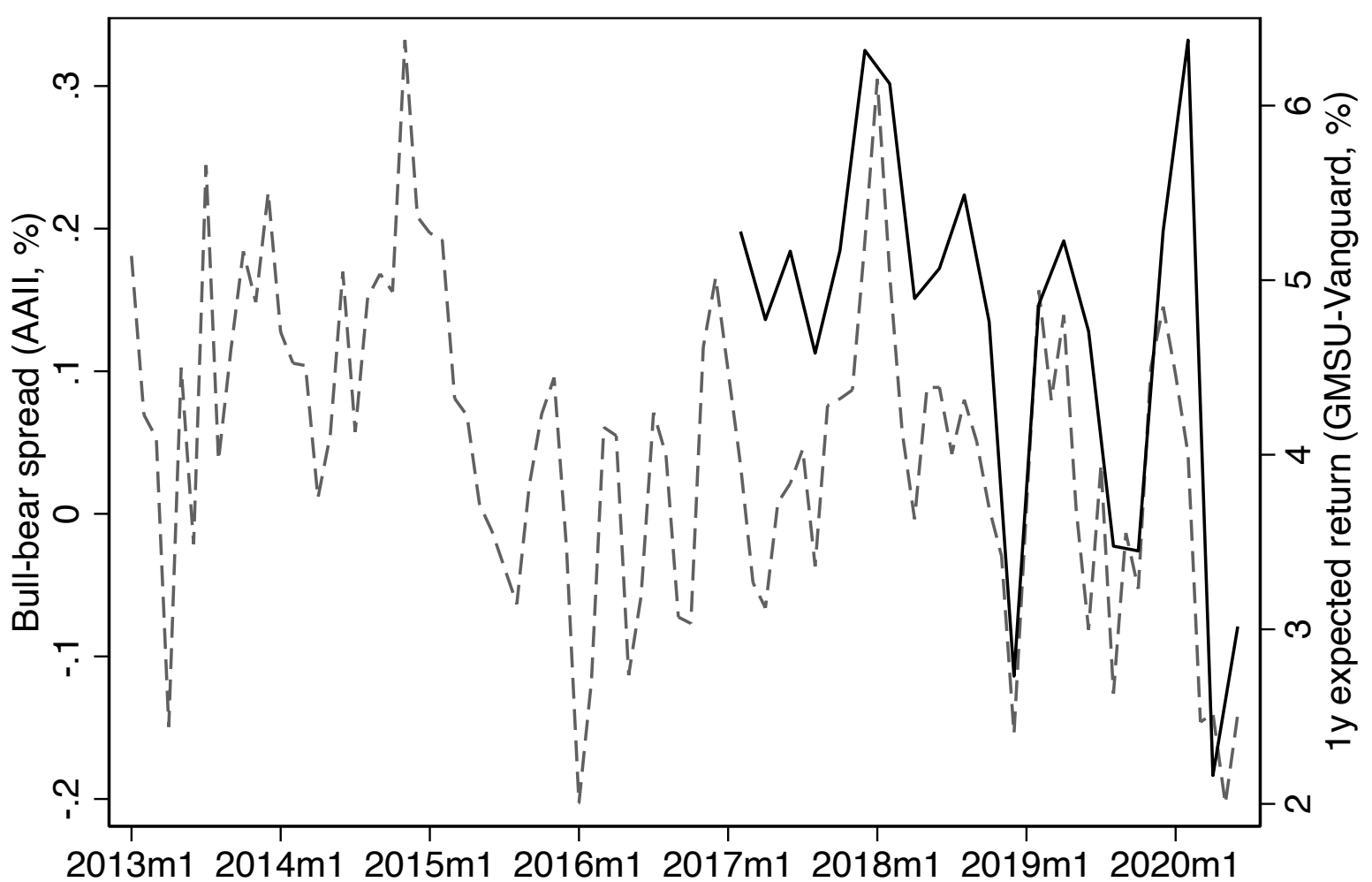

\section{---- AAll GMSU-Vanguard}

(B) GMSU-Vanguard vs. Duke CFO and RAND

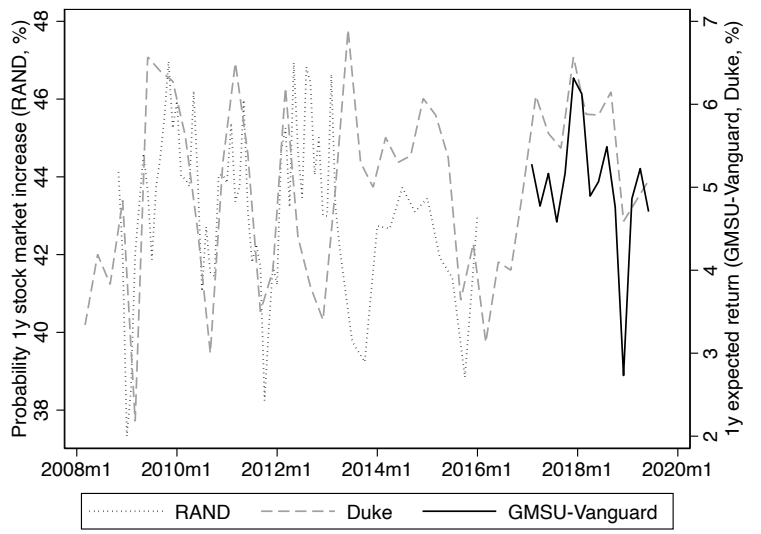

(C) GMSU-Vanguard vs. Shiller

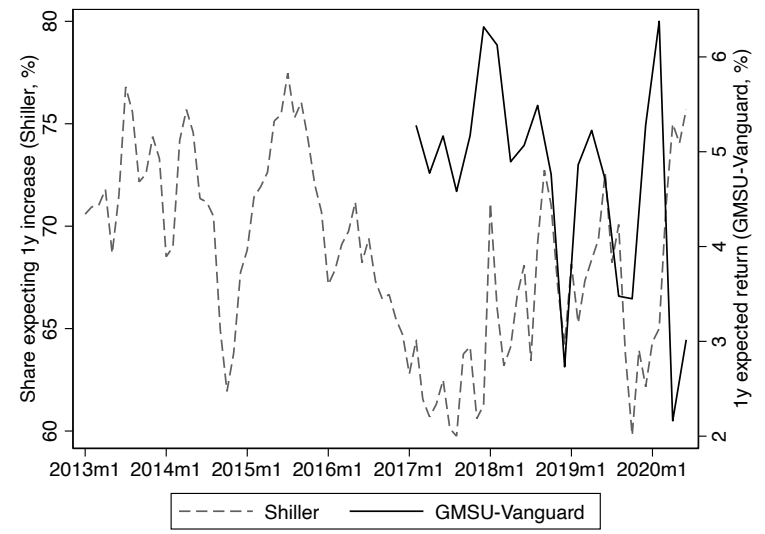

Note: Figure compares average beliefs about the 1-year stock market return in the GMSU-Vanguard survey with questions from other surveys. Panel A shows the bull-bear spread from the AAII survey. Panel B shows the average 1-year expected stock returns from the Duke CFO survey, and the average probability of a 1-year stock market increase from the RAND survey. Panel $C$ reports the share of investors expecting an increase in market values in one year from Shiller's investor survey. 


\section{A.4 Additional Summary Statistics}

In this Appendix, we present additional summary statistics on the sample of respondents and the survey responses. We first describe the correlations between a number of investor characteristics. We then explore the distribution of survey responses, as well as their within-response correlations.

Respondent Characteristics. Table A.2 explores average characteristics across various percentiles of the age and wealth distributions. Specifically, in columns 1, 2, and 3, we show summary statistics for individuals whose age is within one year of the 25th, 50th, and 75th percentiles of the sample age distribution, respectively. In columns 4, 5, and 6, we show summary statistics for individuals who are within $\$ 10 \mathrm{k}$ of the $25 \mathrm{th}, 50 \mathrm{th}$, and 75 th percentiles of the sample wealth distribution, respectively.

Table A.2: Survey Respondent Summary Statistics

\begin{tabular}{|c|c|c|c|c|c|c|}
\hline & \multicolumn{3}{|c|}{ Split by Age } & \multicolumn{3}{|c|}{ Split by total Vanguard Wealth } \\
\hline & $\mathrm{P} 25$ & $\mathrm{P} 50$ & $\mathrm{P} 75$ & $\mathrm{P} 25$ & P50 & $\mathrm{P} 75$ \\
\hline Age (Years) & 51.9 & 63.0 & 70.0 & 55.2 & 60.1 & 63.7 \\
\hline Male & 0.66 & 0.70 & 0.69 & 0.65 & 0.68 & 0.74 \\
\hline \multicolumn{7}{|l|}{ Region } \\
\hline Northeast & 0.24 & 0.23 & 0.21 & 0.19 & 0.25 & 0.22 \\
\hline Midwest & 0.20 & 0.23 & 0.19 & 0.22 & 0.17 & 0.21 \\
\hline South & 0.30 & 0.28 & 0.33 & 0.33 & 0.33 & 0.29 \\
\hline West & 0.26 & 0.25 & 0.26 & 0.26 & 0.25 & 0.28 \\
\hline Total Vanguard Wealth (k\$) & 449.3 & 556.7 & 665.3 & 72.1 & 227.8 & 613.6 \\
\hline Length of Vanguard Relationship (Years) & 15.72 & 18.17 & 19.14 & 14.13 & 16.78 & 18.63 \\
\hline Active Trades / Month & 1.79 & 1.39 & 1.26 & 0.89 & 1.57 & 1.95 \\
\hline Monthly Portfolio Turnover (\%) & 2.48 & 2.60 & 1.78 & 1.90 & 1.99 & 2.26 \\
\hline Days with Log-Ins / Month & 3.15 & 3.64 & 3.69 & 2.60 & 3.59 & 5.02 \\
\hline Total Time Spent / Month (Minutes) & 28.81 & 32.24 & 34.01 & 16.21 & 25.50 & 42.67 \\
\hline \multicolumn{7}{|l|}{ Portfolio Shares (\%) } \\
\hline Equity & 74.5 & 64.7 & 59.3 & 71.2 & 68.3 & 62.8 \\
\hline Fixed Income & 14.7 & 23.2 & 26.6 & 19.6 & 20.3 & 22.4 \\
\hline Cash & 9.2 & 10.7 & 12.2 & 8.3 & 10.0 & 12.2 \\
\hline Other/Unknown & 1.7 & 1.4 & 1.9 & 0.9 & 1.4 & 2.6 \\
\hline Number of Unique Assets & 8.18 & 7.81 & 8.11 & 3.42 & 6.15 & 10.06 \\
\hline Number of Mutual Funds & 4.98 & 5.04 & 5.18 & 2.60 & 4.46 & 5.99 \\
\hline Number of ETFs & 1.00 & 0.79 & 0.77 & 0.35 & 0.65 & 1.37 \\
\hline Number of Stocks & 2.09 & 1.89 & 1.95 & 0.48 & 1.04 & 2.64 \\
\hline Number of Bonds & 0.11 & 0.10 & 0.21 & 0.00 & 0.00 & 0.06 \\
\hline
\end{tabular}

Note: Table shows summary statistics on our survey respondents, similar to Table I. Columns 1, 2, and 3 show summary statistics for individuals whose age is within one year of the 25 th, 50 th, and 75 th percentile of the sample age distribution. Columns 4, 5, and 6 show summary statistics for individuals who are within $\$ 10 \mathrm{k}$ of the $25 \mathrm{th}$, 50th, and 75th percentiles of the sample wealth distribution.

Table A.2 highlights several interesting correlations across different demographic characteristics of our respondents. Age and wealth are strongly positively correlated. Older people pay more attention to their portfolios, but they trade less frequently. Richer clients pay more attention and are more likely to trade. Older and richer clients both hold less equity and more fixed income assets and cash. While wealthier respondents are more likely to be male, we find no strong differences in the gender composition of respondents by age. 
In Section II of the paper, we show heterogeneities in the sensitivity of portfolio allocations to beliefs along a number of observable investor characteristics: investor trading volume (measured as the average monthly turnover as a share of portfolio value), investor attention (measured as the average number of days per month on which investors log into the Vanguard website), and investor confidence (expressed as the confidence in their beliefs about stock returns). Figure A.3 shows that these characteristics are relatively uncorrelated across individuals, and, as a result, that the various splits of the investor sample do capture distinct characteristics.

Figure A.3: Trading Volume, Attention, and Confidence
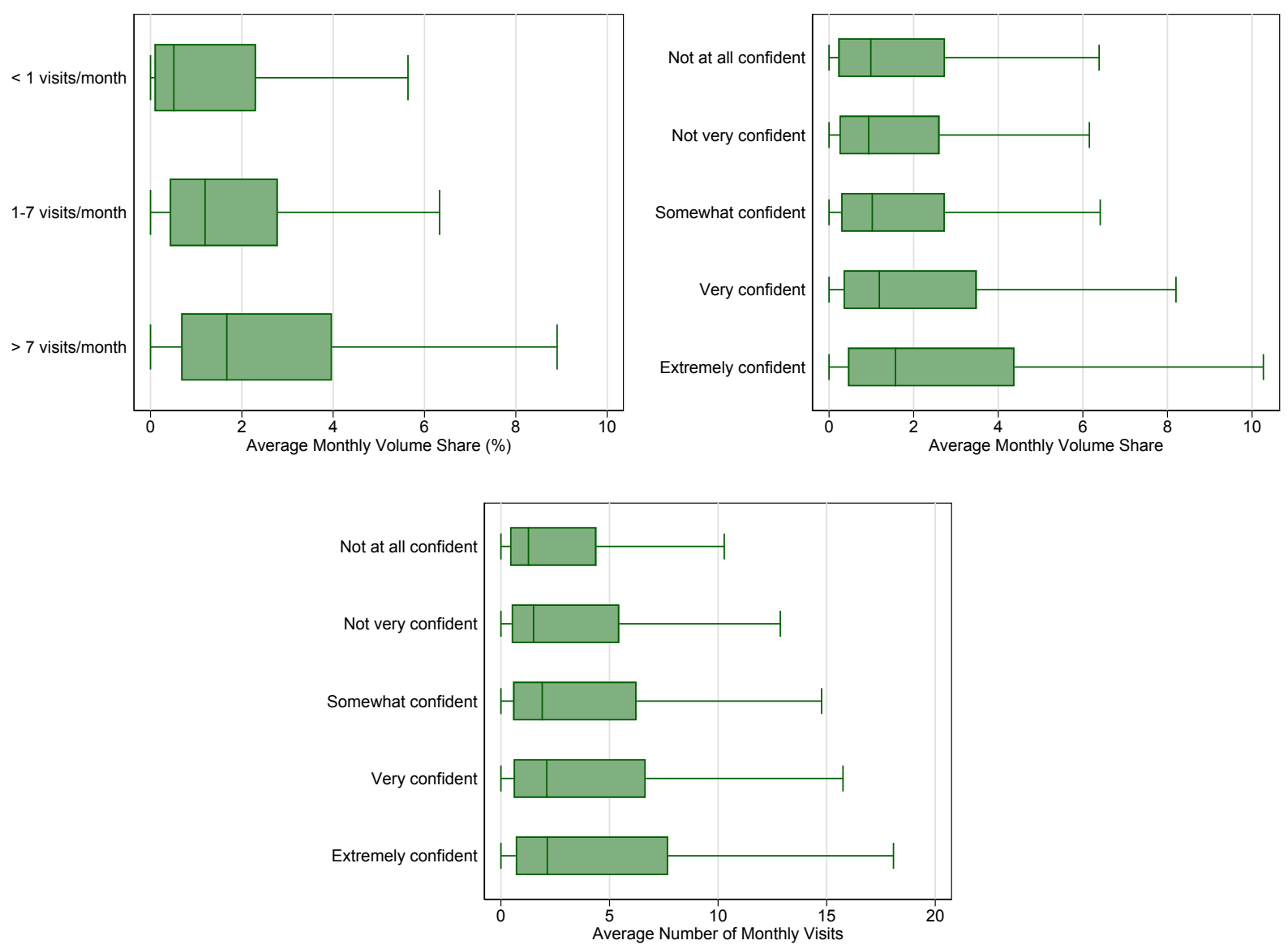

Note: Figure shows the distributions of the average monthly volume share by log-ins (top left panel), the average monthly volume share by confidence (top right panel), and the average number of monthly Vanguard log-ins by confidence (bottom panel). The box plots show the 5th, 25th, 50th, 75th, and 95th percentiles of the distribution.

Distribution of Survey Responses. Figure A.4 presents histograms showing the full distributions of answers for six central questions from the GMSU-Vanguard survey. These figures reinforce our conclusion that there is very substantial heterogeneity in reported beliefs. We also find that the distribution of beliefs over 1-year expected returns is substantially wider than the distribution of beliefs over expected annualized 10-year returns. 
Figure A.4: Distribution of Responses to the GMSU-Vanguard Survey

(A) 1-Year Expected Stock Returns

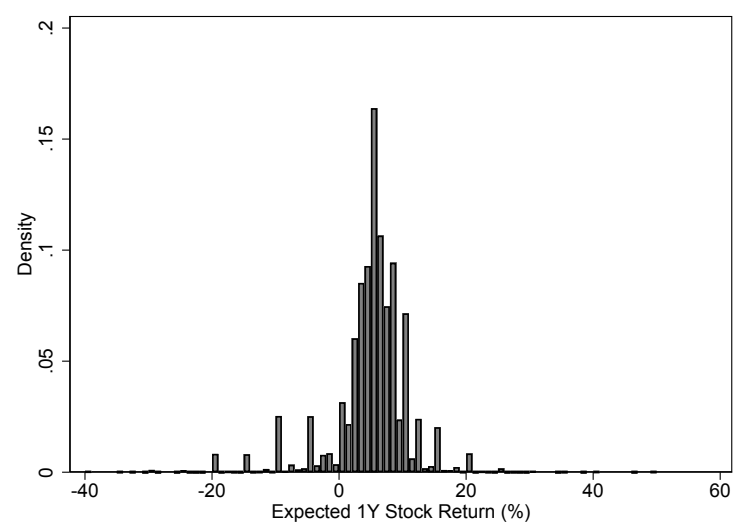

(C) 3-Year Expected GDP Growth (annualized)

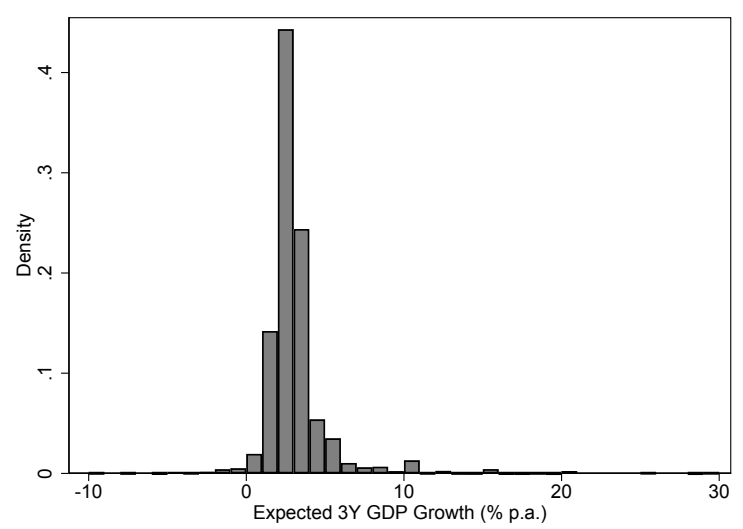

(E) Probability of Stock Market Disaster

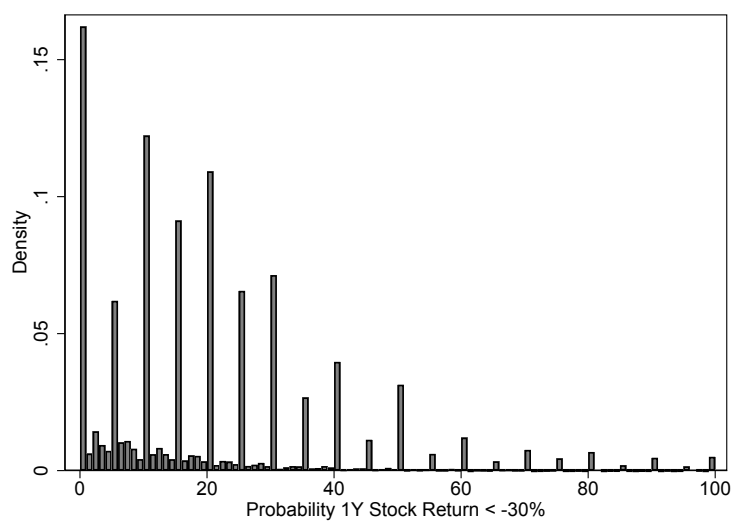

(B) 10-Year Expected Stock Returns (annualized)

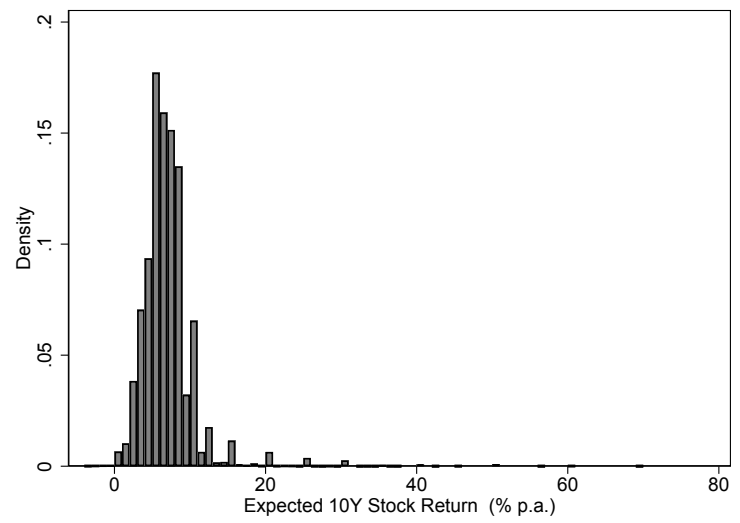

(D) 10-Year Expected GDP Growth (annualized)

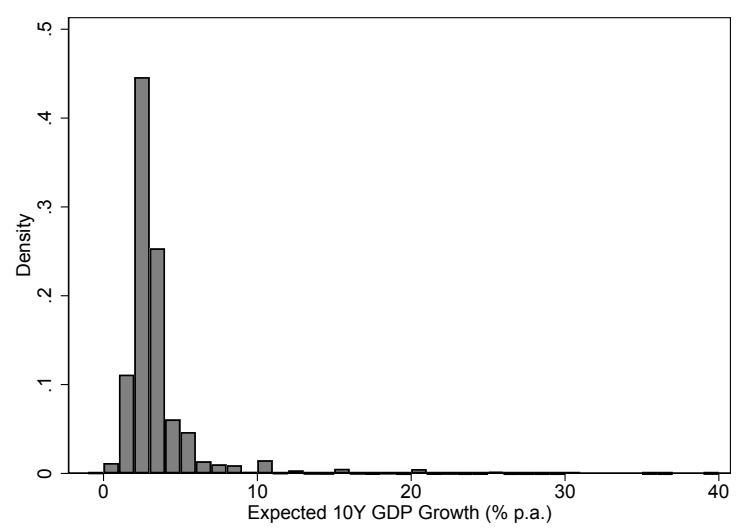

(F) 1-Year Expected Bond Returns

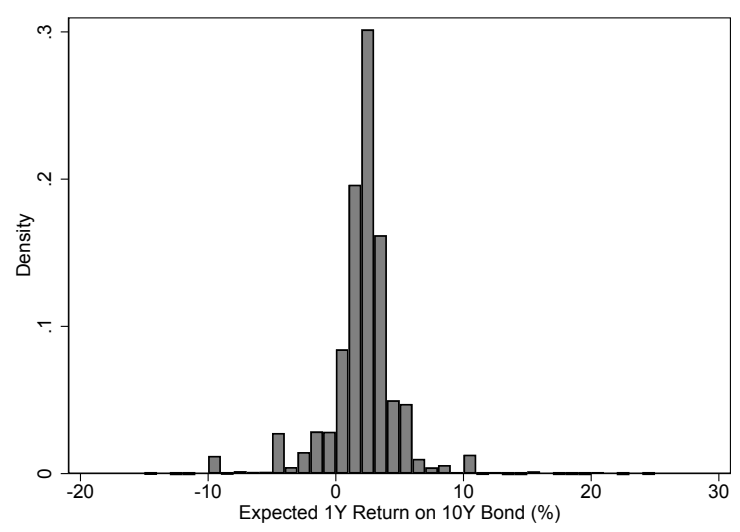

Note: Figure shows histograms of answers across the responses to the first 21 waves of the GMSU-Vanguard survey. 
Table A.3: Correlation Across Survey Responses

\begin{tabular}{|c|c|c|c|c|c|c|c|c|c|}
\hline & (1) & (2) & (3) & (4) & (5) & (6) & (7) & (8) & (9) \\
\hline (1) Expected 1Y Stock Return (\%) & 1 & & & & & & & & \\
\hline (2) Expected 10Y Stock Return (\% p.a.) & 0.304 & 1 & & & & & & & \\
\hline (3) Probability 1Y Stock Return < -30\% (\%) & -0.273 & -0.071 & 1 & & & & & & \\
\hline (4) St.D. Expected 1Y Stock Return (\%) & -0.085 & 0.013 & 0.550 & 1 & & & & & \\
\hline (5) Expected 3Y GDP Growth (\% p.a.) & 0.262 & 0.202 & -0.067 & 0.043 & 1 & & & & \\
\hline (6) Expected 10Y GDP Growth (\% p.a.) & 0.107 & 0.267 & 0.002 & 0.073 & 0.648 & 1 & & & \\
\hline (7) Probability p.a. 3Y GDP Growth <-3\% (\%) & -0.185 & -0.065 & 0.454 & 0.348 & -0.110 & 0.003 & 1 & & \\
\hline (8) St.D. Expected 3Y GDP Growth (\% p.a.) & 0.027 & 0.062 & 0.262 & 0.581 & 0.214 & 0.237 & 0.426 & 1 & \\
\hline (9) Expected 1Y Return of 10Y zero coupon bond (\%) & 0.127 & 0.116 & -0.016 & 0.020 & 0.161 & 0.153 & 0.007 & 0.083 & 1 \\
\hline
\end{tabular}

Note: Table shows within-survey correlations across questions eliciting beliefs about different objects.

Table A.3 shows the correlations across responses to different belief questions in the GMSUVanguard survey. These correlations echo a number of findings in the main body of the paper. Short-run and long-run beliefs about different objects are positively correlated. Consistent with Fact 4, beliefs about GDP growth and expected stock returns are also positively correlated. Consistent with Fact 5, individuals who report a higher probability of a stock market crash also report lower expected stock returns and a higher probability of a GDP disaster. Beliefs about expected bond returns are weakly positively correlated with expected stock returns and expected GDP growth, and uncorrelated with the probability of either a stock market disaster or a GDP disaster. 


\section{A.5 BASELINE REgRESSIONS: Re-WEIGHTED SAMPLE}

In Section I, we discussed how the sample of survey respondents differs from the sample of nonrespondents on several dimensions. In this Appendix, we repeat our baseline analysis in Section II on a sample of respondents designed to match the sample of non-respondents on a number of demographic characteristics. In this approach, we first pool the sample of respondents and nonrespondents, and regress an indicator of whether a person responded on a number of observable characteristics such as age, gender, and wealth. The fitted values from this regression provide, for each individual who received the invitation to take a survey, the corresponding propensity to respond to the survey.

We then create a new regression sample that includes, for each non-respondent, the respondent with the closest propensity score. Since we have more non-respondents than respondents, we match to the distribution of respondents with replacement. We then run our baseline regression 1 on this new sample. The results, based on samples that are re-weighted across different dimensions, are shown in Table A.4.

Column 1 shows the baseline specification corresponding to column 6 in Table III. Column 2 shows the same regression on a sample of non-respondents that match our sample of respondents on the age and wealth dimensions. The average sensitivity in that sample is somewhat lower, consistent with the fact that wealthier people are both more sensitive and more likely to respond to the survey. In the following columns, we construct regression samples based on propensity scores built on age, gender, and wealth (column 3), and age, gender, wealth, and length of Vanguard relationship (column 4). The sensitivities in these samples are marginally smaller than in column 2. Overall, these results highlight that individuals who are more likely to respond to the survey have a somewhat higher sensitivity of portfolio shares to beliefs.

Table A.4: Beliefs and Portfolios: Re-weighted Sample

\begin{tabular}{|c|c|c|c|c|}
\hline & \multicolumn{4}{|c|}{ Equity Share (\%) } \\
\hline & (1) & (2) & (3) & (4) \\
\hline Expected 1Y Stock Return (\%) & $\begin{array}{c}1.177^{* * *} \\
(0.062)\end{array}$ & $\begin{array}{c}1.007^{* * *} \\
(0.089)\end{array}$ & $\begin{array}{c}1.039 * * * \\
(0.105)\end{array}$ & $\begin{array}{c}0.989 * * * \\
(0.088)\end{array}$ \\
\hline Controls & $\mathrm{Y}$ & $\mathrm{Y}$ & $\mathrm{Y}$ & $\mathrm{Y}$ \\
\hline ORIV & $\mathrm{Y}$ & $\mathrm{Y}$ & $\mathrm{Y}$ & $\mathrm{Y}$ \\
\hline Sample & Baseline & $\begin{array}{l}\text { Re-weighted: } \\
\text { Age + Wealth }\end{array}$ & $\begin{array}{c}\text { Re-weighted: } \\
\text { Age + Wealth + } \\
\text { Gender }\end{array}$ & $\begin{array}{l}\text { Re-weighted: } \\
\text { Age + Wealth + } \\
\text { Gender + Length } \\
\text { of Relationship }\end{array}$ \\
\hline $\mathrm{N}$ & 44,235 & 226,627 & 225,884 & 225,606 \\
\hline
\end{tabular}

Note: Table shows results from regression 1. Column 1 shows the baseline specification corresponding to column 5 in Table III. The following columns show the same regression but on a sample of respondents that are re-weighted to match the sample of non-respondents on a number of demographics: age and wealth (column 2); age, wealth, and gender (column 3); and age, wealth, gender, and length of Vanguard relationship (column 4). Significance levels: * $(\mathrm{p}<0.10),{ }^{* *}(\mathrm{p}<0.05),{ }^{* * *}(\mathrm{p}<0.01)$. 


\section{A.6 OTHER Beliefs AND PORTFOlios}

In the main body of the paper, we explored the role of an individual's expectations of 1-year stock returns on her portfolio allocation. In this Appendix, we explore how beliefs about other moments of stock returns as well as beliefs about bond returns and GDP growth affect these portfolio allocations. Since we are not able to instrument for most of these other beliefs, we return to estimating basic tobit models instead of ORIV models.

In column 1 of Table A.5, we control for the subjective standard deviation of 1-year stock returns, in addition to the point estimate for expected returns. ${ }^{3}$ This completes our analysis of the Merton (1969) model by allowing individual-level variation in both the level and the standard deviation of expected returns. A higher standard deviation of returns has a statistically significant negative effect on the equity share. The estimated sensitivity of portfolio shares to 1-year expected stock returns is unchanged when controlling for the standard deviation.

Table A.5: Long-Run Beliefs, Variance, Tail Risk, and Bond Returns

\begin{tabular}{|c|c|c|c|c|c|c|c|c|}
\hline & \multicolumn{6}{|c|}{ Equity Share (\%) } & \multirow{2}{*}{$\begin{array}{c}\begin{array}{c}\text { Fixed Income } \\
\text { Share (\%) }\end{array} \\
(7)\end{array}$} & \multirow{2}{*}{$\begin{array}{c}\text { Cash Share } \\
\text { (\%) }\end{array}$} \\
\hline & (1) & (2) & (3) & (4) & (5) & (6) & & \\
\hline Expected 1Y Stock Return (\%) & $\begin{array}{c}0.773 * * * \\
(0.040)\end{array}$ & $\begin{array}{c}0.737^{* * *} \\
(0.040)\end{array}$ & & $\begin{array}{c}0.624^{* * *} \\
(0.042)\end{array}$ & $\begin{array}{c}0.643^{* * *} \\
(0.042)\end{array}$ & $\begin{array}{c}0.641 * * * \\
(0.044)\end{array}$ & $\begin{array}{c}-0.354^{* * *} \\
(0.039)\end{array}$ & $\begin{array}{c}-0.378^{* * *} \\
(0.038)\end{array}$ \\
\hline Standard Deviation 1Y Stock Return (\%) & $\begin{array}{c}-0.135 * * * \\
(0.047)\end{array}$ & $\begin{array}{l}-0.036 \\
(0.052)\end{array}$ & & $\begin{array}{l}-0.047 \\
(0.052)\end{array}$ & $\begin{array}{c}-0.03 \\
(0.053)\end{array}$ & $\begin{array}{l}-0.022 \\
(0.054)\end{array}$ & $\begin{array}{c}0.073 \\
(0.052)\end{array}$ & $\begin{array}{l}-0.021 \\
(0.046)\end{array}$ \\
\hline Probability 1Y Stock Return <-30\% & & $\begin{array}{c}-0.116 * * * \\
(0.027)\end{array}$ & $\begin{array}{c}-0.215 * * * \\
(0.025)\end{array}$ & $\begin{array}{c}-0.106^{* * *} \\
(0.028)\end{array}$ & $\begin{array}{c}-0.101 * * * \\
(0.028)\end{array}$ & $\begin{array}{c}-0.104^{* * *} \\
(0.029)\end{array}$ & $\begin{array}{c}0.012 \\
(0.026)\end{array}$ & $\begin{array}{c}0.077 * * * \\
(0.027)\end{array}$ \\
\hline Probability $1 Y$ Stock Return $\in[-30 \%,-10 \%)$ & & & $\begin{array}{c}-0.172 * * * \\
(0.016)\end{array}$ & & & & & \\
\hline Probability 1 Y Stock Return $\in[30 \%, 40 \%)$ & & & $\begin{array}{l}0.040^{* *} \\
(0.019)\end{array}$ & & & & & \\
\hline Probability 1 Y Stock Return >= $40 \%$ & & & $\begin{array}{l}0.058^{*} \\
(0.032)\end{array}$ & & & & & \\
\hline Expected 10Y Stock Return (\%) & & & & $\begin{array}{c}0.525^{* * *} \\
(0.062)\end{array}$ & $\begin{array}{c}0.559^{* * *} \\
(0.065)\end{array}$ & $\begin{array}{c}0.607 * * * \\
(0.070)\end{array}$ & $\begin{array}{c}-0.536^{* * *} \\
(0.065)\end{array}$ & $\begin{array}{c}-0.188^{* * *} \\
(0.056)\end{array}$ \\
\hline Expected $1 \mathrm{Y}$ Return of $10 \mathrm{Y}$ bond (\%) & & & & & $\begin{array}{c}-0.221^{* * *} \\
(0.074)\end{array}$ & $\begin{array}{c}-0.235^{* * *} \\
(0.077)\end{array}$ & $\begin{array}{c}0.680^{* * *} \\
(0.070)\end{array}$ & $\begin{array}{c}-0.323 * * * \\
(0.067)\end{array}$ \\
\hline Expected 3Y GDP Growth (\% p.a.) & & & & & & $\begin{array}{c}0.075 \\
(0.119)\end{array}$ & $\begin{array}{l}-0.152 \\
(0.114)\end{array}$ & $\begin{array}{c}0.006 \\
(0.104)\end{array}$ \\
\hline Expected 10Y GDP Growth (\% p.a.) & & & & & & $\begin{array}{c}0.053 \\
(0.096)\end{array}$ & $\begin{array}{c}0.149 \\
(0.091)\end{array}$ & $\begin{array}{c}-0.162^{* *} \\
(0.077)\end{array}$ \\
\hline Controls + Fixed Effects & $\mathrm{Y}$ & $\mathrm{Y}$ & $\mathrm{Y}$ & $\mathrm{Y}$ & $\mathrm{Y}$ & $\mathrm{Y}$ & $\mathrm{Y}$ & $\mathrm{Y}$ \\
\hline $\mathrm{N}$ & 44,235 & 44,235 & 45,079 & 43,402 & 42,388 & 41,029 & 41,029 & 41,029 \\
\hline
\end{tabular}

Note: Table shows summary results from tobit regression 1, where we also include other beliefs elicited by the survey. The dependent variable in columns 1 to 6 is the equity share; in column 7, it is the fixed income share, and in column 8 , it is the cash share. Standard errors are clustered at the respondent level. Significance levels: ${ }^{*}(\mathrm{p}<0.10),{ }^{* *}(\mathrm{p}<0.05)$, $* * *(\mathrm{p}<0.01)$.

Once we move away from the first and second moment of expected returns, or when we

\footnotetext{
${ }^{3}$ To construct the implied standard deviation from the distribution question, we first split each bucket into ranges of 5 percentage points. For each of these ranges, we compute the historical probability of being in that range. We then weight these probabilities by the subjective probability of each bucket reported by the respondent. We finally calculate the standard deviation based on the mid-points of the narrower ranges, and their associated subjective probabilities.
} 
consider beliefs about long-run stock returns, we lose the benchmark of a simple asset pricing model that can be used to assess the quantitative relationship between beliefs and portfolios. We therefore view the estimates presented in the rest of this section as guidance for future asset pricing theories wanting to focus on the relevant moments of the belief distribution.

In column 2 of Table A.5, we control for the probability that individuals assign to a stock market decline of more than $30 \%$. As discussed in Section VI, the probability of these rare disasters plays a prominent role in many macro-finance theories of portfolio formation and, in general equilibrium, of asset returns. Indeed, we find that a higher subjective probability of a rare disaster is associated with declines in the equity portfolio share. A one-standard-deviation increase in the perceived stock market disaster probability is associated with about a one percentage point lower equity share. In addition, after including controls for the perceived disaster probability, differences in the perceived standard deviation of expected returns is no longer associated with significant differences in equity shares.

In column 3, we separately include the probabilities that individuals assign to each of the five buckets of possible realizations of equity returns. Since these probabilities add up to $100 \%$, we drop the middle bucket. Shifting subjective probability mass from the middle bucket to the low-outcome buckets is associated with substantial declines in the equity share, while shifts to high-outcome buckets lead to much smaller increases in the equity share. This is consistent with concavity in the utility function, so that moving mass to negative states in which marginal utility is high has disproportionately large effects on portfolio choice. It is also reminiscent of models of loss aversion and downside-risk in which agents are disproportionally worried about returns below a certain cutoff point.

In column 4, we include an individual's beliefs about the annualized stock return over the coming ten years in addition to the beliefs about the expected stock returns over the coming year. Short-horizon and long-horizon stock-market return expectations are positively correlated (see the discussion of Fact 4 in Section V), but long-run expectations matter for portfolio allocation even after controlling for short-run expectations. Interestingly, the magnitudes of the effects are similar for long-run and short-run expectations. These results suggest that individuals choose their portfolio for the long-run, particularly since they do not adjust it frequently, and do not behave myopically by only focusing on their short-run expectations. ${ }^{4}$

In column 5, we also include controls for a respondent's beliefs about the 1-year return of a 10-year risk-free bond. Holding fixed beliefs about equity returns, increased optimism about bond returns is associated with a lower equity share. Finally, column 6 also includes controls for GDP growth expectations, but these do not have an effect on portfolio shares over and above the stock market and bond market expectations. This is consistent with the vast majority of models in which expectations of cash flows contribute to the level of asset prices, but only expectations about returns influence portfolio choice.

Overall, the findings in this section suggest that the relationship between beliefs and portfolio allocations is more complex than suggested by the simple Merton (1969) model. First, the subjec-

\footnotetext{
${ }^{4}$ A large literature has studied the investment problem of a long-run investor; see for example Merton (1975); Barberis (2000); Brennan, Schwartz and Lagnado (1997); Campbell and Viceira (1999, 2001); Campbell et al. (2002).
} 
tive risk of large stock market declines has larger effects on portfolio allocations than the subjective variance. Second, long-run stock market beliefs matter in addition to short-run beliefs. Third, beliefs about other investments, including fixed income investments, also influence the optimal equity share. We hope that these findings can help guide the development of future macro-finance models that explore the relationship between beliefs, portfolios, and ultimately asset prices.

Substitution Patterns. The previous discussion explored the relationship between various beliefs (about stock returns, bond returns, and GDP growth) and the equity share in investors' portfolios. In columns 7 and 8 of Table A.5, we instead use the fixed income share and the cash share as the dependent variables, allowing us to explore the substitution between stocks, bonds, and cash. About half of the increase in equity shares of individuals who expect higher stock market returns comes from individuals substituting away from cash rather than individuals substituting away from fixed income securities. This is despite the fact that the average fixed income share is substantially larger than the average cash share. Similarly, we find that increases in expected bond returns are associated with increases in the fixed income share, with much of the adjustment coming from reductions in the cash share instead of the equity share. The sensitivity of the bond portfolio shares to bond expected returns is even lower than the corresponding one for equities. Indeed, a back-of-the-envelope calculation is again very illustrative. We can apply the Merton (1969) formula in equation 2 by replacing equities with bonds and using the historical standard deviation of long-term Treasury-bond returns of around $5 \%$. The estimate of $\beta=0.680$ from column 7 of Table A.5 implies a coefficient of relative risk aversion above 500. We conclude that fixed income offers a similar picture as equities: portfolios co-move with beliefs, but substantially less so than implied by frictionless benchmark models. 


\section{A.7 TRAding: DATA AND Further RESUlts}

In this Appendix, we provide more details on the data construction for our trading analysis, as well as some additional results from our analysis of investor trading behavior. For investors with retail accounts (which are $80 \%$ of the investors we contacted), we observe transaction-level data since January 2011.

For each trade by an investor in our sample, we observe the day of the trade, the amount traded, and the CUSIP and/or ticker of the traded security. We also observe the asset class composition of each security (individual security or fund) as the percentage invested in equity, fixed income, cash, other, and unknown (we group other and unknown together). The classification is provided to us directly by Vanguard. For individual securities, the classification is relatively obvious: equity securities are classified as $100 \%$ equity, bonds as $100 \%$ fixed income. For mutual funds and ETFs, Vanguard relies on both internal data (for Vanguard operated funds) and external data (from Morningstar) to apportion the investment of the funds into the various asset classes. Our data also contains a code that describes the type of transaction: whether it is a purchase of an asset with cash, a sale, an exchange of two different stocks, a purchase with cash from outside Vanguard, and so on. We use this information to compute, for each trade, how the portfolio allocation into equity, fixed income, cash, and other investments (as well as outside money) changes as a result of the trade. We do so by combining the information about the type of trade, the dollar amount of the trade, and the allocation of the asset traded into asset classes.

We divide our sample period into two-week "intervals" (for each month, from the 1st to the 15th of the month, and from the 16th to the end of the month). We chose these two-week increments because our survey is administered around the 15th of the month. Each trade is then assigned to the corresponding interval, and all trades are aggregated by interval. This procedure yields, for each interval, the total increase and decrease for equity, fixed income, cash, and other and unknown in the portfolio as a result of an active trade during the interval. We also obtain the total inflow/outflow of money from Vanguard and the total volume of trade during the interval.

We then merge this transaction data with the portfolio data, which provides snapshots of the portfolios held at the end of each month. We can then compute the change during the interval in the fraction of the portfolio allocated to equity, fixed income, cash, and other due to trading. For intervals starting on the 16th of the month (for which we do not observe the snapshot of the market value of the portfolio at that point in time), we use instead the imputed value of the portfolio combining the beginning-of-month portfolio value and the change in value due to trading during the first two weeks. The analysis in the main body of the paper focuses on "windows" between any two consecutive surveys answered by each individual. For example, an individual might have answered waves 1 and 3 of the survey, so that a four-month window has passed between the two answers. For the analysis in the paper, we aggregate all the 15-day intervals over those four months to focus on trading that occurred during the window.

Table A.6 is the same as Table V in the paper, but additionally reports the coefficients on the control variables. Younger, wealthier, and male respondents are all more likely to trade in any given period. There does not seem to be substantial variation in trading propensity across regions. 
Table A.6: Trading Analysis

\begin{tabular}{|c|c|c|c|c|c|}
\hline & $\Delta$ Equity Share $(\%)$ & Probability Trade & Probability Trade & Probability Buy & $\Delta$ Equity Share (\%) \\
\hline & (1) & (2) & (3) & (4) & (5) \\
\hline$\Delta$ Expected 1Y Stock Return (\%) & $\begin{array}{c}0.229 * * * \\
(0.033)\end{array}$ & & & $\begin{array}{c}0.977^{* * *} \\
(0.201)\end{array}$ & $\begin{array}{c}0.587 * * * \\
(0.085)\end{array}$ \\
\hline Expected 1Y Stock Return (\%) & $\begin{array}{c}0.130 * * * \\
(0.019)\end{array}$ & & $\begin{array}{l}0.006 \\
(0.130)\end{array}$ & $\begin{array}{c}1.489^{* * *} \\
(0.199)\end{array}$ & $\begin{array}{c}0.395 * * * \\
(0.062)\end{array}$ \\
\hline Lagged Equity Share (\%) & $\begin{array}{c}-0.048^{* * *} \\
(0.004)\end{array}$ & & $\begin{array}{c}-0.121^{* * *} \\
(0.021)\end{array}$ & $\begin{array}{c}-0.337^{* * *} \\
(0.031)\end{array}$ & $\begin{array}{c}-0.161^{* * *} \\
(0.011)\end{array}$ \\
\hline $\mid \Delta$ Expected $1 Y$ Stock Return (\%) | & & & $\begin{array}{c}0.258 \\
(0.223)\end{array}$ & & \\
\hline Male & $\begin{array}{l}-0.179 \\
(0.126)\end{array}$ & & $\begin{array}{c}5.919 * * * \\
(0.878)\end{array}$ & $\begin{array}{l}-2.805^{*} \\
(1.563)\end{array}$ & $\begin{array}{l}-0.64 \\
(0.472)\end{array}$ \\
\hline Age $\in(40,50]$ & $\begin{array}{l}-0.633^{*} \\
(0.350)\end{array}$ & & $\begin{array}{l}-3.212 \\
(1.983)\end{array}$ & $\begin{array}{c}-7.593 * * \\
(3.254)\end{array}$ & $\begin{array}{c}-2.746^{* * *} \\
(1.057)\end{array}$ \\
\hline Age $\in(50,60]$ & $\begin{array}{c}-1.426 * * * \\
(0.303)\end{array}$ & & $\begin{array}{c}-3.939 * * \\
(1.771)\end{array}$ & $\begin{array}{c}-12.112 * * * \\
(2.882)\end{array}$ & $\begin{array}{c}-4.287^{* * *} \\
(0.910)\end{array}$ \\
\hline Age $\in(60,70]$ & $\begin{array}{c}-1.430^{* * *} \\
(0.290)\end{array}$ & & $\begin{array}{c}-6.197^{* * *} \\
(1.704)\end{array}$ & $\begin{array}{c}-14.143 * * * \\
(2.817)\end{array}$ & $\begin{array}{c}-4.766^{* * *} \\
(0.862)\end{array}$ \\
\hline Age $>70$ & $\begin{array}{c}-1.407^{* * *} \\
(0.292)\end{array}$ & & $\begin{array}{c}-7.382^{* * *} \\
(1.750)\end{array}$ & $\begin{array}{c}-15.839 * * * \\
(2.922)\end{array}$ & $\begin{array}{c}-4.917 * * * \\
(0.884)\end{array}$ \\
\hline Region North & $\begin{array}{c}0.038 \\
(0.152)\end{array}$ & & $\begin{array}{l}-0.436 \\
(1.167)\end{array}$ & $\begin{array}{c}0.894 \\
(1.956)\end{array}$ & $\begin{array}{l}-0.068 \\
(0.530)\end{array}$ \\
\hline Region South & $\begin{array}{l}-0.028 \\
(0.152)\end{array}$ & & $\begin{array}{c}1.699 \\
(1.121)\end{array}$ & $\begin{array}{c}0.49 \\
(1.861)\end{array}$ & $\begin{array}{l}-0.165 \\
(0.513)\end{array}$ \\
\hline Region West & $\begin{array}{l}0.102 \\
(0.150)\end{array}$ & & $\begin{array}{c}1.53 \\
(1.150)\end{array}$ & $\begin{array}{l}-0.897 \\
(1.875)\end{array}$ & $\begin{array}{c}0.133 \\
(0.503)\end{array}$ \\
\hline Wealth Quintile 2 & $\begin{array}{c}0.24 \\
(0.213)\end{array}$ & & $\begin{array}{c}2.589 * * \\
(1.154)\end{array}$ & $\begin{array}{l}-3.359 \\
(2.615)\end{array}$ & $\begin{array}{c}0.241 \\
(0.924)\end{array}$ \\
\hline Wealth Quintile 3 & $\begin{array}{l}-0.287 \\
(0.199)\end{array}$ & & $\begin{array}{c}7.716^{* * *} \\
(1.250)\end{array}$ & $\begin{array}{c}-6.638^{* * *} \\
(2.466)\end{array}$ & $\begin{array}{l}-0.668 \\
(0.827)\end{array}$ \\
\hline Wealth Quintile 4 & $\begin{array}{l}-0.316 \\
(0.203)\end{array}$ & & $\begin{array}{c}11.403^{* * *} \\
(1.289)\end{array}$ & $\begin{array}{c}-8.354^{* * *} \\
(2.473)\end{array}$ & $\begin{array}{l}-0.656 \\
(0.823)\end{array}$ \\
\hline Wealth Quintile 5 & $\begin{array}{l}-0.014 \\
(0.194)\end{array}$ & & $\begin{array}{c}12.365^{* * *} \\
(1.269)\end{array}$ & $\begin{array}{c}-5.513^{* *} \\
(2.475)\end{array}$ & $\begin{array}{c}0.268 \\
(0.801)\end{array}$ \\
\hline Lagged Equity Share $=0 \%$ & $\begin{array}{l}-0.038 \\
(0.524)\end{array}$ & $\begin{array}{c}-27.066^{* * *} \\
(1.495)\end{array}$ & $\begin{array}{c}-30.192^{* * *} \\
(1.790)\end{array}$ & $\begin{array}{c}35.353^{* * *} \\
(2.903)\end{array}$ & $\begin{array}{c}27.567^{* * *} \\
(4.011)\end{array}$ \\
\hline Lagged Equity Share $=100 \%$ & $\begin{array}{c}0.837 * * * \\
(0.242)\end{array}$ & $\begin{array}{c}-28.395^{* * *} \\
(0.884)\end{array}$ & $\begin{array}{c}-20.188^{* * *} \\
(1.029)\end{array}$ & $\begin{array}{c}-22.514^{* * *} \\
(3.255)\end{array}$ & $\begin{array}{c}-12.155^{* * *} \\
(2.383)\end{array}$ \\
\hline Wave Dummies & Y & Y & Y & Y & Y \\
\hline Specification & & & & $\begin{array}{l}\text { Conditional on } \\
\text { Trading }\end{array}$ & $\begin{array}{l}\text { Conditional on } \\
\text { Trading }\end{array}$ \\
\hline R-Squared & 0.031 & 0.364 & 0.38 & 0.483 & 0.154 \\
\hline $\mathrm{N}$ & 22,439 & 23,441 & 22,439 & 6,606 & 6,606 \\
\hline
\end{tabular}

Note: This table is the same as Table V, but shows all coefficient estimates, instead of only focusing on the coefficient estimates for the main variables of interest. 


\section{A.8 Beliefs AND DEMOGRAPHICS}

In Section IV, we documented that individual fixed effects are the most important component for explaining the panel variation in beliefs: optimists are persistently optimistic, and pessimists are persistently pessimistic. We also highlighted that demographic characteristics struggle to explain which individuals are optimistic and which ones are pessimistic. To show this fact, the main body of the paper focused on documenting the relatively low $R^{2}$ s from regressions of the individual fixed effects on demographic characteristics.

Table A.7 shows the coefficients on the control variables from these regressions. Despite the low $R^{2}$ s, a number of systematic patterns emerge. First, in our sample, older individuals are somewhat more optimistic about expected stock returns and about 3-year GDP growth; their subjective distribution over future stock returns also has a lower standard deviation, and they assign smaller probabilities to extreme events such as large stock market declines. There is no large difference between men and women in terms of their stock market expectations, but men expect both GDP growth and bond returns to be lower.

We also find that wealthier individuals are substantially more pessimistic across most of their beliefs. Individuals who log into their Vanguard accounts more frequently are somewhat more optimistic about stock returns. Across Census regions, there is some evidence that residents from the Western region are somewhat more pessimistic, both in terms of expected stock returns and expected GDP growth. Individuals from the Western region also assign larger probabilities to extreme negative realizations of stock market returns and GDP growth.

We also find that individuals who have experienced higher equity returns since 2011 are more optimistic about future stock market returns (and perceive a lower probability of a stock market disaster), while respondents who experienced a higher return on their fixed income assets perceive higher future bond returns. ${ }^{5}$ These results mirror findings from a large literature that has documented how individuals extrapolate from their own experience when forecasting future economic outcomes. Prominent contributions to that literature include Amromin and Sharpe (2009), Greenwood and Shleifer (2014), Malmendier and Nagel (2011), Malmendier and Nagel (2016), Malmendier, Nagel and Yan (2017), and Kuchler and Zafar (2015). ${ }^{6}$

\footnotetext{
${ }^{5}$ We measure these past returns as the geometric average of the monthly equity returns in the portfolios of those individuals between January 2011 and January 2017, expressed in percentage points. For individuals for whom we do not observe such a long portfolio history, we replace this value with "999", while adding a dummy variable that captures these observations. See Dickens and Katz (1987) and Giglio, Maggiori and Stroebel (2015) for a description of this procedure and a discussion of different approaches to dealing with missing characteristics.

${ }^{6}$ Note that the time-series of average beliefs presented in Appendix A.3 also provides suggestive evidence for extrapolative behavior in the belief formation of the average individual: for example, the biggest drop in expected returns occurred in the December 2018 wave, just following a substantial decline in U.S. stock markets. However, given the short time-series of our survey, we do not focus on these patterns.
} 


\section{Table A.7: Beliefs by Demographics}

\begin{tabular}{|c|c|c|c|c|c|c|c|c|c|}
\hline & (1) & (2) & (3) & (4) & (5) & (6) & (7) & (8) & (9) \\
\hline & $\begin{array}{l}\text { Expected 1-Year } \\
\text { Stock Returns }\end{array}$ & $\begin{array}{c}\text { Expected 10- } \\
\text { Year } \\
\text { Stock Returns } \\
\end{array}$ & $\begin{array}{c}\text { Probability } \\
1 \text {-Year Stock } \\
\text { Returns }<-30 \% \\
\end{array}$ & $\begin{array}{l}\text { St. D. Expected } \\
1 \text {-Year } \\
\text { Stock Returns } \\
\end{array}$ & $\begin{array}{l}\text { Expected 3-Year } \\
\text { GDP Growth }\end{array}$ & $\begin{array}{l}\text { Expected 10- } \\
\text { Year } \\
\text { GDP Growth }\end{array}$ & $\begin{array}{c}\text { Probability } \\
\text { 3-Year GDP } \\
\text { Growth }<-3 \% \\
\end{array}$ & $\begin{array}{c}\text { St. D. Expected } \\
\text { 3-Year } \\
\text { GDP Growth } \\
\end{array}$ & $\begin{array}{c}\text { Expected 1-Year } \\
\text { Bond Returns }\end{array}$ \\
\hline Male & $\begin{array}{c}0.025 \\
(0.151)\end{array}$ & $\begin{array}{c}0.016 \\
(0.086)\end{array}$ & $\begin{array}{c}0.548 \\
(0.450)\end{array}$ & $\begin{array}{c}0.564^{* * *} \\
(0.114)\end{array}$ & $\begin{array}{c}-0.154^{* * *} \\
(0.048)\end{array}$ & $\begin{array}{c}-0.370^{* * *} \\
(0.059)\end{array}$ & $\begin{array}{c}0.121 \\
(0.405)\end{array}$ & $\begin{array}{c}0.042 \\
(0.028)\end{array}$ & $\begin{array}{l}-0.115^{*} \\
(0.067)\end{array}$ \\
\hline Age $\in(40,50]$ & $\begin{array}{l}-0.491 \\
(0.345)\end{array}$ & $\begin{array}{c}0.034 \\
(0.196)\end{array}$ & $\begin{array}{c}0.088 \\
(1.027)\end{array}$ & $\begin{array}{l}-0.295 \\
(0.260)\end{array}$ & $\begin{array}{l}-0.005 \\
(0.109)\end{array}$ & $\begin{array}{l}-0.094 \\
(0.134)\end{array}$ & $\begin{array}{c}-0.63 \\
(0.925)\end{array}$ & $\begin{array}{l}-0.116^{*} \\
(0.064)\end{array}$ & $\begin{array}{c}0.017 \\
(0.153)\end{array}$ \\
\hline Age $\in(50,60]$ & $\begin{array}{l}0.714^{* *} \\
(0.302)\end{array}$ & $\begin{array}{c}0.133 \\
(0.171)\end{array}$ & $\begin{array}{c}-2.753^{* * *} \\
(0.898)\end{array}$ & $\begin{array}{c}-0.786^{* * *} \\
(0.228)\end{array}$ & $\begin{array}{c}0.249 * * * \\
(0.096)\end{array}$ & $\begin{array}{c}0.084 \\
(0.117)\end{array}$ & $\begin{array}{c}-4.218^{* * *} \\
(0.809)\end{array}$ & $\begin{array}{c}-0.172^{* * *} \\
(0.056)\end{array}$ & $\begin{array}{c}0.029 \\
(0.134)\end{array}$ \\
\hline Age $\in(60,70]$ & $\begin{array}{c}0.735^{* *} \\
(0.287)\end{array}$ & $\begin{array}{c}-0.12 \\
(0.163)\end{array}$ & $\begin{array}{c}-3.936^{* * *} \\
(0.856)\end{array}$ & $\begin{array}{c}-1.328^{* * *} \\
(0.217)\end{array}$ & $\begin{array}{c}0.333^{* * *} \\
(0.091)\end{array}$ & $\begin{array}{c}0.14 \\
(0.111)\end{array}$ & $\begin{array}{c}-6.171^{* * *} \\
(0.771)\end{array}$ & $\begin{array}{c}-0.267^{* * *} \\
(0.054)\end{array}$ & $\begin{array}{c}0.001 \\
(0.128)\end{array}$ \\
\hline Age $>70$ & $\begin{array}{c}0.987 * * * \\
(0.295)\end{array}$ & $\begin{array}{c}0.097 \\
(0.168)\end{array}$ & $\begin{array}{c}-6.221^{* * *} \\
(0.880)\end{array}$ & $\begin{array}{c}-1.843^{* * *} \\
(0.223)\end{array}$ & $\begin{array}{c}0.537 * * * \\
(0.094)\end{array}$ & $\begin{array}{c}0.382^{* * *} \\
(0.114)\end{array}$ & $\begin{array}{c}-7.742^{* * *} \\
(0.793)\end{array}$ & $\begin{array}{c}-0.285^{* * *} \\
(0.055)\end{array}$ & $\begin{array}{c}0.131 \\
(0.132)\end{array}$ \\
\hline Region North & $\begin{array}{l}-0.149 \\
(0.189)\end{array}$ & $\begin{array}{l}0.181^{*} \\
(0.107)\end{array}$ & $\begin{array}{c}0.273 \\
(0.563)\end{array}$ & $\begin{array}{l}-0.146 \\
(0.143)\end{array}$ & $\begin{array}{c}0.012 \\
(0.060)\end{array}$ & $\begin{array}{c}0.057 \\
(0.073)\end{array}$ & $\begin{array}{l}-0.272 \\
(0.507)\end{array}$ & $\begin{array}{c}-0.084^{* *} \\
(0.035)\end{array}$ & $\begin{array}{l}-0.027 \\
(0.084)\end{array}$ \\
\hline Region South & $\begin{array}{c}0.164 \\
(0.179)\end{array}$ & $\begin{array}{l}0.215^{* *} \\
(0.102)\end{array}$ & $\begin{array}{l}-0.012 \\
(0.533)\end{array}$ & $\begin{array}{l}-0.125 \\
(0.135)\end{array}$ & $\begin{array}{c}0.07 \\
(0.057)\end{array}$ & $\begin{array}{l}0.124^{*} \\
(0.069)\end{array}$ & $\begin{array}{l}-0.068 \\
(0.480)\end{array}$ & $\begin{array}{l}-0.021 \\
(0.033)\end{array}$ & $\begin{array}{c}0.057 \\
(0.080)\end{array}$ \\
\hline Region West & $\begin{array}{c}-0.738^{* * *} \\
(0.185)\end{array}$ & $\begin{array}{l}-0.067 \\
(0.105)\end{array}$ & $\begin{array}{c}1.981^{* * *} \\
(0.553)\end{array}$ & $\begin{array}{c}0.105 \\
(0.140)\end{array}$ & $\begin{array}{c}-0.188 * * * \\
(0.059)\end{array}$ & $\begin{array}{l}-0.038 \\
(0.072)\end{array}$ & $\begin{array}{c}1.950 * * * \\
(0.498)\end{array}$ & $\begin{array}{c}-0.05 \\
(0.035)\end{array}$ & $\begin{array}{l}-0.006 \\
(0.083)\end{array}$ \\
\hline Wealth Quintile 2 & $\begin{array}{l}-0.256 \\
(0.204)\end{array}$ & $\begin{array}{c}-0.262^{* *} \\
(0.116)\end{array}$ & $\begin{array}{c}0.649 \\
(0.607)\end{array}$ & $\begin{array}{c}0.079 \\
(0.154)\end{array}$ & $\begin{array}{c}-0.203^{* * *} \\
(0.065)\end{array}$ & $\begin{array}{c}-0.255^{* * *} \\
(0.079)\end{array}$ & $\begin{array}{c}0.009 \\
(0.547)\end{array}$ & $\begin{array}{l}-0.051 \\
(0.038)\end{array}$ & $\begin{array}{l}-0.101 \\
(0.091)\end{array}$ \\
\hline Wealth Quintile 3 & $\begin{array}{l}-0.234 \\
(0.210)\end{array}$ & $\begin{array}{l}-0.200^{*} \\
(0.119)\end{array}$ & $\begin{array}{c}0.128 \\
(0.625)\end{array}$ & $\begin{array}{l}-0.072 \\
(0.158)\end{array}$ & $\begin{array}{c}-0.183^{* * *} \\
(0.066)\end{array}$ & $\begin{array}{c}-0.212 * * * \\
(0.081)\end{array}$ & $\begin{array}{c}0.201 \\
(0.563)\end{array}$ & $\begin{array}{l}-0.045 \\
(0.039)\end{array}$ & $\begin{array}{l}-0.151 \\
(0.093)\end{array}$ \\
\hline Wealth Quintile 4 & $\begin{array}{c}-0.469 * * \\
(0.218)\end{array}$ & $\begin{array}{c}-0.400 * * * \\
(0.124)\end{array}$ & $\begin{array}{l}-0.004 \\
(0.649)\end{array}$ & $\begin{array}{l}-0.131 \\
(0.164)\end{array}$ & $\begin{array}{c}-0.239 * * * \\
(0.069)\end{array}$ & $\begin{array}{c}-0.288^{* * *} \\
(0.084)\end{array}$ & $\begin{array}{c}0.103 \\
(0.584)\end{array}$ & $\begin{array}{l}-0.066 \\
(0.041)\end{array}$ & $\begin{array}{c}-0.278^{* * *} \\
(0.097)\end{array}$ \\
\hline Wealth Quintile 5 & $\begin{array}{c}-0.878^{* * *} \\
(0.227)\end{array}$ & $\begin{array}{c}-0.490 * * * \\
(0.129)\end{array}$ & $\begin{array}{l}1.292^{*} \\
(0.677)\end{array}$ & $\begin{array}{c}0.042 \\
(0.171)\end{array}$ & $\begin{array}{c}-0.350 * * * \\
(0.072)\end{array}$ & $\begin{array}{c}-0.450 * * * \\
(0.088)\end{array}$ & $\begin{array}{c}0.262 \\
(0.609)\end{array}$ & $\begin{array}{c}-0.101^{* *} \\
(0.042)\end{array}$ & $\begin{array}{c}-0.612^{* * *} \\
(0.101)\end{array}$ \\
\hline Days With Visits Quintile 2 & $\begin{array}{l}-0.176 \\
(0.201)\end{array}$ & $\begin{array}{l}-0.099 \\
(0.114)\end{array}$ & $\begin{array}{c}0.29 \\
(0.600)\end{array}$ & $\begin{array}{c}0.006 \\
(0.152)\end{array}$ & $\begin{array}{l}-0.106^{*} \\
(0.064)\end{array}$ & $\begin{array}{l}-0.104 \\
(0.078)\end{array}$ & $\begin{array}{l}-0.118 \\
(0.540)\end{array}$ & $\begin{array}{l}-0.005 \\
(0.038)\end{array}$ & $\begin{array}{c}-0.211^{* *} \\
(0.090)\end{array}$ \\
\hline Days With Visits Quintile 3 & $\begin{array}{l}0.349^{*} \\
(0.205)\end{array}$ & $\begin{array}{c}0.105 \\
(0.116)\end{array}$ & $\begin{array}{l}-0.918 \\
(0.610)\end{array}$ & $\begin{array}{l}-0.185 \\
(0.155)\end{array}$ & $\begin{array}{l}-0.082 \\
(0.065)\end{array}$ & $\begin{array}{l}-0.140^{*} \\
(0.079)\end{array}$ & $\begin{array}{c}-1.101^{* *} \\
(0.550)\end{array}$ & $\begin{array}{l}-0.061 \\
(0.038)\end{array}$ & $\begin{array}{c}-0.191^{* *} \\
(0.091)\end{array}$ \\
\hline Days With Visits Quintile 4 & $\begin{array}{c}0.481^{* *} \\
(0.210)\end{array}$ & $\begin{array}{c}0.064 \\
(0.119)\end{array}$ & $\begin{array}{l}-0.027 \\
(0.626)\end{array}$ & $\begin{array}{c}0.04 \\
(0.159)\end{array}$ & $\begin{array}{l}-0.128^{*} \\
(0.067)\end{array}$ & $\begin{array}{c}-0.280^{* * *} \\
(0.081)\end{array}$ & $\begin{array}{l}-1.088^{*} \\
(0.564)\end{array}$ & $\begin{array}{l}-0.058 \\
(0.039)\end{array}$ & $\begin{array}{l}-0.172^{*} \\
(0.094)\end{array}$ \\
\hline Days With Visits Quintile 5 & $\begin{array}{c}1.041^{* * *} \\
(0.213)\end{array}$ & $\begin{array}{c}0.262^{* *} \\
(0.121)\end{array}$ & $\begin{array}{l}-0.601 \\
(0.636)\end{array}$ & $\begin{array}{c}0.042 \\
(0.161)\end{array}$ & $\begin{array}{c}0.007 \\
(0.068)\end{array}$ & $\begin{array}{l}-0.095 \\
(0.083)\end{array}$ & $\begin{array}{c}-1.291^{* *} \\
(0.573)\end{array}$ & $\begin{array}{l}-0.053 \\
(0.040)\end{array}$ & $\begin{array}{l}-0.056 \\
(0.095)\end{array}$ \\
\hline Confidence 1 & $\begin{array}{c}0.113 \\
(0.527)\end{array}$ & $\begin{array}{c}0.399 \\
(0.299)\end{array}$ & $\begin{array}{c}-0.801 \\
(1.571)\end{array}$ & $\begin{array}{c}-0.002 \\
(0.398)\end{array}$ & $\begin{array}{c}0.247 \\
(0.167)\end{array}$ & $\begin{array}{c}0.095 \\
(0.204)\end{array}$ & $\begin{array}{l}-1.416 \\
(1.415)\end{array}$ & $\begin{array}{l}-0.043 \\
(0.098)\end{array}$ & $\begin{array}{c}0.093 \\
(0.235)\end{array}$ \\
\hline Confidence 2 & $\begin{array}{l}1.006 * * \\
(0.509)\end{array}$ & $\begin{array}{c}0.874 * * * \\
(0.289)\end{array}$ & $\begin{array}{c}-4.294^{* * *} \\
(1.517)\end{array}$ & $\begin{array}{c}-1.300 * * * \\
(0.384)\end{array}$ & $\begin{array}{c}0.337^{* *} \\
(0.161)\end{array}$ & $\begin{array}{c}0.103 \\
(0.197)\end{array}$ & $\begin{array}{c}-4.886 * * * \\
(1.366)\end{array}$ & $\begin{array}{c}-0.212^{* *} \\
(0.095)\end{array}$ & $\begin{array}{c}0.124 \\
(0.227)\end{array}$ \\
\hline Confidence 3 & $\begin{array}{c}2.304^{* * *} \\
(0.519)\end{array}$ & $\begin{array}{c}1.526 * * * \\
(0.295)\end{array}$ & $\begin{array}{c}-8.535^{* * *} \\
(1.549)\end{array}$ & $\begin{array}{c}-2.798^{* * *} \\
(0.392)\end{array}$ & $\begin{array}{c}0.492^{* * *} \\
(0.165)\end{array}$ & $\begin{array}{c}0.212 \\
(0.201)\end{array}$ & $\begin{array}{c}-9.060 * * * \\
(1.395)\end{array}$ & $\begin{array}{c}-0.490 * * * \\
(0.097)\end{array}$ & $\begin{array}{c}0.259 \\
(0.231)\end{array}$ \\
\hline Confidence 4 & $\begin{array}{c}2.098^{* * *} \\
(0.649)\end{array}$ & $\begin{array}{c}1.239 * * * \\
(0.368)\end{array}$ & $\begin{array}{c}-9.061^{* * *} \\
(1.931)\end{array}$ & $\begin{array}{c}-4.818^{* * *} \\
(0.489)\end{array}$ & $\begin{array}{c}0.472^{* *} \\
(0.205)\end{array}$ & $\begin{array}{c}0.11 \\
(0.251)\end{array}$ & $\begin{array}{c}-9.563^{* * *} \\
(1.736)\end{array}$ & $\begin{array}{c}-0.811^{* * *} \\
(0.121)\end{array}$ & $\begin{array}{c}0.08 \\
(0.289)\end{array}$ \\
\hline Equity return since 2011 & $\begin{array}{c}0.062^{* * *} \\
(0.020)\end{array}$ & $\begin{array}{c}0.027^{* *} \\
(0.011)\end{array}$ & $\begin{array}{c}-0.227^{* * *} \\
(0.060)\end{array}$ & $\begin{array}{l}-0.024 \\
(0.015)\end{array}$ & $\begin{array}{c}0.008 \\
(0.006)\end{array}$ & $\begin{array}{c}0.011 \\
(0.008)\end{array}$ & $\begin{array}{c}-0.143^{* * *} \\
(0.054)\end{array}$ & $\begin{array}{l}-0.002 \\
(0.004)\end{array}$ & $\begin{array}{l}0.016^{*} \\
(0.009)\end{array}$ \\
\hline Fixed income return since 2011 & $\begin{array}{c}0.011 \\
(0.033)\end{array}$ & $\begin{array}{c}0.006 \\
(0.019)\end{array}$ & $\begin{array}{c}0.003 \\
(0.099)\end{array}$ & $\begin{array}{c}0.007 \\
(0.025)\end{array}$ & $\begin{array}{c}0.008 \\
(0.010)\end{array}$ & $\begin{array}{c}0.004 \\
(0.013)\end{array}$ & $\begin{array}{c}0.12 \\
(0.089)\end{array}$ & $\begin{array}{c}0.007 \\
(0.006)\end{array}$ & $\begin{array}{c}0.034^{* *} \\
(0.015)\end{array}$ \\
\hline R-Squared & 0.053 & 0.044 & 0.063 & 0.108 & 0.035 & 0.038 & 0.085 & 0.053 & 0.03 \\
\hline $\mathrm{N}$ & 4,964 & 4,962 & 4,964 & 4,964 & 4,963 & 4,962 & 4,965 & 4,965 & 4,957 \\
\hline
\end{tabular}

Note: Table shows coefficients of regressions of respondent fixed effects for answers to the various survey questions on demographic controls. We include fixed effects for all individuals for whom we observe at least three responses. Standard errors are clustered at the respondent level. Significance levels: ${ }^{*}(\mathrm{p}<0.10),{ }^{* *}(\mathrm{p}<0.05),{ }^{* * *}(\mathrm{p}<0.01)$. 


\section{A.9 VARIANCE DECOMPOSITION OF BELIEFS - RAND SURVEY}

In this Appendix, we repeat the variance decomposition of beliefs from Section IV using the RAND survey. The RAND survey covers a smaller cross-section (4,734 individuals) but a longer time series than the GMSU-Vanguard survey, with 1,032 individuals responding at least 50 times.

Table A.8: Decomposing Variation in Beliefs: Individual and Time Fixed Effects (RAND)

\begin{tabular}{lcccc}
\hline & \multicolumn{4}{c}{$\mathrm{R}^{2}(\%)$} \\
\cline { 2 - 5 } & $\operatorname{Reg}(4)$ & $\operatorname{Reg}(5)$ & $\operatorname{Reg}(6)$ & $\mathrm{N}$ \\
\cline { 2 - 5 } Prob. Ret $>0 \%(1 \mathrm{yr})$ & 0.5 & 56.8 & 57.4 & 3,475 \\
Prob. $\operatorname{Ret}>$ 20\% (1yr) & 1.4 & 47.1 & 48.2 & 3,358 \\
Prob. Ret <-20\% (1yr) & 0.5 & 45.9 & 46.4 & 3,442 \\
Prob. Ret > 0\% (10yr, cumul.) & 1.5 & 67.4 & 68.4 & 3,475 \\
Prob. Ret > 20\% (10yr, cumul.) & 3.8 & 53.3 & 56.1 & 3,052 \\
Prob. Ret <-20\% (10yr, cumul.) & 0.4 & 49.3 & 49.5 & 2,996 \\
\hline
\end{tabular}

Note: Table shows $R^{2}$ s corresponding to the three regressions 4,5 , and 6 , using the RAND survey. Each row corresponds to a different question in the survey.

In Table A.8, we repeat the analysis from Table VI in the main body, and report the share of total variance that is explained by time fixed effects, individual fixed effects, and both. We require that individuals have responded at least three times, consistent with Table VI that uses the GMSUVanguard survey. We perform the analysis using six different questions asked in the RAND survey: the probability that the 1 -year return is above $0 \%$, above $20 \%$, or below $-20 \%$, and the probability that the cumulative 10 -year return is above $0 \%$, above $20 \%$, or below $-20 \%$. Table A. 9 repeats the robustness exercise from Table VII, and increases the number of responses required to be included in the analysis from 3 to 50. Both tables show results qualitatively and quantitatively similar to the ones in the GMSU-Vanguard survey. In particular, the individual fixed effects explain about $45-70 \%$ of the total variation, while the time fixed effects explain only $1-4 \%$.

Table A.9: Decomposing Variation in Beliefs: Robustness (RAND)

\begin{tabular}{|c|c|c|c|c|c|c|c|}
\hline Panel A: $\mathbf{R}^{2}$ (total, \%) & \#Resp $\geq 3$ & \#Resp $\geq 4$ & \#Resp $\geq 5$ & \#Resp $\geq 6$ & \#Resp $\geq 10$ & \#Resp $\geq 30$ & \#Resp $\geq 50$ \\
\hline Prob. Ret $>0 \%$ (1yr) & 56.8 & 56.8 & 56.8 & 56.8 & 56.9 & 57.9 & 58.1 \\
\hline Prob. Ret $>20 \%$ (1yr) & 47.1 & 47.0 & 46.9 & 46.8 & 46.8 & 46.6 & 47.0 \\
\hline Prob. Ret $<-20 \%(1 \mathrm{yr})$ & 45.9 & 45.9 & 45.8 & 45.8 & 45.9 & 45.5 & 49.1 \\
\hline Prob. Ret $>0 \%$ (10yr, cumul.) & 67.4 & 67.4 & 67.4 & 67.4 & 67.6 & 68.7 & 70.2 \\
\hline Prob. Ret $>20 \%$ (10yr, cumul.) & 53.3 & 53.2 & 53.1 & 53.0 & 52.7 & - & - \\
\hline Prob. Ret <-20\% (10yr, cumul.) & 49.3 & 49.3 & 49.2 & 49.1 & 48.2 & - & - \\
\hline Panel B: N. of obs. & \#Resp $\geq 3$ & \#Resp $\geq 4$ & \#Resp $\geq 5$ & \#Resp $\geq 6$ & \#Resp $\geq 10$ & \#Resp $\geq 30$ & \#Resp $\geq 50$ \\
\hline Prob. Ret $>0 \%$ (1yr) & 3,475 & 3,349 & 3,211 & 3,135 & 2,737 & 977 & 552 \\
\hline Prob. Ret $>20 \%(1 \mathrm{yr})$ & 3,358 & 3,215 & 3,067 & 2,970 & 2,587 & 932 & 510 \\
\hline Prob. Ret $<-20 \%(1 \mathrm{yr})$ & 3,442 & 3,305 & 3,163 & 3,077 & 2,667 & 954 & 520 \\
\hline Prob. Ret $>0 \%$ (10yr, cumul.) & 3,475 & 3,345 & 3,205 & 3,123 & 2,728 & 973 & 555 \\
\hline Prob. Ret > 20\% (10yr, cumul.) & 3,052 & 2,836 & 2,654 & 2,425 & 1,156 & - & - \\
\hline Prob. Ret <-20\% (10yr, cumul.) & 2,996 & 2,780 & 2,576 & 2,348 & 1,122 & - & - \\
\hline
\end{tabular}

Note: Panel A reports the $R^{2}$ statistics corresponding to regression 5 . Across columns, we increase from 3 to 50 the minimum number of responses for an individual to be included in the sample. Panel B reports the number of observations. Each row corresponds to a different question in the survey. 


\section{A.10 Persistent Heterogeneity in Beliefs \& Portfolio Shares}

Our main analysis explores the relationship between beliefs and portfolios in our panel of respondents. Since individual beliefs are extremely persistent, we next study the persistence of portfolio shares and examine the relationship between the persistent components of beliefs and portfolios.

We begin by performing a variance decomposition of the equity share similar to the one in Section IV, restricting to respondents for which we observe at least 12 months of portfolio data. We find even more extreme results than we do for beliefs: month fixed effects explain about $0.2 \%$ of the total variation in equity shares, whereas individual fixed effects explain $87 \%$ of the variation.

We next compute individual-level fixed effects for the equity share and for the belief about 1-year expected stock returns. Column 1 of Table A.10 reports the results of a cross-sectional tobit regression of the equity share fixed effect onto the expected return fixed effects, for respondents that answer our survey at least three times. The slope of the regression, 1.19, is similar in magnitude to the one from our panel analysis in Table III, confirming that our main empirical results are mostly driven by persistent cross-sectional differences across individuals. Column 4 restricts the sample to fixed effects estimated off at least 5 responses, and finds even larger responses, consistent with us obtaining more precise estimates of the fixed effects.

Table A.10: Explaining Equity Shares with Individual Belief Fixed Effects

\begin{tabular}{|c|c|c|c|c|c|c|}
\hline & \multicolumn{6}{|c|}{ Equity Share (\%) } \\
\hline & $(1)$ & $(2)$ & (3) & (4) & $(5)$ & $(6)$ \\
\hline & Equity Share FE & 2011 Equity Share & Equity Share & Equity Share FE & 2011 Equity Share & Equity Share \\
\hline Expected $1 Y$ Stock Return (FE) & $\begin{array}{c}1.190^{* * *} \\
(0.084)\end{array}$ & $\begin{array}{c}0.718^{* * *} \\
(0.129)\end{array}$ & $\begin{array}{c}1.387 * * * \\
(0.044)\end{array}$ & $\begin{array}{c}1.350^{* * *} \\
(0.137)\end{array}$ & $\begin{array}{c}0.733^{* * *} \\
(0.204)\end{array}$ & $\begin{array}{c}1.473 * * * \\
(0.059)\end{array}$ \\
\hline Expected 1Y Stock Return (residual) & & & $\begin{array}{c}0.182^{* * *} \\
(0.046)\end{array}$ & & & $\begin{array}{c}0.181^{* * *} \\
(0.057)\end{array}$ \\
\hline Minimum number of responses & 3 & 3 & 3 & 5 & 5 & 5 \\
\hline $\mathrm{N}$ & 3,883 & 5,107 & 25,141 & 1,596 & 2,004 & 14,948 \\
\hline
\end{tabular}

Note: Table shows the results of different specifications for the regression of equity share on beliefs, focusing on the persistent components. The independent variables are individual fixed effects of beliefs and the residual component, computed using at least 3 responses (columns 1-3) or at least 5 responses (columns 4-6). Columns 1 and 4 regress equity share fixed effects onto individual belief fixed effects. Columns 2 and 5 regress the 2011 portfolio share onto the belief fixed effects. Columns 3 and 6 regress the equity share onto the individual belief fixed effects and the residual component in the panel. All regressions are tobit regressions. Significance levels: ${ }^{*}(\mathrm{p}<0.10),{ }^{* *}(\mathrm{p}<0.05),{ }^{* * *}(\mathrm{p}<0.01)$.

Since beliefs and portfolios are persistent, one would expect that current beliefs should relate strongly not only to the current equity share, but also to equity shares measured outside our sample. In column 2, we regress the equity share of our respondents in January 2011 onto the belief fixed effects computed from our survey sample (2017-2019). The relationship is somewhat weaker at around 0.72 , but still of a similar magnitude. This confirms the importance of the persistent component of beliefs in explaining portfolio choices. Column 3 reverts to our panel analysis (as in our baseline results), but decomposes the panel variation in beliefs into the individual fixed effects and the residual (transitory) components. A tobit regression of portfolio shares onto the two components shows that it is the persistent component that quantitatively dominates. The smaller role played by the transitory component of beliefs could partly reflect measurement error, and partly a slow adjustment of portfolios to beliefs due to infrequent trading, which would cause transitory variation in beliefs to not be fully incorporated into portfolios within our sample. 


\section{A.11 Relationship Among Beliefs: Persistent vs. Transitory}

In Section V, we showed that beliefs correlate across domains and horizons: beliefs about stock returns correlate with beliefs about GDP growth, and short-term beliefs correlate with long-term beliefs about the same object. In this Appendix, we explore these relationships in greater detail, by repeating the analysis separately for the persistent and the transitory components of beliefs.

More specifically, for each of the questions, we compute the individual fixed effects (capturing the persistent component of beliefs) and the residual (capturing the transitory component). We then repeat our analysis relating only the fixed effects across questions (Figure A.5) as well as only the transitory component (Figure A.6).

Figure A.5 focuses on the persistent component only. It looks strikingly similar to Figure IV, emphasizing the importance of the persistent component of beliefs in our panel variation.

Figure A.5: Relationships Among Beliefs Within the Same Survey, FE

(A) Stock Returns: 1Y vs. 10Y

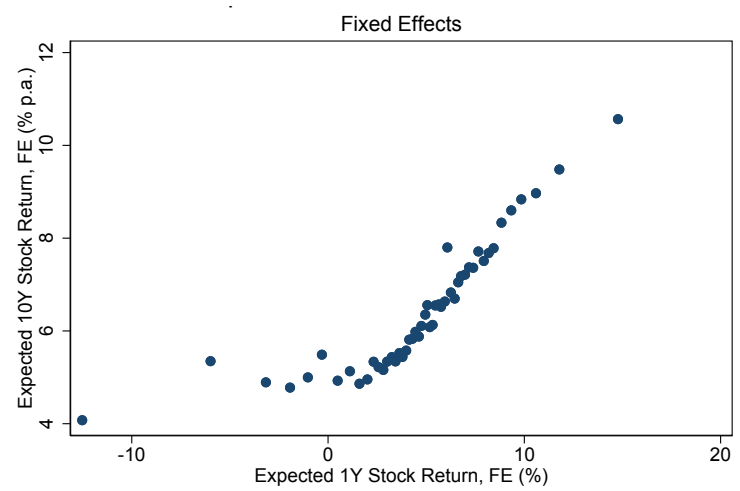

(C) Stock Return vs. GDP Growth (Short Run)

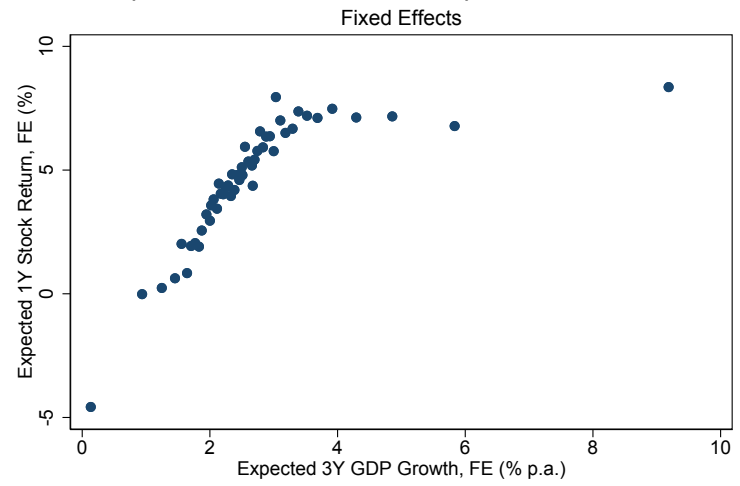

(B) GDP Growth: 3Y vs. 10Y

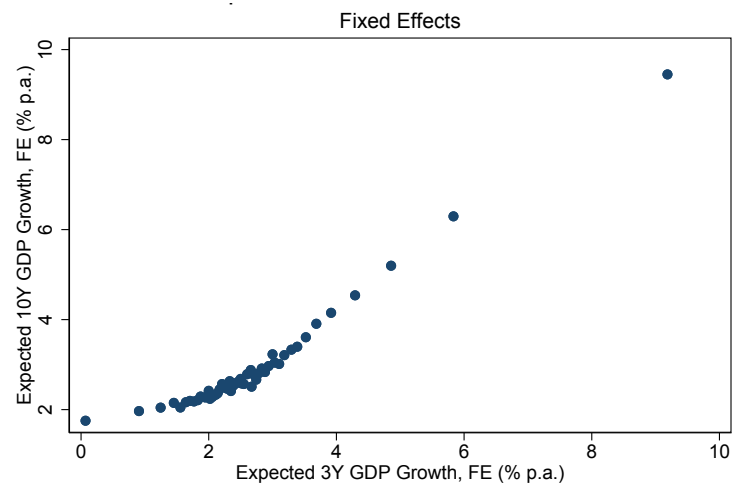

(D) Stock Return vs. GDP Growth (Long Run)

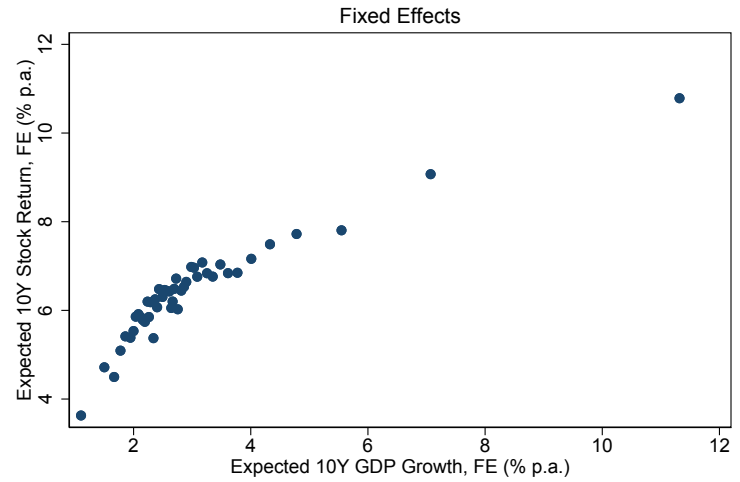

Note: Same as Figure IV, but using only individual fixed effects.

Figure A.6 resembles Figure IV less strongly, but it still confirms a positive correlation of answers across domains, even for the transitory component.

Overall, our results in this section establish that the pattern of correlation across domains documented in the text comes partly from the persistent component of beliefs, and partly from the transitory component, albeit more strongly for the former. 
Figure A.6: Relationships Among Beliefs Within the Same Survey, Transitory

(A) Stock Returns: 1Y vs. 10Y

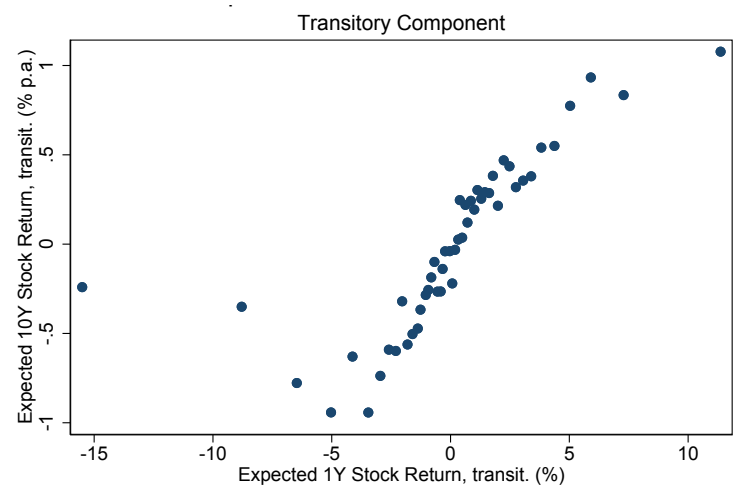

(C) Stock Return vs. GDP Growth (Short Run)

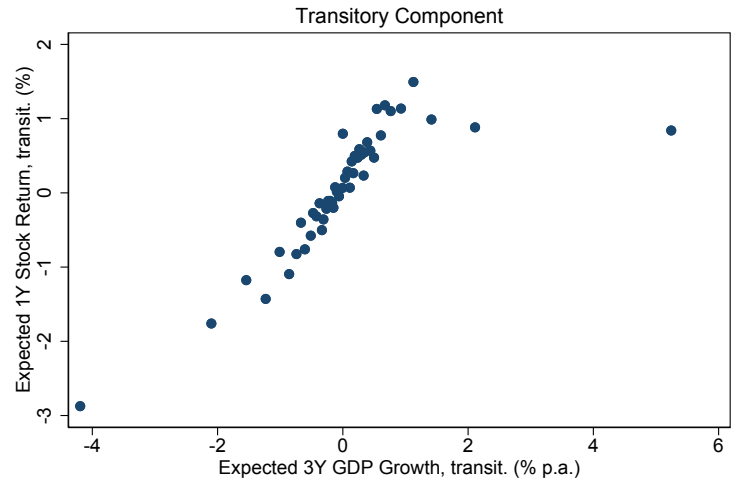

(B) GDP Growth: 3Y vs. 10Y

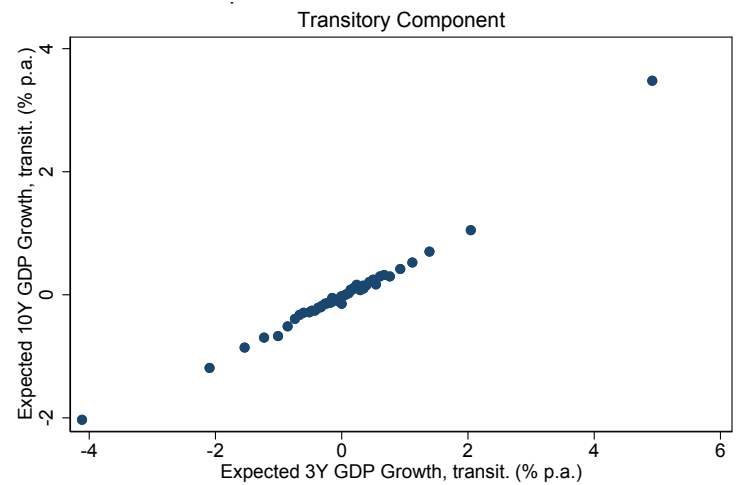

(D) Stock Return vs. GDP Growth (Long Run)

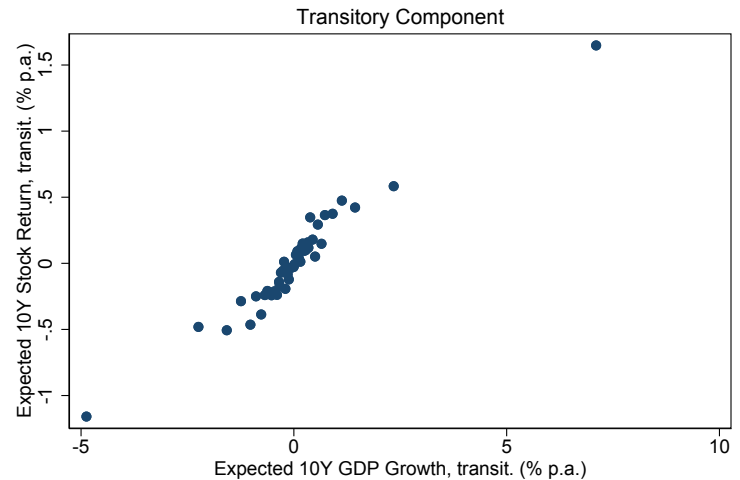

Note: Same as Figure IV, but using only the transitory component of beliefs. 


\section{A.12 Key Results: SAMPle UP tO FEBRUARY 2020}

In the main body of the paper, we use survey data between February 2017 and June 2020 to establish a number of facts about the relationship between beliefs and portfolios as well as the relationships between different beliefs. One natural and relevant question is how robust these facts are to variations in the market environment, and, specifically, to what extent these facts are driven by the large stock market crash in March 2020.

In this Appendix, we document that our analysis is, in fact, remarkably robust to variations in the market environment. To highlight this point, we present versions of the main tables in our paper using only the first 19 waves of the GMSU-Vanguard survey, ending in February 2020, near the all-time high of the S\&P 500 index. For all five facts we establish in the paper, the patterns do not change substantially when we exclude the period covering the COVID-19 crash.

Tables A.11 and A.12 highlight that the findings of Fact 1 are robust to focusing on the preCOVID-19 period. In particular, as discussed in the main body of the paper, the average sensitivity in the pre-COVID-19 period was somewhat higher, but still substantially below the predictions of the frictionless model. All heterogeneities across accounts and individuals highlighted in the main body of the paper also survive the exclusion of the COVID-19 period.

Table A.11: Expected Returns and Portfolio Equity Shares — Feb 2017 to Feb 2020

\begin{tabular}{|c|c|c|c|c|c|c|c|}
\hline & \multicolumn{7}{|c|}{ Equity Share (\%) } \\
\hline & (1) & (2) & (3) & (4) & (5) & (6) & (7) \\
\hline Expected 1Y Stock Return (\%) & $\begin{array}{c}0.782^{* * *} \\
(0.042)\end{array}$ & $\begin{array}{c}0.818^{* * *} \\
(0.042)\end{array}$ & $\begin{array}{c}1.213 * * * \\
(0.066)\end{array}$ & $\begin{array}{c}0.745^{* * *} \\
(0.053)\end{array}$ & $\begin{array}{c}1.415^{* * *} \\
(0.080)\end{array}$ & $\begin{array}{c}1.419 * * * \\
(0.085)\end{array}$ & $\begin{array}{l}1.419 * * * \\
(0.093)\end{array}$ \\
\hline $\begin{array}{l}\text { Expected } 1 \text { Y Stock Return (\%) } \\
\quad x \text { Assets }>\$ 225 \mathrm{k}\end{array}$ & & & & $\begin{array}{l}0.170^{* *} \\
(0.081)\end{array}$ & & & \\
\hline $\begin{array}{l}\text { Expected } 1 Y \text { Stock Return (\%) } \\
\text { x Above Median Time }\end{array}$ & & & & & & $\begin{array}{c}-0.009 \\
(0.060)\end{array}$ & \\
\hline $\begin{array}{l}\text { Expected } 1 Y \text { Stock Return (\%) } \\
\quad x \text { Closest prior trade } 2 \text { weeks before }\end{array}$ & & & & & & & $\begin{array}{c}0.469 \\
(0.432)\end{array}$ \\
\hline $\begin{array}{l}\text { Expected } 1 Y \text { Stock Return (\%) } \\
\quad \text { x Closest prior trade } 1 \text { week before }\end{array}$ & & & & & & & $\begin{array}{c}0.353 \\
(0.277)\end{array}$ \\
\hline $\begin{array}{l}\text { Expected } 1 Y \text { Stock Return (\%) } \\
\quad \text { x Closest next trade } 1 \text { week after }\end{array}$ & & & & & & & $\begin{array}{l}0.477 \\
(0.321)\end{array}$ \\
\hline $\begin{array}{l}\text { Expected } 1 Y \text { Stock Return (\%) } \\
\quad x \text { Closest next trade } 2 \text { weeks after }\end{array}$ & & & & & & & $\begin{array}{c}0.100 \\
(0.334)\end{array}$ \\
\hline Controls & $\mathrm{N}$ & $Y$ & Y & Y & Y & Y & Y \\
\hline ORIV & $\mathrm{N}$ & $\mathrm{N}$ & $\mathrm{N}$ & $\mathrm{N}$ & $Y$ & $\mathrm{Y}$ & $\mathrm{Y}$ \\
\hline Sample & & & $\begin{array}{c}E \text { (Return) } \\
0 \%-15 \%\end{array}$ & & & & $\begin{array}{l}\text { Retail } \\
\text { accounts }\end{array}$ \\
\hline $\mathrm{N}$ & 39,884 & 39,859 & 35,848 & 39,859 & 39,557 & 39,557 & 36,714 \\
\hline
\end{tabular}

Note: Table shows results from regression 1 using the first 19 waves of the GMSU-Vanguard survey (up to February 2020). The unit of observation is a survey response, the dependent variable is the equity share. Columns 2-6 control for the respondents' age, gender, region of residence, wealth, and the survey wave. For the interaction specifications in columns 4, 6, and 7, we also include dummy variables for the respondent characteristics that we estimate the sensitivity for. Standard errors are clustered at the respondent level. Significance levels: ${ }^{*}(\mathrm{p}<0.10),{ }^{* *}(\mathrm{p}<0.05),{ }^{* * *}(\mathrm{p}<0.01)$. 
Table A.12: Expected Returns and Portfolios — Heterogeneity — Feb 2017 to Feb 2020

\begin{tabular}{|c|c|c|c|c|c|c|c|}
\hline & \multicolumn{7}{|c|}{ Equity Share (\%) } \\
\hline & (1) & (2) & (3) & (4) & (5) & (6) & (7) \\
\hline Expected 1Y Stock Return (\%) & $\begin{array}{c}1.555^{* * *} \\
(0.180)\end{array}$ & $\begin{array}{c}1.735^{* * *} \\
(0.128)\end{array}$ & $\begin{array}{c}1.320 * * * \\
(0.191)\end{array}$ & & & & \\
\hline $\begin{array}{l}\text { Expected } 1 Y \text { Stock Return (\%) } \\
\quad x \text { Monthly Turnover }<0.5 \%\end{array}$ & & & & $\begin{array}{c}1.021^{* * *} \\
(0.194)\end{array}$ & & & \\
\hline $\begin{array}{l}\text { Expected } 1 Y \text { Stock Return }(\%) \\
\quad x \text { Monthly Turnover } \in[0.5 \%, 4 \%]\end{array}$ & & & & $\begin{array}{c}1.533^{* * *} \\
(0.108)\end{array}$ & & & \\
\hline $\begin{array}{l}\text { Expected } 1 \text { Y Stock Return (\%) } \\
\quad x \text { Monthly Turnover }>4 \%\end{array}$ & & & & $\begin{array}{c}2.035 * * * \\
(0.316)\end{array}$ & & & \\
\hline $\begin{array}{l}\text { Expected } 1 Y \text { Stock Return }(\%) \\
\quad \times \text { Monthly Vanguard Visits } \in(0,1)\end{array}$ & & & & & $\begin{array}{c}1.170 * * * \\
(0.157)\end{array}$ & & \\
\hline $\begin{array}{l}\text { Expected } 1 Y \text { Stock Return }(\%) \\
\quad x \text { Monthly Vanguard Visits } \in(1,7)\end{array}$ & & & & & $\begin{array}{c}1.447^{* * *} \\
(0.093)\end{array}$ & & \\
\hline $\begin{array}{l}\text { Expected 1Y Stock Return (\%) } \\
\quad \text { x Monthly Vanguard Visits } \in(7,31)\end{array}$ & & & & & $\begin{array}{c}1.877^{* * *} \\
(0.170)\end{array}$ & & \\
\hline $\begin{array}{l}\text { Expected 1Y Stock Return (\%) } \\
\quad x \text { Low Confidence }\end{array}$ & & & & & & $\begin{array}{c}0.990 * * * \\
(0.184)\end{array}$ & \\
\hline $\begin{array}{l}\text { Expected 1Y Stock Return (\%) } \\
\quad \text { x Medium Confidence }\end{array}$ & & & & & & $\begin{array}{c}1.474 * * * \\
(0.093)\end{array}$ & \\
\hline $\begin{array}{l}\text { Expected 1Y Stock Return (\%) } \\
\text { x High Confidence }\end{array}$ & & & & & & $\begin{array}{c}1.689 * * * \\
(0.340)\end{array}$ & \\
\hline $\begin{array}{l}\text { Expected 1Y Stock Return (\%) } \\
\text { x Not Idealized }\end{array}$ & & & & & & & $\begin{array}{c}1.666 * * * \\
(0.096)\end{array}$ \\
\hline $\begin{array}{l}\text { Expected } 1 Y \text { Stock Return (\%) } \\
\quad x \text { Idealized }\end{array}$ & & & & & & & $\begin{array}{c}3.517^{* * *} \\
(1.327)\end{array}$ \\
\hline Controls + Fixed Effects & Y & Y & Y & Y & Y & Y & Y \\
\hline Sample & $\begin{array}{c}\text { Retail } \\
\text { Account }\end{array}$ & $\begin{array}{l}\text { Retail } \\
\text { Account } \\
\text { Tax Adv. }\end{array}$ & $\begin{array}{c}\text { Defined } \\
\text { Contribution } \\
\text { Plans }\end{array}$ & & & & $\begin{array}{c}\text { Retail } \\
\text { Account } \\
\text { Tax Adv. }\end{array}$ \\
\hline $\mathrm{N}$ & 17,711 & 17,711 & 3,760 & 36,831 & 39,557 & 39,557 & 30,765 \\
\hline
\end{tabular}

Note: Table shows results from regression 1, estimated using ORIV and using the first 19 waves of the GMSU-Vanguard survey (up to February 2020). The dependent variable is the equity share. In column 1 it is the equity share in institutionally-managed retirement plans (defined contribution plans); in column 2 it is the equity share in individuallymanaged retail accounts; and in columns 3 and 7, it is the equity share in individually-managed tax-advantaged retail accounts. In columns 4-6, it is pooled across the three types of accounts. In column 6, "low confidence" corresponds to individuals who reported being "not at all confident" or "not very confident" in their answers about expected stock returns; "medium confidence" corresponds to individuals who report being "somewhat confident" or "very confident" about their answers; and "high confidence" corresponds to individuals who report being "extremely confident." "Idealized" respondents in column 7 are those whose behavior most closely corresponds to that of the assumptions in the frictionless model: they have average monthly portfolio turnover of at least $4 \%$, they have at least seven log-ins a month, and they report to be extremely confident in their beliefs. For the interaction specifications in columns 4 , 5, and 6, we also include dummy variables for the respondent characteristics that we estimate the sensitivity for. Standard errors are clustered at the respondent level. Significance levels: ${ }^{*}(\mathrm{p}<0.10),{ }^{* *}(\mathrm{p}<0.05),{ }^{* * *}(\mathrm{p}<0.01)$. 
Table A.13 is the same as Table V in the paper - the table establishing Fact 2 - but restricts the analysis to the pre-COVID-19 period. As discussed in the main body of the paper, the results are broadly unchanged in terms of economic conclusions. In the pre-COVID-19 period, the intensive margin effect of beliefs on trading (i.e., the relationship conditional on a trade occurring) is somewhat bigger in magnitude. This largely reflects the fact that, during the COVID-19 crises, beliefs changed substantially, but portfolio reactions were relatively muted.

Table A.13: Trading Analysis — Feb 2017 to Feb 2020

\begin{tabular}{|c|c|c|c|c|c|}
\hline & $\Delta$ Equity Share (\%) & Probability Trade & Probability Trade & Probability Buy & $\Delta$ Equity Share (\%) \\
\hline & (1) & $(2)$ & (3) & (4) & (5) \\
\hline$\Delta$ Expected 1Y Stock Return (\%) & $\begin{array}{c}0.234^{* * *} \\
(0.033)\end{array}$ & & & $\begin{array}{c}1.008 * * * \\
(0.213)\end{array}$ & $\begin{array}{c}0.601 * * * \\
(0.085)\end{array}$ \\
\hline Expected 1Y Stock Return (\%) & $\begin{array}{c}0.116 * * * \\
(0.019)\end{array}$ & $\begin{array}{l}-0.069 \\
(0.142)\end{array}$ & & $\begin{array}{c}1.412^{* * *} \\
(0.215)\end{array}$ & $\begin{array}{c}0.346 * * * \\
(0.063)\end{array}$ \\
\hline Lagged Equity Share (\%) & $\begin{array}{c}-0.048 * * * \\
(0.004)\end{array}$ & $\begin{array}{c}-0.120 * * * \\
(0.022)\end{array}$ & & $\begin{array}{c}-0.335 * * * \\
(0.032)\end{array}$ & $\begin{array}{c}-0.159 * * * \\
(0.011)\end{array}$ \\
\hline $\mid \Delta$ Expected 1Y Stock Return (\%) | & & $\begin{array}{c}0.264 \\
(0.231)\end{array}$ & & & \\
\hline Extreme Equity Share Dummies & $\mathrm{Y}$ & $\mathrm{Y}$ & $\mathrm{Y}$ & $\mathrm{Y}$ & $\mathrm{Y}$ \\
\hline Time Betweeen Wave Dummies & Y & $\mathrm{Y}$ & $\mathrm{Y}$ & $\mathrm{Y}$ & $\mathrm{Y}$ \\
\hline Other Fixed Effects and Controls & $\mathrm{Y}$ & Y & $\mathrm{N}$ & $\mathrm{Y}$ & Y \\
\hline Specification & & & & $\begin{array}{c}\text { Conditional on } \\
\text { Trading }\end{array}$ & $\begin{array}{c}\text { Conditional on } \\
\text { Trading }\end{array}$ \\
\hline R-Squared & 0.032 & 0.383 & 0.368 & 0.483 & 0.154 \\
\hline $\mathrm{N}$ & 21,766 & 21,766 & 22,749 & 6,478 & 6,478 \\
\hline
\end{tabular}

Note: Table shows results from regression 3 using the first 19 waves of the GMSU-Vanguard survey (up to February 2020). The unit of observation is a window between two consecutive survey responses by the same individual. The dependent variable in columns 1 and 5 is the change in the equity share due to active trading between the two survey waves. The dependent variable in columns 2 and 3 is an indicator for whether there was any active trading between the two survey waves, defined as an active change in the equity share of at least one percentage point. The dependent variable in column 4 is an indicator of whether the individual actively increased her portfolio share in equity by at least one percentage point during the window as a result of trading between the two survey waves. All columns control for the length of time between two consecutive answers, and for dummies capturing extreme start-of-period equity shares of $0 \%$ or $100 \%$. All columns, except column 3, also control for the respondents' age, gender, region of residence, wealth, and the survey wave. Columns 4 and 5 condition the sample on windows with active trades. All results are obtained using ORIV. The $R$-Squared is computed from OLS specifications. Standard errors are clustered at the respondent level. Significance levels: ${ }^{*}(\mathrm{p}<0.10),{ }^{* *}(\mathrm{p}<0.05),{ }^{* * *}(\mathrm{p}<0.01)$.

Similarly, consider Fact 3, which explores the relative importance of individual fixed effects and common time-series movements in explaining the panel variation in beliefs. Table A.14 shows that the inclusion of the crash period - a period in which average expected 1-year returns fell from around $6 \%$ to around $2 \%$ - has somewhat increased the contribution of common time-series variation, but only from about $3.5 \%$ to about $5 \%$, while reducing the contribution of individual fixed effects from $54.2 \%$ to $47.5 \%$. As before, the contribution of individual fixed effects is an order or magnitude larger than the contribution of common time-series variation in beliefs. This is consistent with the findings in Appendix A.10, which also documented that individual fixed effects were dominant in other surveys that covered longer time periods. 
Table A.14: Decomposing the Variation in Beliefs — Feb 2017 to Feb 2020

\begin{tabular}{|c|c|c|c|c|}
\hline & \multicolumn{3}{|c|}{$\mathrm{R}^{2}(\%)$ of Panel Regression } & \multirow[b]{2}{*}{$\mathrm{N}$} \\
\hline & Time FE & Individual FE & Time + Individual FE & \\
\hline Expected 1Y Stock Return (\%) & 3.5 & 54.2 & 57.1 & 1,718 \\
\hline Expected 10Y Stock Return (\% p.a.) & 0.6 & 44.7 & 45.2 & 1,713 \\
\hline Probability 1Y Stock Return < -10\% & 0.7 & 54.3 & 54.9 & 1,762 \\
\hline St.d. Expected 1Y Stock Return (\%) & 0.4 & 57.4 & 57.8 & 1,762 \\
\hline Confidence (Stock Qs) & 0.5 & 62.0 & 62.5 & 1,738 \\
\hline Expected 3Y GDP Growth (\% p.а.) & 2.0 & 47.8 & 49.3 & 1,722 \\
\hline Expected 10Y GDP Growth (\% p.a.) & 0.7 & 40.5 & 41.1 & 1,698 \\
\hline Probability p.a. 3Y GDP Growth < 0\% & 0.6 & 49.7 & 50.1 & 1,762 \\
\hline St.d. Expected p.a. 3Y GDP Growth (\%) & 0.9 & 56.9 & 57.7 & 1,762 \\
\hline Confidence (GDP Qs) & 0.1 & 64.2 & 64.4 & 1,726 \\
\hline Expected $1 Y$ Return of $10 \mathrm{Y}$ bond (\%) & 2.5 & 39.9 & 41.8 & 1,712 \\
\hline Confidence (Bond Qs) & 0.4 & 63.8 & 64.1 & 1,726 \\
\hline
\end{tabular}

Note: Table reports the $R^{2}$ s corresponding to the three regressions 4,5 , and 6 , and the number of individual respondents N. We only include respondents that have responded to at least three waves and use the first 19 waves of the GMSU-Vanguard survey (up to February 2020). Each row corresponds to a different survey question that is used as the dependent variable.

Table A.15: Correlation Across Survey Responses — Feb 2017 to Feb 2020

\begin{tabular}{|c|c|c|c|c|}
\hline \multirow[t]{2}{*}{ PANEL A } & \multicolumn{2}{|c|}{ Expected 10Y Stock Returns (\%, p.a.) } & \multicolumn{2}{|c|}{ Expected 10Y GDP Growth (\%, p.a.) } \\
\hline & $(1)$ & $(2)$ & (3) & (4) \\
\hline Expected 1Y Stock Return (\%) & $\begin{array}{c}0.225^{* * *} \\
(0.006)\end{array}$ & $\begin{array}{c}0.121 * * * \\
(0.011)\end{array}$ & & \\
\hline Expected 3Y GDP Growth (\%, p.a.) & & & $\begin{array}{c}0.867^{* * *} \\
(0.015)\end{array}$ & $\begin{array}{c}0.739 * * * \\
(0.035)\end{array}$ \\
\hline Controls & $\mathrm{Y}$ & Y & $\mathrm{Y}$ & $\mathrm{Y}$ \\
\hline Individual Fixed Effects & $\mathrm{N}$ & Y & $\mathrm{N}$ & $\mathrm{Y}$ \\
\hline R-Squared & 0.116 & 0.713 & 0.451 & 0.815 \\
\hline $\mathrm{N}$ & 38,189 & 38,189 & 38,007 & 38,007 \\
\hline \multirow[t]{2}{*}{ PANEL B } & \multicolumn{2}{|c|}{ Expected 10Y Stock Returns (\%, p.a.) } & \multicolumn{2}{|c|}{ Expected 10Y GDP Growth (\%, p.a.) } \\
\hline & $(1)$ & $(2)$ & (3) & $(4)$ \\
\hline Expected 3Y GDP Growth (\%, p.a.) & $\begin{array}{c}0.627 * * * \\
(0.020)\end{array}$ & $\begin{array}{c}0.210 * * * \\
(0.034)\end{array}$ & & \\
\hline Expected 10Y GDP Growth (\%, p.a.) & & & $\begin{array}{c}0.391 * * * \\
(0.016)\end{array}$ & $\begin{array}{c}0.248 * * * \\
(0.038)\end{array}$ \\
\hline Controls & Y & $\mathrm{Y}$ & $\mathrm{Y}$ & $\mathrm{Y}$ \\
\hline Individual Fixed Effects & $\mathrm{N}$ & Y & $\mathrm{N}$ & Y \\
\hline R-Squared & 0.089 & 0.746 & 0.086 & 0.721 \\
\hline $\mathrm{N}$ & 38,155 & 38,155 & 37,827 & 37,827 \\
\hline
\end{tabular}

Note: Table shows results from regressing answers to different expectation questions onto each other using the first 19 waves of the GMSU-Vanguard survey (up to February 2020); Panel A relates short-run and long-run beliefs within the same domain, while Panel B relates beliefs across domains over similar time horizons. The unit of observation is a survey response. All specifications control for the respondents' age, gender, region of residence, wealth, and the survey wave. Columns 2 and 4 also control for respondent fixed effects. Standard errors are clustered at the respondent level. Significance levels: * $(\mathrm{p}<0.10),{ }^{* *}(\mathrm{p}<0.05), * * *(\mathrm{p}<0.01)$. 
Tables A.15 and A.16 show that the patterns underlying Facts 4 and 5 do not vary substantially when we exclude the pre-COVID-19 period. In both samples, short-run and long-run beliefs about GDP growth and stock returns were positively related, both within and across individuals. Similarly, expected stock returns and expected GDP growth were positively related at all horizons. And expected returns and expected stock market disaster probabilities were negatively related across all samples, both within and across individuals.

Table A.16: Expected Stock Returns and Rare Disasters Beliefs — Feb 2017 to Feb 2020

\begin{tabular}{|c|c|c|c|c|c|c|}
\hline & \multicolumn{6}{|c|}{ Expected 1Y Stock Return (\%) } \\
\hline & $(1)$ & $(2)$ & (3) & $(4)$ & $(5)$ & $(6)$ \\
\hline Probability $1 Y$ Stock Return $<-30 \%$ & $\begin{array}{c}-0.156 * * * \\
(0.007)\end{array}$ & & $\begin{array}{c}-0.235 * * * \\
(0.013)\end{array}$ & & $\begin{array}{c}-0.083 * * * \\
(0.009)\end{array}$ & $\begin{array}{c}-0.117 * * * \\
(0.016)\end{array}$ \\
\hline Probability 1Y Stock Return <-10\% & & $\begin{array}{c}-0.126 * * * \\
(0.003)\end{array}$ & & & & \\
\hline $\begin{array}{l}\text { Probability } 1 \text { Y Stock Return }<-30 \% \\
\text { x Low Bucket First }\end{array}$ & & & & $\begin{array}{c}-0.153^{* * *} \\
(0.008)\end{array}$ & & \\
\hline $\begin{array}{l}\text { Probability } 1 \text { Y Stock Return }<-30 \% \\
\text { x High Bucket First }\end{array}$ & & & & $\begin{array}{c}-0.217^{* * *} \\
(0.012)\end{array}$ & & \\
\hline Controls & $\mathrm{Y}$ & $\mathrm{Y}$ & Y & $\mathrm{Y}$ & Y & Y \\
\hline Individual Fixed Effects & & & & & $\mathrm{Y}$ & $\mathrm{Y}$ \\
\hline Specification & & & $\begin{array}{c}\text { Prob } \in \\
{[0.1 \%, 10 \%]}\end{array}$ & & & $\begin{array}{c}\text { Prob } \in \\
{[0.1 \%, 10 \%]}\end{array}$ \\
\hline R-Squared & 0.086 & 0.204 & 0.053 & 0.503 & 0.750 & 0.793 \\
\hline $\mathrm{N}$ & 38,646 & 38,646 & 21,117 & 38,646 & 38,646 & 20,321 \\
\hline
\end{tabular}

Note: Table shows results from regression 8 using the first 19 waves of the GMSU-Vanguard survey (up to February 2020). The unit of observation is a survey response, the dependent variable is the expected one year stock return. All columns control for the respondents' age, gender, region of residence, wealth, and the survey wave. Columns 5 and 6 include individual fixed effects, wave fixed effects, and a dummy for the randomization order of the buckets in the distribution question. Columns 3 and 6 restrict the sample to individuals who report expected probabilities of a stock market disaster between $0.1 \%$ and $10 \%$. Standard errors are clustered at the respondent level. Significance levels: ${ }^{*}$ $(\mathrm{p}<0.10),{ }^{* *}(\mathrm{p}<0.05),{ }^{* * *}(\mathrm{p}<0.01)$. 


\section{B.1 INVITATION EMAIL AND SURVEy FlOW}

In this Appendix, we present screenshots of one complete survey flow. In this iteration of the flow, questions about expected stock returns were asked ahead of questions about expected GDP growth; the survey implementation randomizes across these two blocks of questions. We begin by reviewing the invitation email sent to individuals from Vanguard.

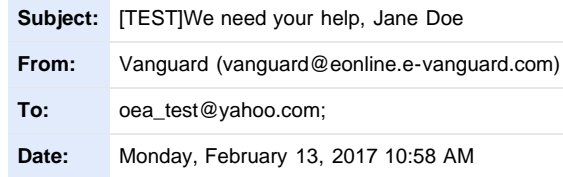

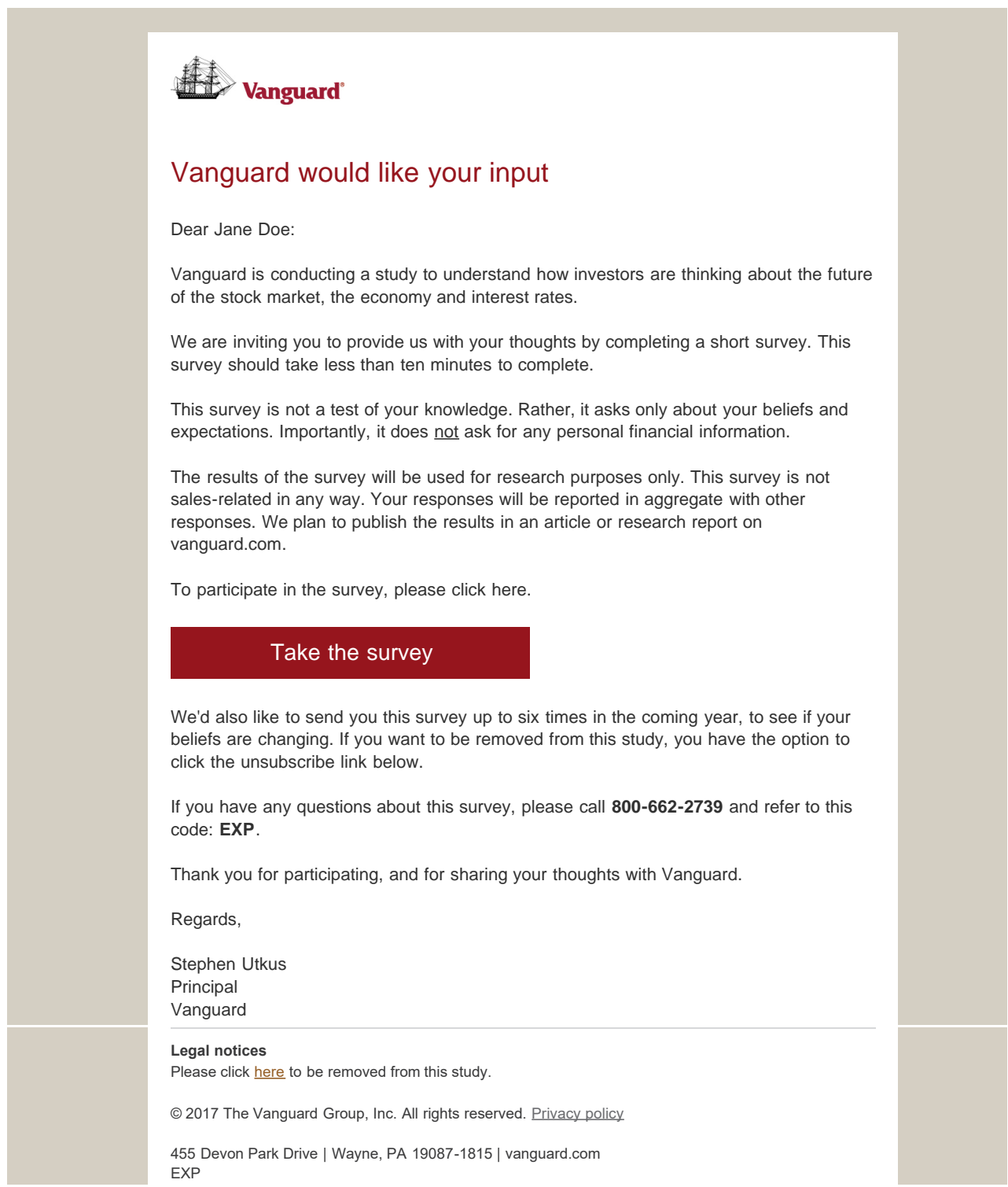

B.1 


\section{连青 Vanguard'}

Dear Investor,

Thank you for participating in this study.

At Vanguard we are interested in understanding investor views on the future of the stock market, the economy and interest rates. We plan to create an investor sentiment index to share these findings with the investing public.

This is a short survey that should take you no more than 5-10 minutes to complete.

The survey does not collect any personal information. It relies on your general knowledge

If you feel you are not familiar with a topic, that is fine. Please just give us your best prediction.

Please do not use the browser's navigation button to move through the survey.

\section{Next}

\section{radi us}

For these questions, we would like to know what you are expecting the future returns of the US stock market to be.

\section{Next}

\section{radi U S}

What do you expect the return of the US stock market to be over the next 12 months?

Note: This expected return is the change in value, in percent, that you expect to receive over the next 12 months from investing in a portfolio that holds all stocks listed on the US stock market. It includes both dividends and capital gains/losses.

(Please answer only with a positive or negative numeric value, with at most 1 decimal.)

$\%$ over the next 12 months

\section{Next}

B.2 


\section{radius}

What do you expect the average annual return of the US stock market to be over the next 10 years?

Note: This expected return is the change in value, in percent, that you expect to receive each year on average over the next 10 years from investing in a portfolio that holds all stocks listed on the US stock market. It includes both dividends and capital gains/losses.

(Please answer only with a positive or negative numeric value, with at most 1 decimal.)

$\%$ per year, over the next 10 years

\section{Next}

\section{radius}

In this question we present you with five possible scenarios for US stock market returns over the next 12 months:

The US stock market return will be...

- Scenario 1: more than $40 \%$ over the next year

- Scenario 2: between $30 \%$ and $40 \%$ over the next year.

- Scenario 3: between $-10 \%$ and $30 \%$ over the next year.

- Scenario 4 : between $-30 \%$ and $-10 \%$ over the next year.

- Scenario 5 : less than $\mathbf{- 3 0 \%}$ over the next year.

Please let us know how likely you think it is that each scenario will occur.

Please type in the number to indicate the probability, in percent, that you attach to each scenario. The probabilities of the five scenarios have to sum up to $100 \%$. The graphic bar chart on the right updates automatically to reflect your answers.

(Please answer only with a positive numeric value, with at most 1 decimal.)
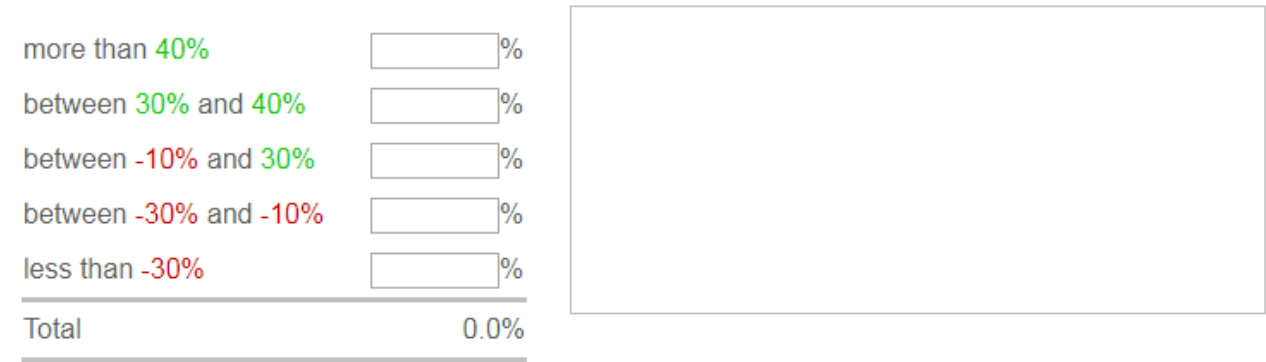

Remaining probability to fill in: $100.0 \%$

B.3 


\section{radius}

In this question we present you with five possible scenarios for US stock market returns over the next 12 months:

The US stock market return will be...

- Scenario 1: more than $40 \%$ over the next year.

- Scenario 2 : between $30 \%$ and $40 \%$ over the next year.

- Scenario 3: between $-10 \%$ and $30 \%$ over the next year.

- Scenario 4 : between $-\mathbf{3 0} \%$ and $-10 \%$ over the next year.

- Scenario 5 : less than $-30 \%$ over the next year.

Please let us know how likely you think it is that each scenario will occur.

Please type in the number to indicate the probability, in percent, that you attach to each scenario. The probabilities of the five scenarios have to sum up to $100 \%$. The graphic bar chart on the right updates automatically to reflect your answers.

(Please answer only with a positive numeric value, with at most 1 decimal.)

\begin{tabular}{lr} 
more than $40 \%$ & $2.5 \%$ \\
between $30 \%$ and $40 \%$ & $20 \%$ \\
between $-10 \%$ and $30 \%$ & $55 \%$ \\
between $-30 \%$ and $-10 \%$ & $15 \%$ \\
\hline less than -30\% & $7.5 \%$ \\
\hline Total & $100.0 \%$ \\
\hline
\end{tabular}

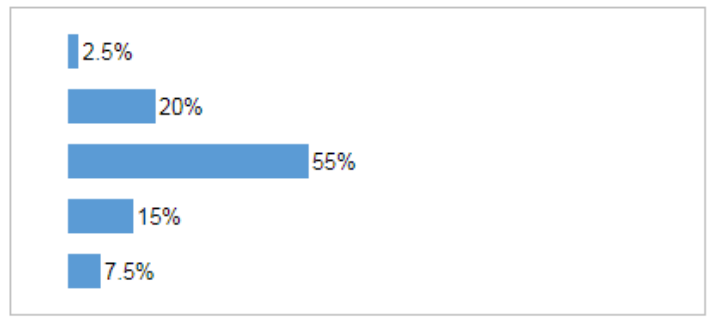

Remaining probability to fill in: $0.0 \%$

\section{rad I U S}

How difficult were the questions about the stock market that you were just asked?
Not at all difficult
Not very difficult
Somewhat difficult
Very difficult
- Extremely difficult 


\section{radius}

How confident are you with your answers to the questions about the stock market that you were just asked?
Extremely confident
Very confident
Somewhat confident
Not very confident
Not at all confident

\section{radi us}

In the next questions, we would like to know what you are expecting future economic growth in the US to be.

Again, even if you feel that you are not familiar with the topic, please give us your best prediction.

What do you expect the average annual growth rate of real GDP in the US to be over the next 3 years?

Note: Real Gross Domestic Product (GDP) is a measure of economic activity. Real GDP is the total real value of goods and services produced in the US in a year.

(Please answer only with a positive or negative numeric value with at most 1 decimal.)

$\%$ per year, over the next $\underline{3}$ years

\section{B.5}


radius

What do you expect the average annual growth rate of real GDP in the US to be over the next 10 years?

Note: Real Gross Domestic Product (GDP) is a measure of economic activity. Real GDP is the total real value of goods and services produced in the US in a year.

(Please answer only with a positive or negative numeric value with at most 1 decimal.)

$\%$ per year, over the next 10 years

\section{Next}

\section{radius}

In this question we present you with five possible scenarios for US real GDP average annual growth rate, over the next 3 years:

US real GDP average annual growth rate over the next 3 years will be...

- Scenario 1: more than $9 \%$ per year.

- Scenario 2: between $3 \%$ and $9 \%$ per year.

- Scenario 3 : between $0 \%$ and $3 \%$ per year.

- Scenario 4: between $-3 \%$ and $0 \%$ per year

- Scenario 5 : less than $\mathbf{- 3 \%}$ per year.

Please let us know how likely you think it is that each scenario will occur.

Please type in the number to indicate the probability, in percent, that you attach to each scenario. The probabilities of the five scenarios have to sum up to $100 \%$. The graphic bar chart on the right updates automatically to reflect your answers.

(Please answer only with a positive numeric value, with at most 1 decimal.)
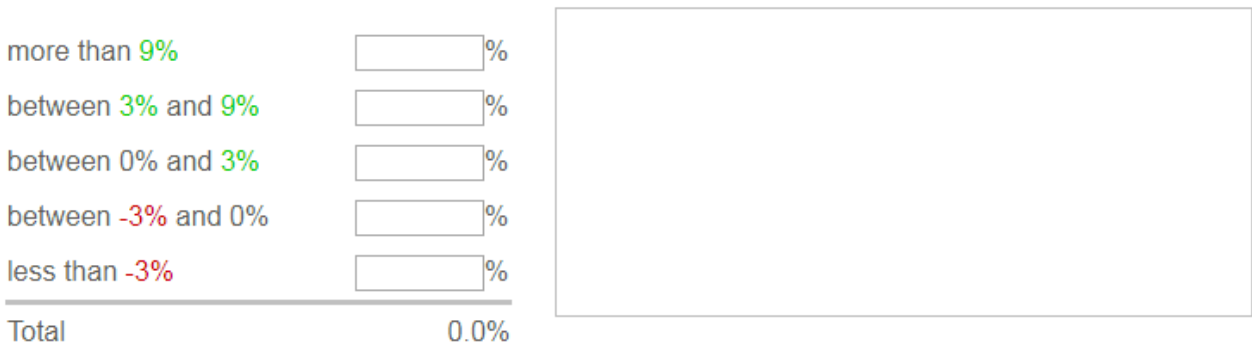

Remaining probability to fill in: $100.0 \%$

\section{Next}

\section{B.6}




\section{radi u S}

How difficult were the questions about real GDP growth that you were just asked?
Not at all difficult
Not very difficult
Somewhat difficult
Very difficult
Extremely difficult

\section{radius}

How confident are you with your answers to the questions about real GDP growth that you were just asked?
Extremely confident
Very confident
- Somewhat confident
Not very confident
Not at all confident

\section{radius}

In these final questions, we would like to know what you are expecting future returns on US bonds and future US interest rates to be.

Again, even if you feel that you are not familiar with the topic, please give us your best prediction. 


\section{radius}

Suppose that you were to buy a 10-year US Treasury bond today that makes all of its payments at maturity 10 years from now.

Suppose that you were to sell this bond a year from today. What do you expect the return from this bond investment to be over the next 12 months?

Note: This expected return is the change in price of the bond that you expect to occur during the next 12 months

(Please answer only with a positive or negative numeric value with at most 1 decimal.)

$\%$ over the next 12 months

\section{Next}

radius

How difficult were the questions about bonds and interest rates that you were just asked?
Not at all difficult
Not very difficult
Somewhat difficult
Very difficult
Extremely difficult

\section{Next}

\section{radius}

How confident are you with your answers to the questions about bonds and interest rates that you were just asked?
Extremely confident
Very confident
Somewhat confident
Not very confident
Not at all confident

\section{B.8}




\section{APPENDIX REFERENCES}

Amromin, Gene, and Steven A Sharpe. 2009. "Expectations of risk and return among household investors: Are their Sharpe ratios countercyclical?"

Barberis, Nicholas. 2000. "Investing for the long run when returns are predictable." The Journal of Finance, 55(1): 225-264.

Brennan, Michael J, Eduardo S Schwartz, and Ronald Lagnado. 1997. "Strategic asset allocation." Journal of Economic Dynamics and Control, 21(8-9): 1377-1403.

Campbell, John Y, and Luis M Viceira. 1999. "Consumption and portfolio decisions when expected returns are time varying." The Quarterly Journal of Economics, 114(2): 433-495.

Campbell, John Y, and LuisM Viceira. 2001. "Who should buy long-term bonds?" American Economic Review, 91(1): 99-127.

Campbell, John Y, Luis M Viceira, Luis M Viceira, et al. 2002. Strategic asset allocation: portfolio choice for long-term investors. Clarendon Lectures in Economic.

Coval, Joshua, and Erik Stafford. 2007. "Asset fire sales (and purchases) in equity markets." Journal of Financial Economics, 86(2): 479-512.

Del Guercio, Diane, and Paula A Tkac. 2002. "The determinants of the flow of funds of managed portfolios: Mutual funds vs. pension funds." Journal of Financial and Quantitative Analysis, 37(4): 523-557.

Dickens, William, and Lawrence F. Katz. 1987. "Interindustry Wage Differences and Industry Characteristics." NBER Working Paper.

Giglio, Stefano, Matteo Maggiori, and Johannes Stroebel. 2015. "Very long-run discount rates." The Quarterly Journal of Economics, 130(1): 1-53.

Greenwood, Robin, and Andrei Shleifer. 2014. "Expectations of returns and expected returns." The Review of Financial Studies, 27(3): 714-746.

Kuchler, Theresa, and Basit Zafar. 2015. "Personal experiences and expectations about aggregate outcomes."

Malmendier, Ulrike, and Stefan Nagel. 2011. "Depression babies: do macroeconomic experiences affect risk taking?" The Quarterly Journal of Economics, 126(1): 373-416.

Malmendier, Ulrike, and Stefan Nagel. 2016. "Learning from inflation experiences." The Quarterly Journal of Economics, 131(1): 53-87.

Malmendier, Ulrike, Stefan Nagel, and Zhen Yan. 2017. "The making of hawks and doves: Inflation experiences on the FOMC." National Bureau of Economic Research.

Merton, Robert C. 1969. "Lifetime portfolio selection under uncertainty: The continuous-time case." The review of Economics and Statistics, 247-257.

Merton, Robert C. 1975. "Optimum consumption and portfolio rules in a continuous-time model." In Stochastic Optimization Models in Finance. 621-661. Elsevier.

Sirri, Erik R, and Peter Tufano. 1998. "Costly search and mutual fund flows." The journal of finance, 53(5): 1589-1622. 